FERNANDO TARLÁ CARDOSO LEMOS

UMA ARQUITETURA OTIMIZADA PARA A DETECÇÃO DE FALHAS EM GRADES COMPUTACIONAIS 
FERNANDO TARLÁ CARDOSO LEMOS

\title{
UMA ARQUITETURA OTIMIZADA PARA A DETECÇÃO DE FALHAS EM GRADES COMPUTACIONAIS
}

\author{
Dissertação apresentada à Escola \\ Politécnica da Universidade de São Paulo \\ para obtenção do título de Mestre em \\ Ciências
}


Este exemplar foi revisado e alterado em relação à versão original, sob responsabilidade única do autor e com a anuência de seu orientador.

São Paulo, de dezembro de 2012.

Assinatura do autor

Assinatura do orientador

FICHA CATALOGRÁFICA

Lemos, Fernando Tarlá Cardoso

Uma arquitetura otimizada para a detecção de falhas em grades computacionais / F.T.C. Lemos. - ed.rev. -- São Paulo, 2012.

$105 \mathrm{p}$.

Dissertação (Mestrado) - Escola Politécnica da Universidade de São Paulo. Departamento de Engenharia de Computação e Sistemas Digitais.

1. Sistemas distribuídos 2. Falhas computacionais 3 . Arquitetura e organização de computadores 4 . Redes de computadores 5. Metodologia e técnicas de computação I. Universidade de São Paulo. Escola Politécnica. Departamento de Engenharia de Computação e Sistemas Digitais II. t. 
FERNANDO TARLÁ CARDOSO LEMOS

\title{
UMA ARQUITETURA OTIMIZADA PARA A DETECÇÃO DE FALHAS EM GRADES COMPUTACIONAIS
}

\author{
Dissertação apresentada à Escola \\ Politécnica da Universidade de São Paulo \\ para obtenção do título de Mestre em \\ Ciências \\ Área de concentração: \\ Sistemas Digitais
}

Orientadora: Profa. Livre-Docente Liria Matsumoto Sato 


\section{AGRADECIMENTOS}

Agradeço acima de tudo a minha família e amigos, em especial aos meus pais Carlos e Leda, pela paciência e suporte nos momentos difíceis. Não teria sido possível concluir este trabalho sem seu carinho e conforto.

Agradeço a minha orientadora Profa. Liria Sato pelo seu apoio e dedicação incansáveis. Seus ensinamentos foram essenciais durante esta jornada. Agradeço também a todos meus colegas no LAHPC pelos momentos de descontração e amizade e pelos tantos conselhos compartilhados nestes anos.

Agradeço ainda a meu chefe e amigo Pedro Paulo Magalhães de Olveira Jr., que não somente abriu muitas portas para mim na esfera acadêmica e profissional, mas também pelo constante incentivo para o progresso dos meus estudos. Agradeço imensamente a NetFilter/SpeedComm e funcionários por investirem no meu desevolvimento profissional. 


\section{RESUMO}

A detecção de falhas em uma plataforma distribuída é um componente essencial para uma grande quantidade de estratégias de tolerância a falhas, como a restauração do estado das aplicações distribuídas através de checkpointing e message logging. Porém, esta detecção frequentemente depende da comunicação confiável entre os nós de processamento e os módulos de detecção de falhas. Em grades computacionais hierárquicas com limitações de conectividade, a comunicação direta entre nós e módulos de detecção é muitas vezes impossível. Outro fator que dificulta a detecção de falhas em grades computacionais é a localização geograficamente esparsa entre as instituições e os recursos computacionais disponíveis na grade e a consequente utilização de redes de longa distância para os conectar. Esta dissertação apresenta uma arquitetura para a detecção de falhas em plataformas distribuídas otimizada para o funcionamento em grades computacionais hierárquicas, levando suas limitações e requisitos em consideração. A arquitetura, denominada GFDA (Grid Fault Detection Architecture), é estruturada em módulos de detecção das falhas que afetam nós computacionais disponibilizados na grade, módulos de detecção de falhas das aplicações distribuídas, e módulos de coleção, processamento e encaminhamento das notificações de falha e recuperação emitidas pelos módulos de detecção. Detalhes da implementação e da verificação do funcionamento correto da arquitetura são apresentados, bem como resultados obtidos através da execução de componentes da arquitetura em um cluster de computadores simulado através de máquinas virtuais. São propostas técnicas para a otimização da qualidade de serviço de detecção de falhas. Os resultados obtidos com a utilização destas técnicas são comparados com resultados obtidos com abordagens tradicionais. Observa-se que as técnicas implementadas na arquitetura GFDA para o processamento de notificações de falha e recuperação e a introdução de redundância nas mensagens trocadas entre os módulos de detecção de falhas traz resultados positivos em condições adversas de conectividade. Conclui-se que a arquitetura GFDA contribui para o estabelecimento de uma solução viável para a detecção de falhas em uma grade computacional hierárquica em que há restrições de conectividade entre os nós computacionais.

Palavras-chave: Detecção de falhas. Detecção distribuída de falhas. Tolerância a falhas. Grades computacionais. 


\begin{abstract}
In distributed platforms, fault detection is an essential requirement to a wide range of fault tolerance techniques, such as restoring the state of distributed applications with checkpointing and message logging. However, fault detection often depends on reliable communication between the processing nodes and detection fault modules. Direct communication between the nodes and detection modules is often impossible in hierarchical grid computing platforms. The physical distance between the institutions and resources available on the grid, and thus the requirement of long distance networks connecting them, is another factor that makes direct fault detection in computer grids a challenge. This thesis presents a fault detection architecture for distributed platforms, optimized for usage in hierarchical grids and thus taking into account its restrictions and requirements. The architecture, named GFDA (Grid Fault Detection Architecture), is structured as fault detection modules for faults that affect the computing nodes available on the grid, detection modules for faults that affect the distributed applications, and modules that perform the collection, processing and forwarding of the fault and recovery notifications generated by the detection modules. This thesis presents implementation details, an evaluation of the correctness of the designed architecture, and results obtained through the deployment of parts of the architecture in a simulated cluster that uses virtual machines to simulate computing nodes. Techniques to optimize the quality of the detection fault service are proposed. The results obtained through the usage of such techniques are compared to the results obtained through traditional approaches. Positive results were extracted even under adverse connectivity conditions by using techniques such as the processing of fault and recovery notifications and the introduction of redundant information in the messages exchanged between the detection modules. It is concluded that the GFDA architecture contributes to the establishment of a viable solution for fault detection in a hierarchical grid computing platform that presents connectivity restrictions between the nodes.
\end{abstract}

Keywords: Fault detection. Distributed fault detection. Fault tolerance. Grid computing. 


\section{LISTA DE ILUSTRAÇÕES}

Figura 2.1 - Relação entre faults (falhas), erros e failures (AVIZIENIS et al., 2004). . . . . . . . . . . . . . . . . . p. . . . . . . . .

Figura 2.2 - Modelo push (HAYASHIBARA; CHERIF; KATAYAMA, 2002). . . . p p. 27

Figura 2.3 - Modelo pull (HAYASHIBARA; CHERIF; KATAYAMA, 2002) . . . . . p. 27

Figura 4.1 - Exemplo de grade em que os recursos não podem ser acessados diretamente. . . . . . . . . . . . . . . . . . . . . 37

Figura 4.2 - Grafos mostrando seções da grade com limitações de conectividade. . . . . . . . . . . . . . . . . p. 38

Figura 4.3 - Exemplo da estrutura dos componentes da arquitetura proposta em uma grade. . . . . . . . . . . . . . . . . . . . . p. 40

Figura 4.4 - Fluxos possíveis de notificações entre os componentes da arquitetura proposta. . . . . . . . . . . . . . . . p.41

Figura 4.5 - Representação simplificada da Tarefa 2 no gossip payload. . . . . p p. 43

Figura 4.6 - Exemplo da utilidade do intervalo de limpeza $\Delta_{c l}$ para o funcionamento de detectores de falhas distribuídos. . . . . . . . . . . p. 44

Figura 4.7 - Estrutura básica do detector multicast. . . . . . . . . . . . . p. p. 45

Figura 4.8 - Procedimento visto para o detector multicast simples. . . . . . . p. p. 46

Figura 4.9 - Procedimento visto para o detector multicast adaptativo. . . . . p. p. 47

Figura 4.10 - Comunicação para estabelecimento da visão da topologia. . . . . p.50

Figura 5.1 - Diagrama de classes dos detectores de falhas de infraestrutura. . p.54

Figura 5.2 - Estrutura de uma mensagem heartbeat. . . . . . . . . . . . p.55

Figura 5.3 - Tamanho das mensagens heartbeat enviadas pelos detectores implementados. . . . . . . . . . . . . p. 56

Figura 5.4 - Procedimento para a obtenção da chave criptográfica utilizada na assinatura de mensagens heartbeat. . . . . . . . . . . . p.59

Figura 6.1 - Número de enganos no cenário 1. . . . . . . . . . . . p. 69 
Figura 6.2 - Duração média dos enganos no cenário $1 \ldots$. . . . . . . . . . p. 70

Figura 6.3 - Média de detecções por falha no cenário $1 . \ldots \ldots$. . . . . . . 72

Figura 6.4 - Atraso médio das detecções no cenário 1. . . . . . . . . . . . p. 72

Figura 6.5 - Efeito na estimação do horário de recepções futuras de mensagens heartbeat causado por variações nas condições de rede, perdas de pacotes e falhas de detectores. . . . . . . . . . . . p.73

Figura 6.6 - Estimação do horário de recepções futuras de mensagens heartbeat em condições de rede favoráveis. . . . . . . . . . . . . . p.74

Figura 6.7 - Atraso médio das detecções na metade final do intervalo de testes no cenário $1 \ldots \ldots \ldots \ldots \ldots$. . . . . . . . . . . . . . . . . .

Figura 6.8 - Número de enganos no cenário $2 \ldots \ldots$. . . . . . . . . . . 76

Figura 6.9 - Duração média dos enganos no cenário $2 \ldots$. . . . . . . . . . p.77

Figura 6.10 - Média de detecções por falha no cenário $2 \ldots \ldots$. . . . . . p. 78

Figura 6.11 - Atraso médio das detecções no cenário 2 . . . . . . . . . . . . p. p. 79

Figura 6.12 - Atraso médio das detecções na metade final do intervalo de testes no cenário $2 \ldots \ldots \ldots$. . . . . . . . . . . . . . . . . . . . . . . .

Figura 6.13 - Número de enganos no cenário $3 . \ldots \ldots$. . . . . . . . 80

Figura 6.14 - Média de detecções por falha no cenário $3 . \quad \ldots \ldots$. . . . . . p. 82

Figura 6.15 - Duração média dos enganos no cenário 3. . . . . . . . . . . . p. 83

Figura 6.16 - Atraso médio das detecções no cenário 3. . . . . . . . . . . p. 83

Figura 6.17 - Atraso médio das detecções na metade final do intervalo de testes no cenário $3 \ldots \ldots \ldots \ldots$. . . . . . . . . . . . . 84

Figura 6.18 - Número de enganos no cenário $4 \ldots \ldots$. . . . . . . . . 85

Figura 6.19 - Duração média dos enganos no cenário $4 \ldots \ldots$. . . . . . . . p. 86

Figura 6.20 - Média de detecções por falha no cenário $4 \ldots \ldots$. . . . . . . p. 87

Figura 6.21 - Atraso médio das detecções no cenário $4 \ldots \ldots$. . . . . . . . . p. 87

Figura 6.22 - Atraso médio das detecções na metade final do intervalo de testes no cenário $4 \ldots \ldots \ldots \ldots \ldots$. . . . . . . . . . . . . . . . . 
Figura A.1 - Exemplo dos comandos do gerenciador de falhas que tratam de tarefas. . . . . . . . . . . . . . . . . . . . . . p. . . . . . . . . .

Figura A.2 - Exemplo dos comandos do gerenciador de falhas que tratam de dependências entre os recursos. . . . . . . . . . . . . . p. 100

Figura A.3 - Exemplo dos comandos do gerenciador de falhas que tratam de publicação de presença e notificações de falha e recuperação. . . p.101

Figura A.4 - Exemplo dos comandos do gerenciador de falhas para observação do estado do processamento de notificações e da chave de criptografia usada pelos detectores. . . . . . . . . . . . . . . . p.102

Figura A.5 - Exemplo dos comandos do gerenciador de falhas para transmissão de mensagens de replicação. . . . . . . . . . . . . . . . p. 103

Figura B.1 - Exemplo de comunicação entre um gerenciador de falhas central e o consumidor final das notificações de falha. . . . . . . . . . . . p.104 


\section{LISTA DE TABELAS}

Tabela 2.1 - Exemplos de falhas de infraestrutura e falhas locais. . . . . . . . p. 24

Tabela 6.1 - Operações exercitadas pela suíte de testes. . . . . . . . . . . . p. 62

Tabela 6.2 - Resultados da análise de cobertura da suíte de testes. . . . . . . p. 62

Tabela 6.3 - Configurações do modelo de adversidades. . . . . . . . . . . . p. 65

Tabela 6.4 - Cenários considerados para a execução dos testes. . . . . . . . p. 66

Tabela A.1 - Comandos disponíveis no protocolo de comunicação com gerenciadores de falhas. . . . . . . . . . . . . . . . p. 98 


\section{LISTA DE ABREVIATURAS E SIGLAS}

API Application Programming Interface

BRR Binary Round-Robin

CARP Common Address Resolution Protocol

DBRR Double Binary Round-Robin

FQDN Fully Qualified Domain Name

GCSE Grid Cooperative Scheduling Environment

GFDA Grid Fault Detection Architecture

GRE Generic Routing Encapsulation

GRIP Grid Information Protocol

GRRP Grid Registration Protocol

HMAC Hash-based Message Authentication Code

LDAP Lightweight Directory Access Protocol

LIMA Light-weight Monitoring Architecture

MDS Monitoring and Discovery System

MPI Message Passing Interface

MTU Maximum Transmission Unit

NAT Network Address Translation

PRMM Pool Resource Monitoring Manager

QoS Quality of Service

RRSC Round-Robin with Sequence Check

RTO Retransmission Timeout

SHA Secure Hash Algorithm

SQL Structured Query Language

TCP Transmission Control Protocol 
TLS Transport Layer Security

UDP User Datagram Protocol

VPN Virtual Private Network

VRRP Virtual Router Redundancy Protocol 


\section{LISTA DE SÍMBOLOS}
$\Delta_{i}$
intervalo entre o envio de mensagens heartbeat
$\Delta_{c l}$
intervalo de limpeza
$\Delta_{t o}$
intervalo de timeout
$\alpha$
ganho da média para a estimação de $\Delta_{t o}$
$\bar{x}$
média histórica de $R$
$\beta$
ganho do desvio da média para a estimação de $\Delta_{t o}$
$\diamond P$
classe de detectores de falhas eventualmente perfeitos
$\gamma$
influência do desvio da média para a estimação de $\Delta_{t o}$
$R$
intervalo entre recepções de mensagens heartbeat 


\section{SUMÁRIO}

1 Introdução $\quad$ p. 16

1.1 Objetivos . . . . . . . . . . . . . . . . . . . 18

1.2 Motivação . . . . . . . . . . . . . . . . . . . p. 20

1.3 Proposta . . . . . . . . . . . . . . . . . . p. 21

1.4 Organização do texto $\ldots \ldots \ldots \ldots \ldots \ldots$ p. 22

2 Conceitos $\quad$ p. 23

2.1 Falhas em ambientes distribuídos $\ldots \ldots \ldots$. . . . . . . . . . . . . 23

2.2 Detecção distribuída de falhas . . . . . . . . . . . . . . . p. 25

2.2.1 Estratégias de monitoração de nós . . . . . . . . . . . . . p. 26

2.2.2 Protocolos gossip tradicionais . . . . . . . . . . . . p. 27

2.2.3 Qualidade de serviço e protocolos adaptativos . . . . . . . . . p. 28

3 Detecção de falhas em plataformas distribuídas $\quad$ p. 30

3.1 Protocolos baseados em broadcast e multicast . . . . . . . . . . . . p. 30

3.2 Protocolos gossip . . . . . . . . . . . . . . . . . . p. 32

3.3 Sistemas de monitoramento $\ldots \ldots \ldots \ldots$. . . . . . . . . . . . . . . .

4 Arquitetura para detecção de falhas em grades computacionais $\quad$ p. 36

4.1 Visão geral da arquitetura . . . . . . . . . . . . . . . . . p. 38

4.2 Detectores de falhas de infraestrutura $\ldots \ldots \ldots \ldots$ p. . . . . . . . . . .

4.2 .1 Gossip payload . . . . . . . . . . . . . . . . . p. p. 42

4.2.2 Detectores adaptativos com gossip payload . . . . . . . . . . . p. 44

4.3 Detectores de falhas locais . . . . . . . . . . . . . . . . p. 47

4.4 Gerenciadores de falhas . . . . . . . . . . . . . . . . p. 48 
4.5 Considerações sobre a arquitetura proposta . . . . . . . . . . . . . p. p1

5 Implementação $\quad$ p. 53

5.1 Detectores de falhas de infraestrutura $\ldots \ldots \ldots$. . . . . . . . . . . .

5.2 Detectores de falhas locais . . . . . . . . . . . . . . . p. 55

5.3 Gerenciadores de falhas . . . . . . . . . . . . . . . . p. 57

5.4 Comunicação criptografada . . . . . . . . . . . . . . . . . p. 58

5.5 Replicação dos gerenciadores de falhas . . . . . . . . . . . . . . . p. p. 59

6 Testes e resultados $\quad$ p. 61

6.1 Suíte de testes $\ldots \ldots \ldots \ldots \ldots \ldots \ldots$ p. 61

6.2 Modelo de adversidades $\ldots \ldots \ldots \ldots \ldots \ldots$ p. . . . . . . . . . . . . . .

6.3 Ambiente de testes $\ldots \ldots \ldots \ldots \ldots \ldots$ p. 64

6.4 Métricas . . . . . . . . . . . . . . . . . . . . p. 67

6.5 Análise dos resultados $\ldots \ldots \ldots \ldots$. . . . . . . . . . . . . . . . . . . . . .

6.6 Resultados do cenário 1 (nenhum processamento) $\ldots \ldots$. . . . . . . . p. 68

6.7 Resultados do cenário 2 (filtragem de conflitos) $\ldots \ldots \ldots$. . . . . . . . . p. 74

6.8 Resultados do cenário 3 (quórum) $\ldots \ldots \ldots$. . . . . . . . . . 80

6.9 Resultados do cenário 4 (filtragem de notificações e exigência de quórum) p. 85

6.10 Discussão . . . . . . . . . . . . . . . . . . . . . . . . . . . p. 88

7 Conclusões $\quad$ p. 90

7.1 Restrições . . . . . . . . . . . . . . . . . . . . . . . . . p. 91

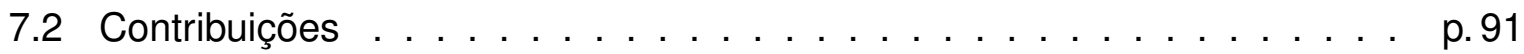

7.3 Trabalhos futuros $\ldots \ldots \ldots \ldots \ldots$ p. 92

7.4 Publicações . . . . . . . . . . . . . . . . . . . . . p. . . . . . . . . .

$\begin{array}{lr}\text { Referências } & \text { p. } 94\end{array}$ 
Apêndice A - Protocolo de comunicação com o gerenciador de falhas

p. 97

Apêndice B - Protocolo de integração com o gerenciador de falhas

p. 104 


\section{INTRODUÇÃO}

O campo da computação de alto desempenho estuda soluções para problemas que exigem alto poder de processamento computacional, tais como a distribuição da computação entre nós autônomos conectados em rede. Grades computacionais são plataformas para a distribuição e compartilhamento de recursos entre instituições e usuários, consumidores e disponibilizadores de recursos, generalizados na forma de organizações virtuais. Grades computacionais oferecem soluções para os problema de distribuição e uso de recursos computacionais de maneira controlada e coordenada entre organizações virtuais. São compostas por sistemas computacionais de alto desempenho, incluindo muitas vezes clusters de computadores, recursos de armazenamento e instrumentos científicos específicos. Todos estes recursos são interconectados por redes. As grades maximizam a utilização de recursos através do compartilhamento de sua utilização entre diversas organizações e domínios administrativos. Estas organizações estão frequentemente separadas geograficamente e conectadas por redes de longa distância. A origem do termo "grade" é atribuída a outros modelos de distribuição de recursos, tais como grandes grades de distribuição de energia (FOSTER; KESSELMAN, 1999).

O compartilhamento e distribuição de recursos em uma grade deve respeitar as políticas definidas pelas organizações virtuais que os disponibilizam. Foster, Kesselman e Tuecke (2001) descrevem o problema do compartilhamento coordenado de recursos e resolução de problemas em organizações virtuais multidimensionais e dinâmicas. $O$ acesso aos recursos computacionais torna necessária a identificação clara e precisa das condições sob as quais o compartilhamento ocorre. É comum a utilização de middlewares, que são bibliotecas e ferramentas que permitem o uso cooperativo de recursos geograficamente distribuídos e unificados, atuando como plataformas computacionais poderosas para a execução de aplicações distribuídas (PAULA, 2009). Middlewares oferecem serviços aos usuários da grade computacional de maneira que as diferenças de infraestrutura entre as organizações virtuais são minimizadas e os recursos são expostos de maneira consistente e modular, sendo integrados e disponibilizados aos usuários da grade. Entre estes recursos, estão disponíveis clusters de computadores para os quais o agendamento de tarefas é controlado por escalonadores, normalmente instalados em nós de entrada. Meta-escalonadores instalados na grade realizam a distribuição de tarefas entre os recursos disponíveis, entre os quais clusters de computadores gerenciados por escalonadores comuns. Os usuários da grade submetem tarefas com a utilização do meta-escalonador, 
que agenda sua execução de acordo com as políticas estabelecidas pelas organizações virtuais. A utilização de um meta-escalonador permite aumentar a eficiência na utilização da grade, já que estes realizam a coordenação do agendamento das tarefas entre escalonadores de clusters e outros recursos (PAULA, 2009).

Algumas implementações de grades computacionais, tais como o projeto Grid'5000 (BOLZE et al., 2006), utilizam abstrações como Virtual Private Networks ou VPNs para prover uma plataforma que se assemelha a um conjunto de computadores conectados a uma única rede, sem nenhum tipo de hierarquia. Em sua maioria, porém, grades computacionais que integram instituições acadêmicas apresentam uma estrutura hierárquica. Nesta estrutura, recursos estão localizados em redes sem endereçamento público, como no caso de nós de processamento de um cluster que integra a grade (PAULA, 2009). Grades tradicionais são formadas por clusters de computadores e supercomputadores que recebem tarefas (jobs) registradas em seus nós de entrada. Tradicionalmente, estes nós de entrada também são o único canal de comunicação com o restante da grade. Isto representa desafios adicionais quanto à transmissão de informações através da infraestrutura. É razoável, porém, exigir maior disponibilidade de serviço de um nó de entrada, já que se trata de uma peça chave na infraestrutura do cluster.

Um sistema tolerante a falhas (fault tolerant) apresenta comportamento compatível com sua especificação até mesmo na presença de falhas (faults). Grades computacionais, assim como outros sistemas distribuídos, apresentam características que permitem que uma aplicação distribuída em execução se mantenha em funcionamento correto mesmo na presença de falhas que prejudiquem sua execução. Na ocasião de uma falha em um nó de processamento, é possível que a computação não seja terminada imediatamente ou até mesmo que os outros nós envolvidos na computação não sejam afetados (STELLING et al., 1999). Uma combinação de diversas técnicas pode ser empregada para atingir este objetivo. É possível que as unidades de trabalho associadas aos nós em falha sejam distribuídas entre os nós sobreviventes, ou outros nós computacionais disponíveis podem ser convocados para a distribuição deste trabalho remanescente. Técnicas que utilizam redundância no agendamento de tarefas (GENAUD; JEANNOT; RATTANAPOKA, 2009) podem ser empregadas. Para a ativação da maioria destas técnicas, no entanto, é necessário que estas falhas sejam detectadas por um sistema de detecção de falhas. O bom aproveitamento das diferenças de disponibilidade e posicionamento na topologia entre os nós computacionais que integram grades permite a otimização da qualidade de detecção. 
Uma qualidade do serviço de detecção de falhas elevada em um sistema distribuído é um fator importante para o sucesso de uma implementação de tolerância a falhas. Um longo período de detecção pode anular os benefícios trazidos pela detecção de falhas, enquanto uma alta quantidade de detecções incorretas pode levar a terminação precoce da execução das aplicações em andamento. Há ainda a preocupação com situações em que falhas não são detectadas pelo sistema de detecção. A cobertura de um sistema de detecção de falhas deve ser adequada às necessidades das aplicações que executam na grade, de tal maneira que as falhas mais frequentes possam ser identificadas e tratadas.

Uma arquitetura de detecção de falhas otimizada para a utilização em grades computacionais deve buscar explorar as características da grade para maximizar a qualidade do serviço de detecção de falhas, lidando porém com as limitações de conectividade impostas pela sua estrutura. Adicionalmente, grades compostas por recursos e redes heterogêneas apresentam propriedades que podem afetar positivamente ou negativamente a qualidade de detecção de falhas. Diferenças no tipo de meio que conecta redes, como as diferenças entre redes cabeadas e sem fios, ou entre a utilização de fibra ótica e cabeamento convencional, por exemplo, se refletem na alteração de propriedades como o atraso e a probabilidade da necessidade de retransmissão de pacotes. A detecção de falhas deve ser flexível de maneira que o administrador possa extrair qualidade de detecção satisfatória de redes com diferentes características. Isso pode ser feito com o ajuste de parâmetros ou com a escolha de detectores de falhas que se adaptem às características do ambiente de maneira automática.

\subsection{Objetivos}

Considerando as restrições impostas pelo ambiente de uma grade computacional hierárquica, o presente trabalho tem como objetivo apresentar uma arquitetura para a detecção de falhas que, caso não sejam tratadas, venham a causar a interrupção do processamento de uma aplicação distribuída em execução na plataforma da grade. Esta arquitetura, denominada Grid Fault Detection Architecture ou GFDA, deve ser composta de módulos de software que realizam a detecção de falhas que podem ocorrer nos nós que participam da execução da aplicação distribuída, assim como módulos de software para a monitoração dos processos da aplicação em execução em cada nó computacional participante. Também compõem esta arquitetura módulos que permitem a análise e reunião das notificações de detecção para eventual processamento por parte de um sistema externo. 
A arquitetura proposta deve ser otimizada para grades hierárquicas conectando recursos disponibilizados entre várias organizações virtuais geograficamente distantes, utilizando redes que expõem condições adversas à comunicação entre os nós e à sua monitoração. No entanto, a flexibilidade da arquitetura proposta também deve permitir sua utilização em ambientes que se assemelham a clusters de computadores ou outros sistemas distribuídos implantados em ambientes mais controlados. Grades computacionais projetadas exclusivamente para um modelo de computação distribuída que independe de comunicação entre os nós de processamento, como o projeto SETI@home (ANDERSON et al., 2002), não são contempladas. A ausência de comunicação entre os nós impede a monitoração remota e envio de notificações, que formam a base da arquitetura proposta. Estas plataformas também são menos beneficiadas por técnicas de detecção e tolerância a falhas, uma vez que a ausência de comunicação entre os nós de processamento implica na ausência de um estado global (SANKARAN et al., 2005) a ser restaurado na ocasião de falhas, simplificando procedimentos de restauração e possibilitando alternativas à detecção de falhas.

Esta arquitetura busca atender aos seguintes requisitos:

- Utilização do conhecimento da estrutura da grade para benefício da qualidade de serviço de detecção e caracterização dos eventos de falhas em um ambiente hierárquico e heterogêneo que apresenta restrições à comunicação direta entre nós computacionais;

- Permitir o desenvolvimento de módulos detectores de falhas com características especializadas, visando a) a comparação das diferentes estratégias de detecção de falhas e b) a exploração dos benefícios relacionados à qualidade de serviço trazidos pela aplicação destas estratégias em redes com diferentes características;

- Possibilitar a criação de diferentes módulos de monitoração dos processos que compõem uma aplicação distribuída;

- Possibilitar a alimentação de meta-escalonadores na grade com informações necessárias para a ativação de técnicas para a recuperação de falhas.

Este trabalho visa ainda a elaboração de novas estratégias de detecção de falhas com o propósito de melhorar o qualidade de serviço de detecção com relação a critérios como o número de detecções incorretas e o atraso entre uma falha e sua detecção. Estas estratégias se baseiam na teoria já estabelecida sobre a detecção distribuída de falhas. A 
criação de estratégias para o tratamento das notificações de falha emitidas pelos módulos de detecção também é um objetivo deste trabalho.

O funcionamento correto da arquitetura deve ser avaliado por meio de testes automatizados que exercitam o funcionamento da arquitetura em um ambiente simulado que apresenta as características dos ambientes estudados. Testes experimentais que utilizam os módulos de detecção de falhas criados poderão permitir a comparação entre diferentes estratégias de detecção. Métricas de qualidade de serviço poderão então ser extraídas, permitindo a análise do desempenho das técnicas comparadas.

\subsection{Motivação}

As aplicações executadas em grades computacionais tradicionais muitas vezes têm cunho científico ou outros propósitos relacionados à computação de alto desempenho. Tais aplicações normalmente são executadas por um grande período de tempo. Durante a execução de uma aplicação, é possível que um ou mais nós computacionais sofram interrupção de serviço. A presença de um sistema de tolerância a falhas se torna um requisito para a conclusão de algumas destas tarefas, já que a disponibilidade do sistema fica prejudicada pela possibilidade da interrupção de serviço. Neste sentido, a utilização de técnicas de detecção de falhas contribui para o sucesso na execução de aplicações distribuídas de longa duração.

Grande parte das técnicas de tolerância a falhas são dependentes do serviço de detecção de falhas. Uma vez informado sobre a falha de um nó, um sistema pode escolher recuperar o estado da aplicação distribuída, como através da restauração de checkpoints (STELLNER, 1996; SANKARAN et al., 2005; HURSEY et al., 2007), message logging (JOHNSON; ZWAENEPOEL, 1987; BOSILCA et al., 2002; BOUTEILLER et al., 2006) ou através de outras técnicas (GENAUD; JEANNOT; RATTANAPOKA, 2009). A quantidade de detecções incorretas deve ser minimizada, já que há um custo significativo associado às técnicas de restauração do estado da aplicação. Por outro lado, as falhas devem ser identificadas com prontidão, de maneira que as ações associadas à detecção de falhas sejam rapidamente tomadas, minimizando o intervalo de tempo sem processamento.

Embora seja uma área bem estudada, as abordagens atuais para detecção de falhas em sistemas distribuídos ainda apresentam limitações quanto a sua utilização em grades computacionais hierárquicas. Muitas das abordagens atuais não se aplicam a grades computacionais ou não levam em consideração a estrutura da grade para otimizar a qualidade 
de detecção (BERTIER; MARIN; SENS, 2002; BERTIER; MARIN; SENS, 2003; SANKARAN et al., 2005; HURSEY et al., 2007), enquanto outras não consideram redes com alta perda de pacotes (DÉFAGO; HAYASHIBARA; KATAYAMA, 2003). Grande parte das técnicas não realizam processamento algum das notificações de falhas emitidas pelos módulos detectores e não há a presença de um observador com informações privilegiadas da estrutura e situação da rede (STELLING et al., 1999). Em outras abordagens, a estrutura da grade é levada em consideração apenas para o transporte de informações, mas não há um observador inteligente que possa otimizar a qualidade do serviço de detecção de falhas (DÉFAGO; HAYASHIBARA; KATAYAMA, 2003).

Grades computacionais apresentam características de conectividade e tempo de vida dos nós computacionais ignoradas nas publicações que contemplam apenas clusters de computadores. Estes ambientes distribuídos são menos controlados em comparação a clusters de computadores, que são a plataforma alvo para comparações entre módulos de detecção de falhas. Em grades computacionais, a monitoração do estado dos recursos computacionais e de suas conexões na rede são responsabilidade das instituições que os disponibilizam, e portanto as condições em que os nós computacionais são mantidos podem não ser ideais ou homogêneas. Neste ambiente hostil, a utilização de técnicas de tolerância a falhas na ausência de uma arquitetura de detecção de falhas flexível às flutuações nas condições da rede ocasiona a interrupção desnecessária do processamento de aplicações distribuídas para a ativação de mecanismos de recuperação.

\subsection{Proposta}

Em um sistema distribuído com comunicação entre nós computacionais, é possível que uma unidade de informação seja perdida durante sua transmissão através da rede. Se esta mesma informação for enviada a um grande número de nós, porém, a possibilidade de que a mensagem não chegue a nenhum dos destinatários é reduzida. Esta replicação de informações é uma maneira de melhorar a confiabilidade da comunicação em um sistema distribuído em face a condições de rede desfavoráveis. Esta técnica pode ser aplicada a um sistema de detecção de falhas que funciona com base na comunicação entre nós computacionais, reduzindo a probabilidade de que as falhas que venham a ser detectadas não estejam associadas a uma falha real.

A estrutura formada pelas conexões entre os nós existentes nas grades computacionais traz limites quanto a conectividade entre estes. A disposição dos nós computacionais em sub-redes impõe certa carga de responsabilidade sobre estações específicas. Em 
uma grade computacional hierárquica, nós de entrada de clusters de computadores e os demais nós que conectam sub-redes são pontos de falha para os nós computacionais que estes conectam ao restante da grade. Portanto, é possível utilizar estes nós que já contam com maiores requisitos de disponibilidade para efetuar o processamento de informações desencontradas obtidas pelos módulos de detecção, desta forma melhorando a qualidade do serviço de detecção de falhas.

O propósito deste trabalho é utilizar tais técnicas na implementação de uma arquitetura para a detecção de falhas em ambientes distribuídos, mas otimizada para grades computacionais hierárquicas com restrições de conectividade entre os nós computacionais e redes em condições adversas. Esta arquitetura deve ser extensível para que diferentes estratégias de detecção de falhas possam ser criadas e comparadas.

\subsection{Organização do texto}

O Capítulo 2 apresenta os conceitos necessários para o entendimento do conteúdo apresentado neste documento.

O Capítulo 3 apresenta alguns trabalhos que compõem o estado da arte em detecção de falhas em plataformas distribuídas.

O Capítulo 4 define a proposta de arquitetura para detecção de falhas otimizada para grades computacionais hierárquicas e seus componentes.

O Capítulo 5 descreve a implementação da arquitetura proposta.

O Capítulo 6 descreve os testes realizados com a arquitetura implementada e apresenta a análise dos resultados obtidos com a testes em um ambiente simulado.

O Capítulo 7 apresenta as conclusões atingidas com este trabalho, bem como sugestões para trabalhos e modificações futuras. 


\section{CONCEITOS}

Neste capítulo são descritos os principais conceitos relacionados à detecção de falhas que fundamentam um melhor entendimento das propostas apresentadas neste trabalho, que são discutidas nos capítulos seguintes.

\subsection{Falhas em ambientes distribuídos}

Avizienis et al. (2004) identifica três eventos relacionados à tolerância a falhas. Service failures ou simplesmente failures são eventos que fazem com que o serviço oferecido por um sistema passe a diferir do serviço considerado correto. Um erro, por sua vez, é um desvio do estado do sistema em relação ao estado correto. Uma failure é, portanto, resultado da propagação de um ou mais erros. Já uma fault é a causa hipotética ou comprovada de um erro. A Figura 2.1 ilustra a relação entre estes eventos. Neste documento, as referências a falhas têm o sentido de faults, e não failures, embora ambas as traduções sejam possíveis. Portanto, este documento se refere a tolerância a faults (fault tolerance) e detecção de faults como tolerância a falhas e detecção de falhas, respectivamente.

Avizienis et al. (2004) também define sistema como uma entidade que interage com outras entidades, enquanto o limite do sistema é a fronteira entre o sistema e o ambiente no qual está inserido. Adotando esta nomenclatura, o sistema analisado é a grade computacional como plataforma para a execução de aplicações distribuídas, enquanto o ambiente é composto por operadores ou usuários da grade. Neste sistema, a impossibilidade de executar corretamente uma aplicação distribuída, ao ser exposta ao operador, é considerada uma failure. Esta failure representa a propagação de um ou mais erros, que no sistema considerado são associados a erros na infraestrutura ou nos processos que compõem a aplicação distribuída. Estes erros, por sua vez, são ativados por uma variedade de falhas (faults) específicas. Neste sistema, a tolerância a falhas se encarrega em garantir que as aplicações distribuídas possam continuar em execução correta, ou seja, que a grade computacional não apresente failures, mesmo na presença destas falhas. $A$

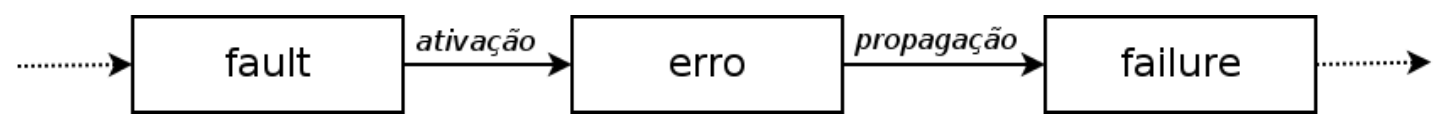

Figura 2.1 - Relação entre faults (falhas), erros e failures (AVIZIENIS et al., 2004). 
Tabela 2.1 - Exemplos de falhas de infraestrutura e falhas locais.

\begin{tabular}{|l|l|}
\hline Categoria & Exemplos \\
\hline \hline \multirow{5}{*}{ Falhas de infraestrutura } & $\begin{array}{l}\text { Falha fatal do sistema operacional do nó (falha de soft- } \\
\text { ware essencial ao funcionamento do nó) }\end{array}$ \\
\cline { 2 - 2 } & $\begin{array}{l}\text { Falha fatal no sistema de um equipamento de rede (falha } \\
\text { de software que isola o nó do restante da rede) }\end{array}$ \\
\cline { 2 - 2 } & $\begin{array}{l}\text { Falha em uma placa-mãe, processador, fonte, etc. (falha } \\
\text { de hardware essencial ao funcionamento do nó) }\end{array}$ \\
\cline { 2 - 2 } & $\begin{array}{l}\text { Falha na placa lógica de um roteador ou no cabeamento } \\
\text { (falha de hardware que isola o nó do restante da rede) }\end{array}$ \\
\hline \hline \multirow{5}{*}{ Falhas locais } & Falha no software do processo da aplicação distribuída \\
\cline { 2 - 2 } & $\begin{array}{l}\text { Falha no sistema que leva à terminação anormal da apli- } \\
\text { cação distribuída (software ou hardware) }\end{array}$ \\
\cline { 2 - 2 } & $\begin{array}{l}\text { Falha de operação que leva à terminação anormal da } \\
\text { aplicação distribuída }\end{array}$ \\
\hline
\end{tabular}

detecção de falhas, por sua vez, visa identificar tais falhas de modo que notificações de falha possam ser repassadas a um mecanismo de recuperação adequado.

Falhas podem ser classificadas de acordo com sua natureza. Sobre a natureza de faIhas, Johnson (1989) diferencia falhas de software e hardware. Na área de engenharia de software baseada em componentes, Mariani (2003) adota a classificação de falhas de infraestrutura para falhas ocasionadas por expectativas de um componente de software que não são atendidas pela infraestrutura do sistema. Neste trabalho, falhas de infraestrutura são definidas como defeitos de software ou hardware que impedem o funcionamento correto de um nó computacional que participa da execução de aplicações distribuídas. Também são assim classificadas as falhas no funcionamento das redes de comunicação que conectam estes nós, quando estas isolam o nó computacional do restante da rede. Em contraste, falhas locais são consideradas falhas que fazem com que um ou mais processos da aplicação distribuída sejam interrompidas, embora o nó continue em funcionamento e conectado à grade computacional. Esta distinção se justifica devido aos diferentes métodos de detecção empregados para estas categorias de falhas. A Tabela 2.1 apresenta alguns exemplos de falhas classificadas de acordo com esta nomenclatura.

Para grande parte das aplicações distribuídas, como programas que utilizam bibliotecas MPI, a comunicação entre os nós é necessária para seu funcionamento. Portanto, a falta de comunicação entre os nós também pode ativar erros para estas aplicações. Falhas de infraestrutura, como defeitos nos nós computacionais ou nas redes que os conectam, podem ser detectadas pelos nós vizinhos através da verificação da conectividade de rede com o uso de detectores de falhas distribuídos. Falhas locais, em contrapartida, podem 
ser detectadas diretamente através de monitores de processos, locais aos nós computacionais em que executam, e que se utilizam da funcionalidade de monitoração fornecida pelo sistema operacional.

Falhas de infraestrutura são tipicamente transientes quanto a sua duração em grades computacionais, já que nós computacionais apresentam defeitos e voltam a integrar a grade após manutenção. Uma plataforma tolerante a falhas deve observar esta transitoriedade de modo que os recursos possam voltar a ser utilizados ao serem novamente integrados em funcionamento na grade. De maneira similar, detectores de falhas nestes ambientes devem reconhecer a volta destes nós ao seu funcionamento normal e integração com a grade.

A arquitetura apresentada neste trabalho assume um modelo de falha de parada (failstop ou fail-halt). Neste modelo, um sistema apresenta somente falhas que caracterizam o sistema como parado (halted), com estado externo constante e sem atividade perceptível (AVIZIENIS et al., 2004). A detecção de outros modelos de falha exigiria conhecimento dos componentes específicos em questão (STELLING et al., 1999), como maneiras de validar resultados da computação. Portanto, falhas de infraestrutura infrequentes e que não seguem padrões discerníveis, como um chip de memória que ocasionalmente e de maneira aleatória inverte os bits em uma área de memória utilizada por uma aplicação distribuída, ou locais, como um defeito de desenvolvimento na aplicação distribuída, não serão detectadas a menos que causem a parada de um nó ou seu isolamento da rede. Outros componentes frequentemente utilizados para a computação distribuída, como bibliotecas MPI, também seguem este modelo, interrompendo a execução da aplicação ao detectar problemas (COTI et al., 2006).

Em plataformas distribuídas em que há uma hierarquia de redes conectando os recursos computacionais, é possível que a falha de um nó leve à indisponibilidade de diversos outros nós. Em uma grade computacional, por exemplo, é possível que a falha de um nó de entrada de um cluster integrado à grade desconecte os nós do cluster do restante da grade. Uma plataforma tolerante a falhas deve tratar esta situação, identificando as consequências da falha do recurso e evitando a propagação da falha.

\subsection{Detecção distribuída de falhas}

Detectores de falhas distribuídos, em sua definição mais pura, são módulos de detecção que monitoram um subconjunto de processos no sistema, mantendo uma lista dos proces- 
sos atualmente suspeitos de terem falhado (CHANDRA; TOUEG, 1996). Estes detectores de falhas são considerados não confiáveis pois podem cometer enganos ao passar a suspeitar de um processo que não falhou, ou ao não suspeitar de um processo que falhou. Os enganos são decorrentes da dificuldade em distinguir situações onde processos se encontram em falha de situações onde a comunicação apenas apresenta lentidão. Um detector pode alterar sua opinião sobre o estado dos processos conhecidos a qualquer momento. Diferentes detectores podem apresentar diferentes e até mesmo conflitantes visões do estado dos processos monitorados a qualquer dado instante. Chandra e Toueg (1996) identificam classes de detectores de falha que podem resolver problemas como o consenso e broadcast atômico em um sistema distribuído assíncrono.

Em uma plataforma para a execução de aplicações distribuídas, a detecção distribuída de falhas pode ser utilizada para monitorar nós computacionais sujeitos a falhas de infraestrutura. A lista de processos suspeitos mantida por cada detector identifica, portanto, outros detectores instalados em nós computacionais suspeitos de estarem indisponíveis para a execução de aplicações distribuídas. O conjunto dos demais detectores de falhas conhecidos por um detector é conhecido como sua lista de detectores vizinhos.

Diferentes estratégias de monitoração de nós podem ser empregadas de acordo com as características da plataforma.

\subsubsection{Estratégias de monitoração de nós}

Detectores podem ser categorizados em duas políticas de interação distintas: o modelo push e o modelo pull (HAYASHIBARA; CHERIF; KATAYAMA, 2002). Os detectores apresentados neste trabalho seguem o modelo push. Neste modelo, conforme apresentado na Figura 2.2, um detector de falhas periodicamente envia mensagens heartbeat a seus vizinhos. O intervalo entre o envio das mensagens é conhecido como intervalo de envio ou interrogação $\Delta_{i}$. Para um detector $p$, passando-se o intervalo de timeout $\Delta_{t o}$ da última recepção de uma mensagem heartbeat enviada por um detector vizinho $q, p$ adiciona $q$ a sua lista de detectores suspeitos. Caso em qualquer momento posterior $p$ venha a receber uma mensagem heartbeat de $q$, $p$ remove $q$ de sua lista de detectores suspeitos, pois conclui que $q$ não está falho. Os protocolos que seguem o modelo push são diferenciados pela maneira em que os parâmetros $\Delta_{i}$ e $\Delta_{t o}$ são definidos, pela escolha dos destinatários ou pela forma de transmissão das mensagens heartbeat.

No modelo pull, ilustrado na Figura 2.3, um processo monitorador $p$ periodicamente consulta o estado do processo monitorado $q$ e recebe uma mensagem de retorno caso $o$ 


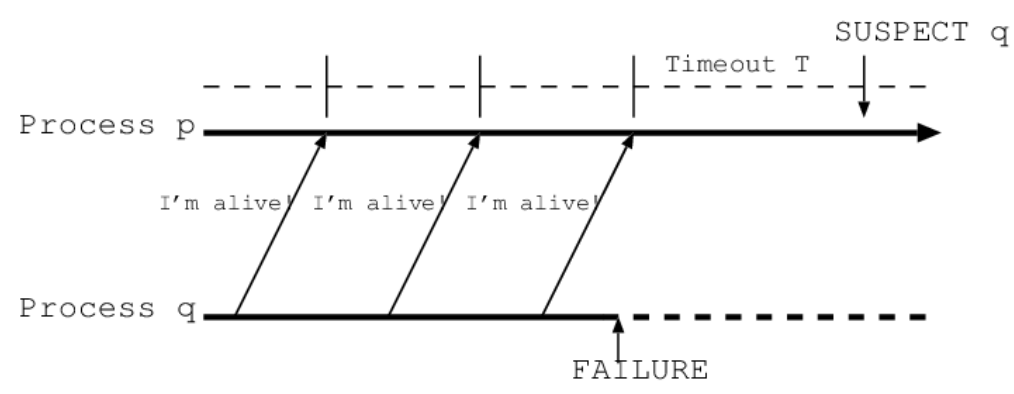

Figura 2.2 - Modelo push (HAYASHIBARA; CHERIF; KATAYAMA, 2002).

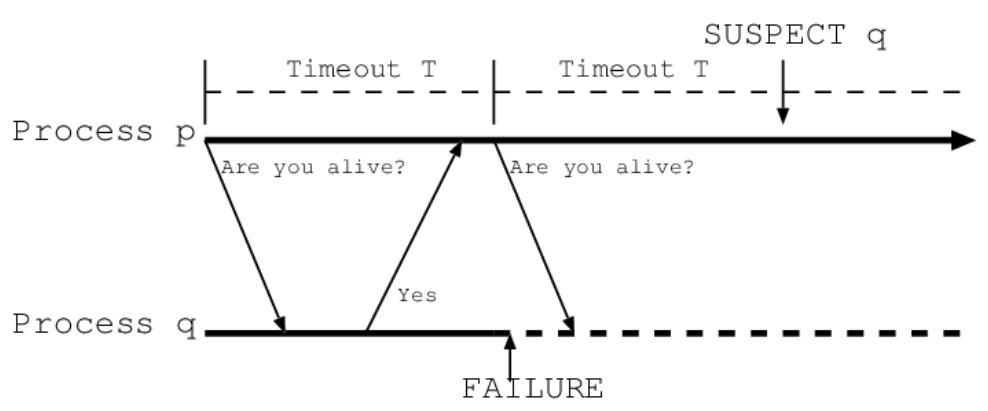

Figura 2.3 - Modelo pull (HAYASHIBARA; CHERIF; KATAYAMA, 2002).

processo monitorado não esteja em falha. Neste modelo, os intervalos de interrogação e timeout podem ser controlados exclusivamente por uma das partes, o que pode levar a uma redução da utilização de banda através da adaptação do protocolo às condições do ambiente (HAYASHIBARA; CHERIF; KATAYAMA, 2002). O modelo pull, porém, apresenta desvantagens como a transferência de duas vezes mais mensagens em comparação ao método push. Neste modelo, também há a necessidade da consideração dos tempos de transmissão da mensagem de interrogação e do tempo de reação do processo monitorado no cálculo do intervalo de timeout estimado (BERTIER; MARIN; SENS, 2002).

\subsubsection{Protocolos gossip tradicionais}

Uma das diferenças entre os detectores que seguem o modelo push é o destino das mensagens heartbeat enviadas. Uma estratégia é o envio de mensagens através de um canal compartilhado utilizando técnicas de broadcast ou multicast, de forma que todos os vizinhos de um detector possam receber e processar suas mensagens. Uma abordagem diferente é a divisão da execução de um detector em ciclos nos quais uma ou mais mensagens são enviadas a detectores escolhidos. As mensagens enviadas contém informações 
sobre os vizinhos do remetente. Ao serem recebidas por um detector, estas informações são integradas com as informações já conhecidas sobre seus vizinhos. Protocolos de detecção que funcionam desta maneira são conhecidos como protocolos gossip (RENESSE; MINSKY; HAYDEN, 1998), e disseminam um grande número de informações com o envio de poucas mensagens.

A cada ciclo, nos algoritmos originais, um detector escolhe de maneira aleatória um único detector vizinho e envia a este uma mensagem contendo as informações de sua lista de vizinhos. Idealmente, durante o intervalo de timeout $\Delta_{t o}$, todos os detectores recebem informações suficientes para que não suspeitem de vizinhos que não estejam em falha. Como a escolha do destinatário é aleatória, há apenas uma probabilidade de que isso aconteça, e esta probabilidade varia de acordo com a relação entre o intervalo entre o envio de mensagens e o intervalo de timeout. Adicionalmente, como a entrega de mensagens é realizada a poucos destinatários, a possibilidade de perda de pacotes torna o algoritmo frágil. Estes protocolos podem ser modificados para que se tornem menos sensíveis a adversidades com a introdução de redundância adicional na distribuição de informações. Como exemplo, detectores que implementam o protocolo Double Binary Round-Robin (GENAUD; JEANNOT; RATTANAPOKA, 2009) enviam mais mensagens heartbeat do que seria necessário para a formação do grafo conectado dos nós. Isto reduz a probabilidade de falha de detecção no caso de falhas de alguns detectores e confere maior previsibilidade ao algoritmo, mas o protocolo requer que os detectores tenham conhecimento prévio de uma lista fixa de detectores vizinhos. Caso uma lista diferente seja utilizada por alguns dos detectores, a escolha de destinatários não funciona adequadamente, potencialmente causando detecções incorretas. Enquanto modificações na lista podem ser negociadas entre os detectores, este procedimento é lento e potencialmente custoso.

\subsubsection{Qualidade de serviço e protocolos adaptativos}

Chen, Toueg e Aguilera (2002) definem o conceito de qualidade de serviço (Quality of Service ou QoS) para detectores de falha como uma especificação que quantifica o comportamento de um detector de falhas de acordo com diversos parâmetros, como o intervalo de tempo entre uma falha e sua correspondente detecção e a capacidade do detector em evitar detecções falsas. O intervalo de tempo entre uma falha e sua correspondente detecção deve ser minimizado para garantir a utilidade do serviço de detecção. Por outro lado, a capacidade do detector em evitar detecções incorretas deve ser priorizada. Detectores adaptativos podem ser utilizados para garantir uma boa qualidade de serviço de 
detecção em uma rede com alterações de comportamento em determinados momentos (HAYASHIBARA; CHERIF; KATAYAMA, 2002).

Detectores adaptativos alteram seus parâmetros para se adequar às condições de rede e atender aos requisitos das aplicações que executam no sistema (BERTIER; MARIN; SENS, 2002). Para as comparações experimentais sobre o comportamento de detectores de falhas distribuídos apresentadas neste trabalho, foi utilizado um simples detector adaptativo baseado no algoritmo para o cálculo do timeout de retransmissão (Retransmission Timeout ou RTO) do protocolo TCP (JACOBSON, 1988):

$$
\begin{aligned}
\text { erro } & \leftarrow R-\bar{x} \\
\bar{x} & \leftarrow \bar{x}+\alpha . \text { erro } \\
\text { desvio } & \leftarrow \text { desvio }+\beta .(\mid \text { erro } \mid- \text { desvio }) \\
\Delta_{t o} & \leftarrow \bar{x}+\gamma . \text { desvio }
\end{aligned}
$$

O intervalo de tempo entre as duas últimas recepções de uma mensagem heartbeat de um mesmo detector remetente $(R)$ é calculado a cada recepção de mensagem heartbeat. O valor da média estimada de $R(\bar{x})$ é mantido em sucessivos cálculos, assim como 0 valor do desvio médio (desvio). Em 2.1, o erro é calculado como a diferença entre $R$ e a média histórica de intervalos de tempo entre mensagens. Em 2.2, um novo valor para a $\bar{x}$ é calculado utilizando o valor atual, o erro calculado e uma constante $\alpha$. Em 2.3, o desvio da média é calculado utilizando o valor atual, o erro calculado e uma constante $\beta$. Finalmente em 2.4, o novo intervalo de timeout $\Delta_{t o}$ é calculado utilizando a média histórica, o desvio e uma constante $\gamma$. $\alpha, \beta$ e $\gamma$ são parâmetros configurados pelo administrador para ajustar o comportamento da estimação quanto a sua reatividade a diferenças entre valores históricos e medições recentes.

O resultado do algoritmo é o intervalo de timeout $\Delta_{t o}$ considerado para a próxima recepção de mensagem do remetente. Esta adaptação permite que o intervalo de timeout $\Delta_{t o}$ seja reduzido, aproximando-se do intervalo de envio de mensagens heartbeat $\Delta_{i}$ se as mensagens forem recebidas em intervalos regulares. A função de estimação reagirá a uma variação no intervalo entre o recebimento de duas mensagens aumentando o intervalo de timeout. 


\section{DETECÇÃO DE FALHAS EM PLATAFORMAS DISTRIBUÍDAS}

A detecção de falhas em um ambiente distribuído se refere a identificação de falhas na infraestrutura da plataforma distribuída ou de falhas locais dos processos da aplicação dis-

tribuída. É, portanto, uma função importante para a implementação de muitas das técnicas de tolerância a falhas. Cabe aos detectores de falhas a identificação de falhas, buscando otimizar o tempo de reação aos eventos e minimizar a quantidade de detecções incorretas.

$\mathrm{Na}$ literatura existente são encontrados diversos trabalhos referentes à construção de detectores de falhas de infraestrutura. Hayashibara, Cherif e Katayama (2002) identificam requisitos para a detecção de falhas em plataformas distribuídas de grande escala e apresentam as abordagens existentes. Estes detectores normalmente seguem o modelo push para a distribuição de heartbeats, em que a ausência da recepção de uma mensagem heartbeat por certo período de tempo é considerada uma indicação de falha do remetente. Alguns detectores de falhas de infraestrutura podem ser classificados como adaptativos. Detectores de falhas adaptativos alteram os parâmetros referentes à detecção ao longo de sua execução, tais como intervalos de timeouts, de modo a melhor acomodar as necessidades das aplicações ou as flutuações da rede.

Neste capítulo são apresentadas as publicações relevantes na área de detecção de falhas em ambientes distribuídos.

\subsection{Protocolos baseados em broadcast e multicast}

Stelling et al. (1999) apresentam um serviço para a detecção de falhas de infraestrutura em grades computacionais integrado ao middleware Globus (FOSTER, 2005) conhecido como Globus Heartbeat Monitor. O serviço, disponível a usuários do middleware, permite que as próprias aplicações distribuídas em execução possam reagir a eventos de falha. Uma aplicação pode escolher ser terminada, ignorar a falha e continuar a execução normalmente, alocar novos recursos para reiniciar os componentes em falha, ou ainda utilizar a replicação e outras técnicas para continuar em execução. Os autores argumentam que apenas as aplicações podem decidir a técnica de recuperação mais apropriada, e portanto o trabalho não implementa nenhuma destas estratégias de recuperação de forma automática. São especificados requisitos para a arquitetura de detecção de falhas, e as decisões de projeto são justificadas neste contexto. A arquitetura é composta por monitores locais, responsáveis pela observação do computador em que executam, geradores de 
mensagens heartbeat que seguem o modelo push; e coletores de dados, que recebem as mensagens heartbeat geradas pelos monitores locais, e identificam componentes em falha com base na ausência destas mensagens. São definidas APls para a interação com estes componentes. O protocolo apresentado realiza o envio de mensagens heartbeat através do transporte UDP e possivelmente utiliza multicast. A eficiência do protocolo quanto ao atraso na detecção e à taxa de falso positivos são constatados através de resultados experimentais. O trabalho propõe o sistema global de detecção de falhas distribuídas como uma alternativa à criação de mecanismos para a detecção de falhas diretamente em cada aplicação.

Bertier, Marin e Sens (2002) apresentam a implementação de um detector distribuído de falhas de infraestrutura. O detector é considerado parte de uma classe de detectores eventualmente perfeitos $(\diamond P)$ segundo a classificação proposta por Chandra e Toueg (1996). Este detector garante que existe um limite de tempo após o qual todos os processos em falha são permanentemente suspeitos por todos os seus vizinhos, e que existe um limite de tempo após o qual detectores em funcionamento correto não são considerados suspeitos por nenhum vizinho em funcionamento correto. O protocolo proposto realiza a adaptação de seus parâmetros em duas camadas. Em uma camada inferior, o intervalo entre a recepção de duas mensagens heartbeat é adaptado de acordo com a estimação proposta por Chen, Toueg e Aguilera (2002), utilizando a estimação do timeout de retransmissão TCP (JACOBSON, 1988) para o cálculo de uma margem de segurança. A camada de adaptação superior utiliza informações sobre as necessidades das aplicações em execução para determinar os parâmetros que governam a adaptação da camada inferior. Desta forma, os autores buscam minimizar os efeitos da flutuação no desempenho da rede, balanceandoos em relação às características das aplicações específicas em execução. Os autores provam a correção do algoritmo proposto e apresentam comparações de desempenho. Em um trabalho posterior, os autores apresentam uma possibilidade de distribuição dos detectores de falhas em domínios, evitando a explosão no número de mensagens heartbeat em circulação na rede (BERTIER; MARIN; SENS, 2003). Esta distribuição é feita automaticamente por meio de um algoritmo de eleição de líderes que farão a comunicação com camadas superiores, e portanto não leva em consideração possíveis limitações de topologia. O protocolo de detecção de falhas exige que a lista de detectores participantes da monitoração mútua seja fixa e conhecida por todos os detectores.

Défago, Hayashibara e Katayama (2003) propõem um sistema de detecção de falhas para sistemas distribuídos em grande escala utilizando detectores de falhas de infraestrutura adaptativos. Os autores buscam a adaptação de parâmetros em três aspectos: 
flutuações nas condições de rede, requisitos e comportamento da aplicação. Os autores argumentam que detectores tradicionais não conseguem conciliar estas diferentes propriedades, e portanto propõem um detector adaptativo que disponibiliza um grau de confiança $\varphi_{p}$ na informação de que determinado processo $p$ se encontra em falha. Uma aplicação interpreta a informação com base neste grau de confiança de maneira arbitrária, de acordo com seus requisitos e sua habilidade em lidar com falhas e notificações de falha incorretas. Este limite não centralizado permite que aplicações tenham diferentes visões sobre requisitos de disponibilidade. Por outro lado, a interpretação dos timeouts que determinam a suspeita ou não de um nó se torna uma responsabilidade exclusiva da aplicação, e não mais uma responsabilidade conjunta do protocolo de detecção e de sua configuração realizada por um administrador com conhecimento das características da rede. A arquitetura proposta pelos autores consiste de detectores de falhas de infraestrutura e locais integrados em um módulo de detecção de falhas, uma biblioteca para interação entre aplicações e os módulos de detecção, e um watchdog responsável por assegurar que o detector de falhas se mantenha em execução. As aplicações se comunicam através da biblioteca com os módulos de detecção para obter informações sobre $\varphi$. Os módulos de detecção são distribuídos de maneira hierárquica em tempo de execução, utilizando o conhecimento da topologia, configurado estaticamente, e através da análise dos padrões de monitoração das aplicações.

Hwang e Kesselman (2003) apresentam um framework para a detecção e recuperação de falhas em grades computacionais que utilizam o middleware Globus. A detecção de falhas é baseada na transmissão de heartbeats e a recuperação é baseada em workflows especificados pelas aplicações. A utilização de um workflow permite a estruturação da aplicação em um grafo direcionado acíclico, em que cada nó representa uma tarefa e as arestas representam as dependências entre as tarefas. O framework proposto permite a recuperação em dois níveis. No nível da tarefa, técnicas como a repetição de uma tentativa de execução ou a replicação de tarefas podem ser usadas para mascarar a falha de uma tarefa. Alternativamente, o checkpointing, que envolve a restauração de um estado da aplicação previamente armazenado, pode ser utilizado neste nível. Já no nível de workflow, tarefas alternativas podem ser lançadas para lidar com as situações de falha. A técnica de detecção de falhas utilizada é descrita como genérica, baseada na transmissão de heartbeats. O requerimento da estruturação de aplicações distribuídas de acordo com workflows reduz a utilidade do framework como uma ferramenta para a detecção de falhas de uso geral. 


\subsection{Protocolos gossip}

Renesse, Minsky e Hayden (1998) introduziram o conceito original de detecção de falhas de infraestrutura com a utilização de protocolos gossip. No protocolo original, as mensagens heartbeat são transmitidas a um nó escolhido aleatoriamente, evitando inundar a rede com mensagens heartbeat. Para grandes redes, os autores propõem um algoritmo gossip multicamada. Os autores assumem um modelo de endereçamento dos nós que reflete a proximidade geográfica, dos quais são derivados limites dos domínios de monitoração. A frequência de comunicação entre detectores em camadas diferentes é reduzida, desta forma buscando reduzir o consumo de banda utilizado pelo protocolo. Com esta menor frequência de comunicação, a qualidade de serviço de detecção de falhas é penalizada quanto ao atraso associado à detecção.

Ranganathan et al. (2001) apresentam novos protocolos gossip, otimizados para a redução de detecções falsas, consumo de banda e escalabilidade. Com o protocolo RoundRobin, o detector envia uma única mensagem a cada turno. Cada detector possui uma cópia da lista ordenada de todos os detectores na rede, e pode portanto identificar qualquer detector através de um índice nesta lista. O destinatário das mensagens heartbeat enviadas a cada turno é calculado com base em uma equação que leva em consideração o número de turnos já ocorridos e o índice associado ao remetente. Este protocolo garante que todos os detectores receberão informações geradas por qualquer detector em um intervalo de tempo máximo limitado. É necessário, porém, que a lista de detectores seja conhecida por todos os detectores e se mantenha inalterada durante toda a execução do protocolo.

O segundo protocolo apresentado por Ranganathan et al. (2001) é o protocolo Binary Round-Robin ou BRR. De maneira similar ao protocolo Round-Robin, o protocolo BRR garante a distribuição de informações em um intervalo de tempo máximo limitado. O protocolo BRR também compartilha as mesma limitações do protocolo Round-Robin, e adicionalmente exige que o número de detectores seja uma potência de 2 . Com esta exigência adicional, o protocolo elimina transmissões redundantes para garantir um menor limite de tempo máximo para a propagação de informações entre os detectores. Outro protocolo derivado do protocolo Round-Robin é apresentado, conhecido como Round-Robin with Sequence Check ou RRSC. Este protocolo permite que um detector identifique uma falha ao deixar de receber uma única mensagem de um remetente, já que cada detector conhece a ordem em que deve receber as mensagens. Desta forma, a detecção de falhas é agilizada. 
Genaud, Jeannot e Rattanapoka (2009) detalham a implementação de tolerância a faIhas em uma plataforma para a execução de aplicações distribuídas que utilizam uma implementação do protocolo MPI (Message Passing Interface) para máquinas virtuais Java em grades computacionais conhecida como P2P-MPI. A detecção de falhas é realizada através de um protocolo gossip conhecido como Double Binary Round-Robin ou DBRR. Neste protocolo, similar ao BRR, os nós enviam mensagens heartbeat a dois nós determinados em cada round. São apresentadas comparações da eficiência do protocolo DBRR em relação ao BRR. Assim como o RR e o BRR, o DBRR exige um número fixo de nós, com endereçamento conhecido. Assim como o BRR, o DBRR exige que o número de detectores seja uma potência de 2. Para implementar a recuperação de falhas, a plataforma utiliza a replicação de tarefas integrada ao sistema de comunicadores do MPI, provendo transparência à aplicação em execução. A plataforma não lida com ambientes com restrições hierárquicas de conectividade.

\subsection{Sistemas de monitoramento}

Plataformas distribuídas frequentemente contam com sistemas de monitoramento. Estes sistemas mantém informações sobre o estado atual e histórico dos recursos monitorados (ZANIKOLAS; SAKELLARIOU, 2005). Estas informações são utilizadas por um sistema de agendamento de tarefas ou para a geração de estatísticas de uso. Paula (2009) divide as informações armazenadas por este tipo de sistema em informações estáticas e dinâmicas. Uma informação é considerada estática se esta é alterada com pouca frequência. Um exemplo de informação estática é o nome associado a um recurso computacional. Já uma informação dinâmica é modificada com grande frequência, tal como a carga de utilização de memória ou processador. Embora sistemas de monitoramento ofereçam informações sobre recursos indisponíveis, as técnicas utilizadas são tipicamente distintas das técnicas utilizadas em detectores de falhas distribuídos, já que a preocupação principal de sistemas de monitoramento é a obtenção de métricas de utilização e a transmissão de grande quantidade destas métricas com baixo consumo de banda, enquanto detectores de falha enfocam a qualidade de serviço de detecção de falhas.

O sistema de monitoramento Hawkeye, desenvolvido para o sistema de agendamento de tarefas para clusters Condor (LITZKOW; LIVNY; MUTKA, 1988), utiliza sensores instalados nos recursos monitorados. Estes sensores periodicamente contatam um servidor centralizado para o envio de mensagens contendo informações de monitoração. As mensa- 
gens seguem o protocolo utilizado para transmissão de informações do Condor conhecido como ClassAds. Não há, portanto, nenhuma forma de detecção distribuída de falhas.

O toolkit Globus oferece um serviço de detecção de falhas através do protocolo GRRP (Grid Registration Protocol), parte do sistema MDS (Monitoring and Discovery System). Este detector de falhas opera com base em heartbeats no modelo push (CZAJKOWSKI et al., 2001). As mensagens heartbeat são enviadas a entidades conhecidas como provedores de informação (information providers) espalhados pela grade computacional. As informações de monitoração são resgatadas através de um protocolo conhecido como GRIP (Grid Information Protocol), que adota o padrão LDAP (Lightweight Directory Access Protocol) para consulta.

O sistema de monitoramento R-GMA (COOKE et al., 2003) especifica a existência de um registro que armazena listas de produtores e consumidores de informações de monitoração em um determinado momento. Para manter seu cadastro junto ao registro, produtores e consumidores enviam mensagens heartbeat simples para indicar sua presença. Diversos registros podem existir em uma mesma grade computacional, e as informações são replicadas entre estes através de um protocolo gossip. Quando um produtor deixa de comunicar-se com o registro, o registro informa agentes consumidores.

O sistema de monitoramento Ganglia (MASSIE; CHUN; CULLER, 2004), originalmente projetado para utilização em clusters de computadores, utiliza mensagens enviadas através de um canal multicast para a distribuição de informações de monitoração. As informações de monitoração também servem como mensagens heartbeat no modelo push. As informações de monitoração coletadas são disponibilizadas através de um canal TCP. $O$ horário de envio das mensagens é randomizado de forma a reduzir o consumo de banda do protocolo. Cada métrica monitorada pelo sistema está associada a um timeout que define sua validade. Caso a validade tenha expirado, a informação associada à métrica deixa de ser considerada confiável. Cada mensagem heartbeat está associada ao horário em que o processo monitorador foi iniciado. Desta maneira, é possível que os vizinhos do processo monitorador identifiquem processos que foram reiniciados e devem ser populados novamente com métricas de monitoramento.

O sistema de monitoramento LIMA (Light-weight Monitoring Architecture), utilizado pelo meta-escalonador GCSE (PAULA, 2009), foi desenvolvido visando facilitar a integração de um sistema de monitoração de recursos computacionais com meta-escalonadores. O sistema conta com pools constituídos de módulos produtores e coletores de dados e um módulo de monitoramento denominado PRMM (Pool Resource Monitoring Manager). Os 
módulos PRMM de diversos clusters estão conectados em uma rede hierárquica, e são contatados para a obtenção de informações de monitoração através de consultas de estrutura similar a consultas SQL a gerenciadores de banco de dados relacionais. As informações estáticas são distribuídas entre os diversos módulos disponíveis na grade, enquanto as informações dinâmicas são armazenadas apenas nos módulos PRMM que as receberam. Não existe monitoração das aplicações em execução nos recursos computacionais ou detecção distribuída de falhas. 


\section{ARQUITETURA PARA DETECÇÃO DE FALHAS EM GRADES COMPUTACIONAIS}

Este capítulo apresenta a arquitetura otimizada para a detecção de falhas em grades computacionais denominada GFDA (Grid Fault Detection Architecture), proposta neste trabaIho. Detectores de falhas produzem notificações de falha e recuperação referentes a recursos computacionais e aplicações distribuídas em execução na grade. Estas notificações são coletadas e transmitidas através das redes que compõem a grade computacional, e ao chegarem a seu destino, podem ser utilizadas para ativar mecanismos automatizados de recuperação das aplicações afetadas pelo evento. Este fluxo de notificações é detalhado nas seções seguintes.

As grades computacionais consideradas neste trabalho são compostas de clusters de computadores e supercomputadores, entre outros recursos. Em cada nó de entrada de um cluster ou supercomputador, um escalonador pode decidir a ordem de execução de tarefas pendentes. As grades também contém computadores conectados diretamente ou em uma hierarquia composta por múltiplas camadas, e estes recursos podem ser gerenciados por escalonadores ou apresentar conectividade direta a grade. Todos os recursos estão conectados através de diversas redes, até mesmo redes de longa distância como a Internet. Os recursos também estão interligados através de um middleware que oferece serviços básicos, tais como a verificação de políticas de acesso, transferência de arquivos entre nós e execução remota de aplicativos.

Neste ambiente, o meta-escalonador da grade, responsável pelo agendamento de tarefas aos escalonadores conectados à grade, pode contar com um módulo para a recuperação de falhas. Este módulo é responsável por recuperar o estado de execução de aplicações distribuídas através de métodos como a restauração de checkpoints, replay de message logging e técnicas de recuperação que contam com a participação da aplicação, entre outras possibilidades. Para a ativação dos mecanismos de recuperação automatizados, o sistema depende de informações sobre o estado das tarefas em execução e o estado dos recursos computacionais que podem ser convocados para substituir recursos em falha. A arquitetura GFDA provê estas informações.

A Figura 4.1 apresenta uma grade computacional que possui as características e limitações descritas, onde parte dos recursos computacionais não podem ser acessados diretamente. Em a), um firewall pode trazer restrições de conectividade para alguns dos recursos computacionais na rede interna. Em b), é possível perceber que os recursos es- 


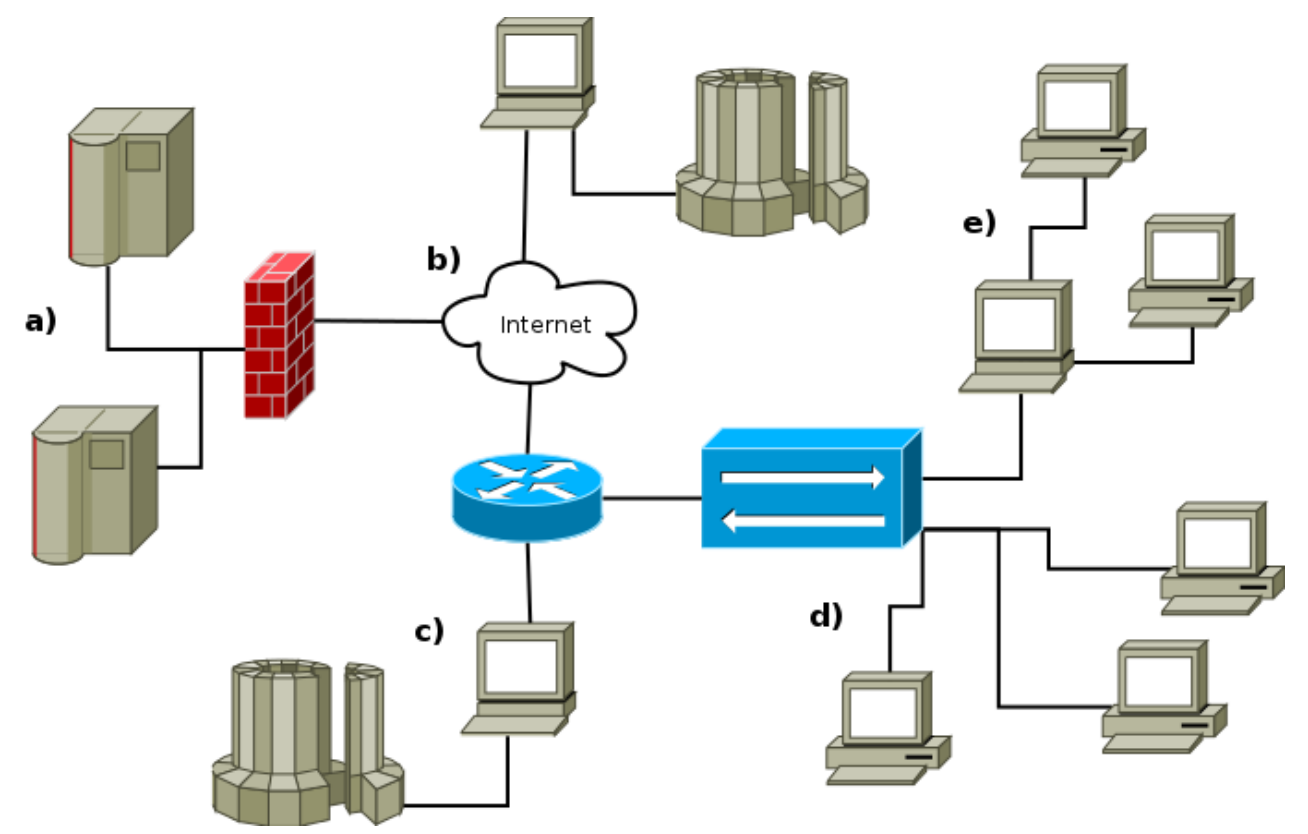

Figura 4.1 - Exemplo de grade em que os recursos não podem ser acessados diretamente.

tão conectados através de uma rede de longa distância (a Internet). Em b) e c), é possível notar que nós de entrada controlam o acesso aos supercomputadores. Já em $d$ ), os recursos estão isolados devido à tradução de endereços de rede (Network Address Translation ou NAT). Em e), uma sub-rede aninhada traz limitações adicionais de conectividade.

As ligações entre computadores conectados em rede podem ser vistas como um grafo direcionado conectado, onde os vértices correspondem aos nós computacionais e as arestas correspondem à capacidade de conexão na camada de rede em cada direção. Em ambientes com tradução de endereço ou outras limitações de acesso, tais como firewalls corporativos, algumas destas ligações são interrompidas. A Figura 4.2 apresenta grafos correspondentes a uma pequena seção de uma rede de computadores. O grafo da Figura 4.2a mostra uma seção onde o nó $A$ não tem conexão direta com os outros nós além de $B$, como aconteceria devido a uma tradução de endereços realizada pelo nó $B$. Já no grafo da Figura 4.2b, os nós $C$ e $D$ não podem receber mensagens de $A$, como poderia acontecer em uma situação com a utilização de firewalls. A arquitetura GFDA foi projetada para que a detecção de falhas que depende da conectividade de rede possa ser realizada mesmo em ambientes com estas restrições.

Este trabalho visa propor uma arquitetura de detecção de falhas otimizada para o cenário descrito. Limitações causadas pela topologia e o baixo desempenho das redes que conectam os recursos são levadas em consideração. Notificações de falha e recuperação são geradas por componentes da arquitetura, e são utilizadas técnicas para minimizar o número de detecções incorretas e falhas não detectadas. A proposta da arquitetura GFDA 


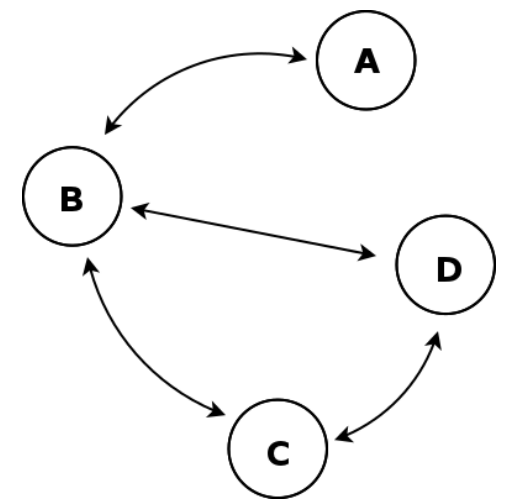

(a) Limitações típicas do NAT

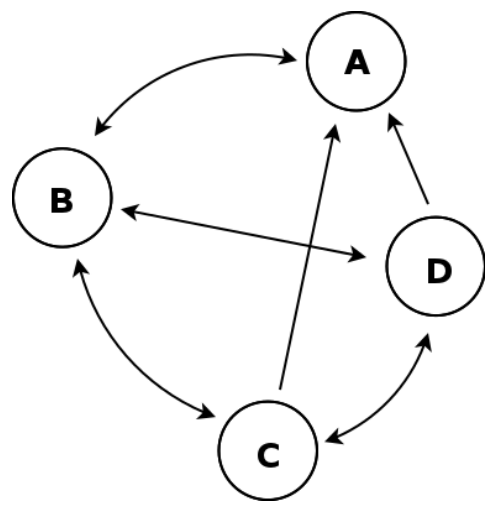

(b) Limitações típicas de firewalls

Figura 4.2 - Grafos mostrando seções da grade com limitações de conectividade.

assume que a grade computacional permite a instalação dos componentes de software da arquitetura nos nós computacionais que integram a grade. A arquitetura proposta pode ser utilizada sem a necessidade de modificação das aplicações distribuídas executadas na grade. Opcionalmente, as aplicações podem ser integradas com bibliotecas oferecidas pela arquitetura GFDA para habilitar a detecção de falhas locais. Também de forma opcional, o meta-escalonador e outros componentes de controle da grade podem ser adaptados para utilizar as informações geradas pela arquitetura para registro, recuperação de falhas ou consulta dos nós disponíveis.

O restante do capítulo está estruturado da seguinte maneira. Uma descrição geral da arquitetura é apresentada, com relação aos componentes de software que a compõem e sua integração. Nos tópicos posteriores, cada componente específico é examinado em maior detalhe e novas técnicas são apresentadas para a funcionalidade de alguns dos componentes. Após este detalhamento, uma análise da proposta apresentada é realizada.

\subsection{Visão geral da arquitetura}

Para atender aos objetivos apresentados, este trabalho propõe uma arquitetura segmentada em três componentes de software: detectores de falhas de infraestrutura, detectores de falhas locais e gerenciadores de falhas. Esta seção descreve brevemente estes componentes e sua integração na arquitetura GFDA. Os componentes são apresentados em detalhe nas seções seguintes.

Os detectores de falhas de infraestrutura são detectores de falhas distribuídos, instalados em cada recurso computacional que deve ser monitorado. Estes funcionam através da 
troca de mensagens heartbeat no modelo push, conforme descrito em detalhes na Seção 2.2 deste documento. Após um intervalo de timeout $\Delta_{t o}$, caso o detector $p$ não tenha recebido uma mensagem heartbeat periódica do detector $q$, $p$ passa a considerar o detector $q$ suspeito de ter falhado. Em um momento posterior, $p$ pode receber nova mensagem de $q$ e removê-lo de sua lista de detectores suspeitos, já que esta informação indica que $q$ não está em falha. Quando um detector passa a suspeitar de outro detector, uma notificação de falha é gerada e propagada através da arquitetura. De maneira similar, quando um detector é removido da lista de suspeitos de outro detector, uma notificação de recuperação é gerada. Já os detectores de falhas locais monitoram os processos que compõem uma aplicação distribuída utilizando a funcionalidade de monitoração disponível, normalmente fornecida pelo sistema operacional ou bibliotecas adicionais. Ao detectar uma falha local, uma notificação de falha também é gerada.

$\mathrm{Na}$ arquitetura GFDA, as notificações de falha e recuperação geradas pelos detectores são recebidas e processadas por gerenciadores de falhas. Os gerenciadores de falhas distribuídos, espalhados na hierarquia da grade, transmitem as notificações através de um canal ponto a ponto até um gerenciador de falhas central, contornando assim as limitações impostas pela topologia da grade. Ao receber uma notificação diretamente de um detector, o gerenciador de falhas distribuído ou central pode estar configurado para realizar seu processamento. O processamento destas notificações visa reduzir a possibilidade da existência de detecções incorretas utilizando a informação recebida de diversos detectores.

O gerenciador de falhas central também recebe informações periódicas sobre o posicionamento dos recursos na hierarquia da grade. Ao receber uma notificação de um gerenciador de falhas distribuído ou após o processamento de uma notificação recebida diretamente de um detector, o gerenciador de falhas central utiliza estas informações de topologia para construir um conjunto de informações de alto nível que são expostas a um consumidor final. Este consumidor final, não definido pela arquitetura GFDA, pode utilizar estas informações para ativar métodos de recuperação ou efetuar o registro detalhado das notificações. O consumidor final pode ser um meta-escalonador que realiza a recuperação de aplicações distribuídas interrompidas por uma falha, por exemplo.

A arquitetura proposta posiciona os componentes conforme ilustrado no exemplo da Figura 4.3. Os domínios de monitoração, delimitados pelos círculos maiores, são agrupamentos de recursos computacionais definidos pelo administrador e gerenciados por um único gerenciador de falhas. Sua função é restringir o escopo da monitoração, já que os detectores em um mesmo domínio de monitoração não monitoram ou se comunicam com 


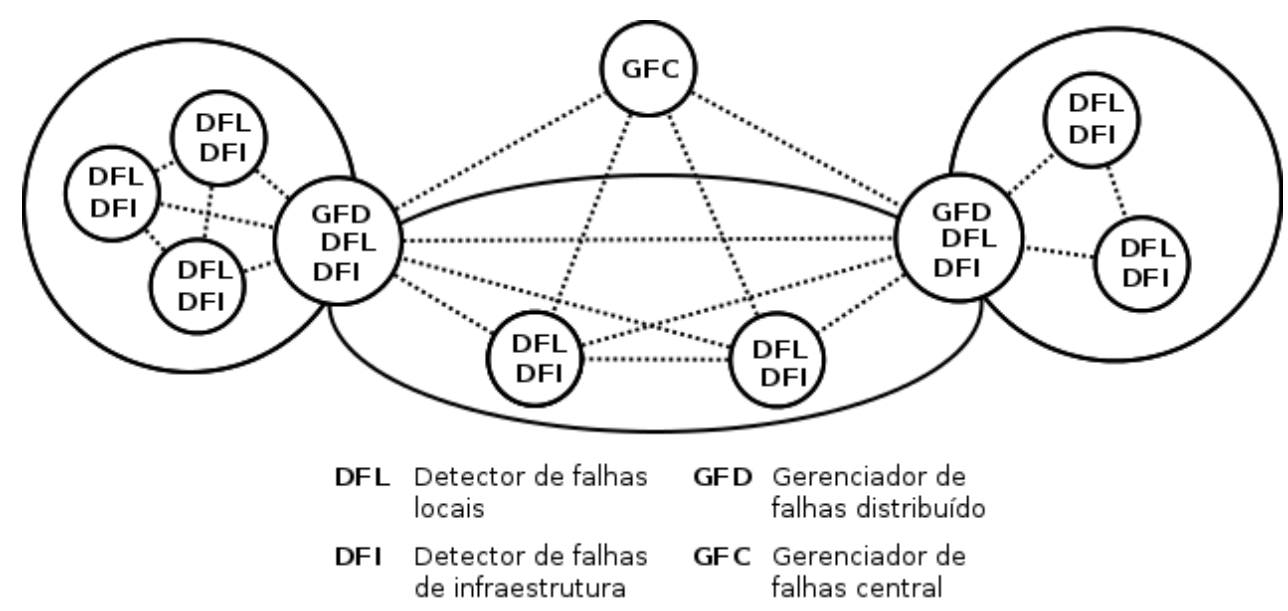

Figura 4.3 - Exemplo da estrutura dos componentes da arquitetura proposta em uma grade.

detectores além do domínio. Desta maneira, a criação de domínios de monitoração pode ser utilizada para reduzir o tráfego de mensagens heartbeat em redes de longa distância ou com outras limitações de consumo de banda. A utilização de domínios de monitoração separados também permite a utilização de diferentes técnicas de detecção de falhas de infraestrutura na mesma grade computacional.

A separação dos nós em domínios de monitoração também possibilita a detecção de falhas de infraestrutura em redes hierárquicas, como grades computacionais compostas de clusters com endereçamento privado ou outras restrições de conectividade. Para estes casos, os nós com comunicação restrita podem ser agrupados em domínios de monitoração. Um gerenciador de falhas distribuído é instalado no nó de entrada do cluster, já que este nó especial tem conectividade com o restante da grade. As notificações de falha e recuperação geradas pelos detectores em execução no domínio são enviadas a este gerenciador de falhas, que assim pode então transmiti-las através da topologia da grade.

Os nós computacionais nos quais está instalado um gerenciador de falhas distribuído também podem manter detectores de falhas distribuídos em execução para que possam ser monitorados, conforme ilustrado no exemplo da Figura 4.3. Nesta situação, estes nós estão presentes em dois domínios de monitoração. Em um domínio, estes nós servem de gerenciadores de falhas para o recebimento das notificações de falha e recuperação. No outro domínio a que estão associados, estes nós são monitorados e enviam notificações de falha e recuperação a um outro gerenciador de falhas, posicionado em uma camada superior na hierarquia da grade.

A Figura 4.4 resume todos os fluxos possíveis de notificação de falha e recuperação entre os componentes de arquitetura, partindo da notificação gerada por um detector e chegando na apresentação do evento ao consumidor final. Diversos gerenciadores de fa- 


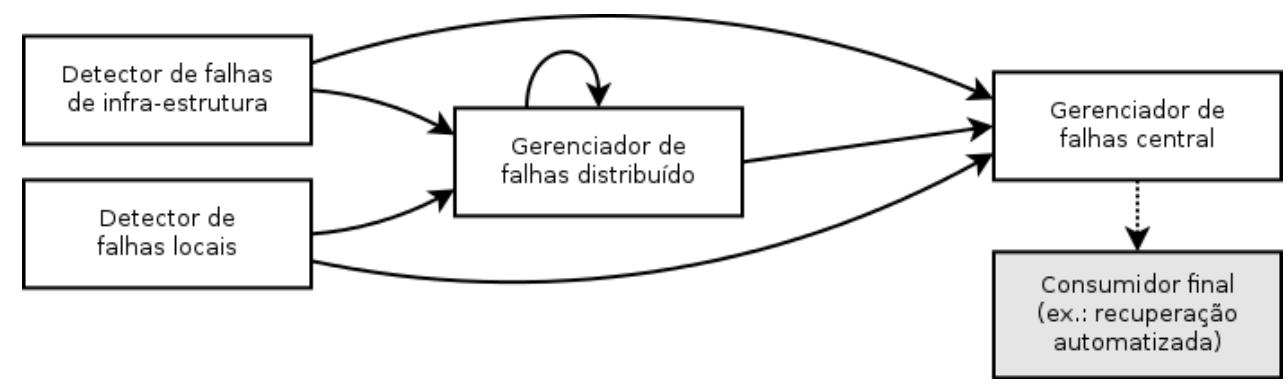

Figura 4.4 - Fluxos possíveis de notificações entre os componentes da arquitetura proposta.

Ihas podem participar da transmissão de uma única notificação, em cadeia. Não há limite definido pela arquitetura GFDA para o número de gerenciadores de falhas a serem utilizados em cadeia, mas as configurações mais comuns contam com duas ou três camadas, espelhando a hierarquia da grade computacional.

\subsection{Detectores de falhas de infraestrutura}

Os detectores de falhas de infraestrutura operam com base na recepção de mensagens heartbeat para a detecção de falhas de componentes da infraestrutura. Um simples detector de falhas de infraestrutura envia mensagens heartbeat através de um canal compartiIhado utilizando técnicas de multicast ou broadcast. O detector também recebe mensagens heartbeat de detectores vizinhos, também chamados de peers. Caso as mensagens heartbeat de certo vizinho não sejam recebidas por um intervalo de timeout $\Delta_{t o}$, o detector considera o vizinho suspeito de estar em falha. No momento em que um vizinho é considerado suspeito, o gerenciador de falhas responsável para o domínio de monitoração em que o detector se encontra é notificado através de um canal ponto a ponto. Enquanto outras arquiteturas separam os detectores entre módulos de detecção e coletores de heartbeats, trazendo assim uma maior flexibilidade nas opções para o posicionamento dos componentes, a arquitetura GFDA mantém estas duas funcionalidades juntas no detector. Esta decisão simplifica a implementação e implantação dos componentes.

$\mathrm{Na}$ arquitetura GFDA, os detectores de falhas dispensam configuração prévia da lista de vizinhos presentes em seu domínio de monitoração. Desta maneira, em ambientes dinâmicos como grades computacionais de grande escala, novos recursos são descobertos de maneira automática por cada detector de falhas. Ao receber a primeira mensagem heartbeat de um vizinho até então desconhecido através de um canal multicast, este é adicionado à lista de vizinhos do detector. Caso as mensagens provenientes deste vizinho 
deixem de ser recebidas, o vizinho será considerado suspeito e o evento será traduzido em uma notificação de falha enviada ao gerenciador de falhas.

A separação da grade em domínios de monitoração permite que diferentes estratégias de detecção de falhas possam estar em funcionamento em paralelo, em domínios diferentes. Além da monitoração através do envio de mensagens heartbeat em canais multicast, estratégias como o envio através de canais ponto a ponto também podem ser exploradas, desde que sejam utilizadas em um domínio diferente. Em protocolos gossip (RENESSE; MINSKY; HAYDEN, 1998), os detectores de falhas enviam mensagens heartbeat a seus vizinhos através de canais ponto a ponto. Estas mensagens contém informações de terceiros, visando compensar com redundância a potencial perda de informação devido ao envio de mensagens a poucos receptores. Os protocolos gossip são descritos em mais detalhes no item 2.2.2. Uma técnica que combina a redundância adicional dos protocolos gossip ao envio de heartbeats através de canais multicast é apresentada a seguir.

\subsubsection{Gossip payload}

O gossip payload é uma estratégia proposta para a detecção de falhas de infraestrutura na arquitetura GFDA. A técnica visa obter maior resistência a condições adversas na rede em que a comunicação entre os detectores acontece. A estrutura básica do detector multicast é mostrada na Figura 4.7. A robustez adicional proporcionada pelo protocolo é atingida através da introdução de redundância nas mensagens heartbeat enviadas pelos detectores. Cada mensagem conta com informações provenientes da lista de detectores vizinhos mantida pelo remetente. Este conceito se assemelha ao funcionamento de protocolos gossip tradicionais, mas aplicado a detectores baseados em comunicação multicast, desta forma combinando as vantagens dos dois tipos de protocolos. O conteúdo adicional presente no corpo (payload) de cada mensagem é chamado gossip payload.

O detector envia mensagens heartbeat a cada intervalo $\Delta_{i}$ através de um canal multicast, conforme observado na Tarefa 1. Estas mensagens contêm a identificação do detector remetente e seu número de sequência. Se o gossip payload está sendo utilizado, informações sobre os vizinhos de $p$ devem ser adicionadas à mensagem. Para cada vizinho que não está considerado em falha, são adicionadas à mensagem seu identificador e seu número de sequência. A utilização de números de sequência ao invés de horários permite o funcionamento do protocolo mesmo que os relógios locais dos detectores não estejam sincronizados. $O$ algoritmo requer que os detectores possam ser identificados de maneira única e que estejam cientes de sua própria identificação. 


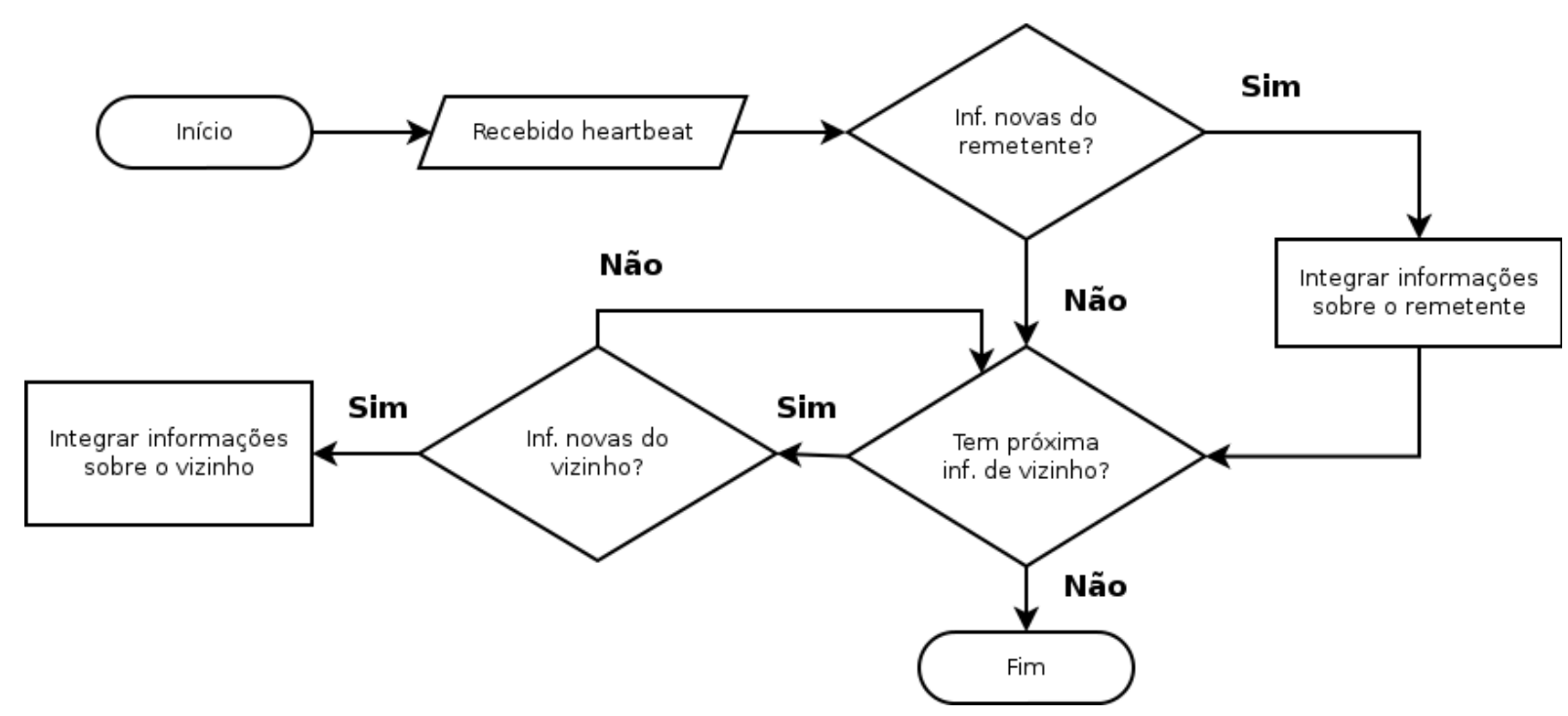

Figura 4.5 - Representação simplificada da Tarefa 2 no gossip payload.

A Tarefa 2 mostra a recepção de uma mensagem heartbeat. Ao receber uma mensagem, o procedimento visto é invocado para o detector remetente da mensagem, assim como para todos seus vizinhos encontrados no gossip payload. Este procedimento, mostrado na Figura 4.8, recebe como parâmetros o identificador do detector, seu número de sequência contido na mensagem e o horário de recebimento da mensagem. O procedimento é responsável pela atualização das informações conhecidas por um detector. Caso o vizinho q não seja conhecido, este é adicionado à lista de vizinhos, desta forma realizando a descoberta automática de detectores. Caso contrário, a informação só é processada se o número de sequência associado à informação sobre o vizinho supera o número de sequência já conhecido pelo detector. Com isso, somente informações atualizadas de terceiros são processadas. Se as informações processadas indicam que um vizinho previamente considerado em falha está em funcionamento normal, uma notificação de recuperação é gerada. A Figura 4.5 representa de maneira simplificada a Tarefa 2 a partir do recebimento de uma mensagem heartbeat, omitindo o procedimento de descoberta automática de vizinhos. Os números de sequência são comparados para determinar se as informações sobre o remetente e vizinhos já foram integradas anteriormente.

A verificação dos timeouts é realizada na Tarefa 3. Cada detector armazena o horário de última recepção de informações de cada detector vizinho em ult_visto. Quando informações sobre um vizinho não são recebidas por um intervalo de timeout $\Delta_{t o}$, o vizinho passa a ser considerado suspeito e uma notificação de falha é gerada. Caso nenhuma informação seja recebida em um intervalo de limpeza $\Delta_{c l}>\Delta_{t o}$, o vizinho, já considerado em falha, passa a ser considerado parado ou inequivocamente em falha. Neste caso, o número de sequência associado ao vizinho é reinicializado para zero. 


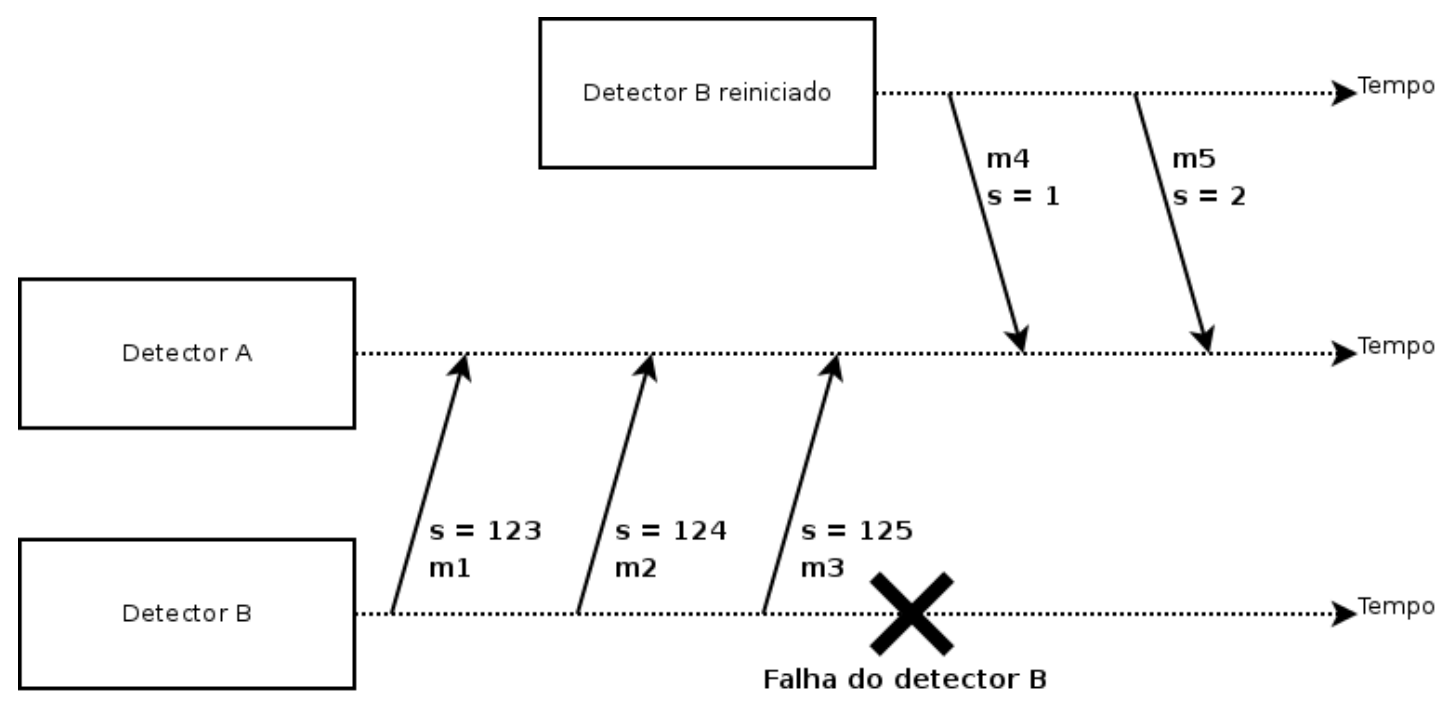

Figura 4.6 - Exemplo da utilidade do intervalo de limpeza $\Delta_{c l}$ para o funcionamento de detectores de falhas distribuídos.

A utilização de um intervalo de limpeza permite que os detectores voltem a ser considerados em funcionamento correto após manutenção. Um detector que sofre manutenção é reiniciado com um número de sequência 1 . Se o intervalo de limpeza não fosse considerado, seus vizinhos somente reconheceriam as informações contidas em suas mensagens heartbeat após o número de sequência encontrado nas mensagens do detector recuperado superar o número de sequência encontrado em sua última mensagem enviada antes de sua interrupção. Com o intervalo de limpeza, após $\Delta_{c l}$, o número de sequência é reiniciado e portanto as mensagens enviadas pelo detector recuperado deixam de ser ignoradas. A Figura 4.6 mostra a importância do intervalo de limpeza. Neste diagrama, o detector $B$ envia mensagens heartbeat ao detector $A$, e eventualmente vem a falhar após o envio da mensagem $m 3$. Caso o intervalo de limpeza não tenha expirado até o recebimento das mensagens $m 4$ e $m 5$, estas serão ignoradas, já que $A$ somente aceitaria mensagens heartbeat com número de sequência superior a 125 .

\subsubsection{Detectores adaptativos com gossip payload}

Conforme detalhado no item 2.2.3, detectores adaptativos estimam seus parâmetros de maneira dinâmica a fim de melhorar a qualidade de serviço do sistema de detecção de faIhas de infraestrutura. Esta adaptação pode ser feita com base nas condições detectadas da rede, com base nos requisitos das aplicações ou das políticas em vigor, ou ainda com base em uma combinação destes parâmetros. Este tópico apresenta modificações realizadas no detector multicast que utiliza a técnica de gossip payload nas mensagens heartbeat para que o intervalo de timeout $\Delta_{t o}$ seja adaptado às condições da rede. Esta adaptação 
1: $\{$ Para cada detector $p:\}$

2:

3: $\{$ Inicialização\}

4: vizinhos $\leftarrow \emptyset$ \{Conjunto de detectores vizinhos\}

5: suspeitos $\leftarrow \emptyset$ \{Conjunto de detectores suspeitos\}

6: parados $\leftarrow \emptyset$ \{Conjunto de detectores considerados interrompidos\}

7: ult_visto $\leftarrow \emptyset$ \{Conjunto de horários de última recepção de heartbeats por detector\}

8: $s e q \leftarrow \emptyset$ \{Conjunto de números de sequência por detector\}

9: $\operatorname{seq}(p) \leftarrow 1$ \{Sequência inicial do detector em execução\}

10:

11: $\{$ Tarefa 1: Envio periódico de heartbeats $\}$

12: A cada intervalo $\Delta_{i}$ :

13: $m \leftarrow\{p, \operatorname{seq}(p)\}$

14: if gossip payload habilitado pelo administrador then

15: $\quad$ for all detector $q \in$ vizinhos - suspeitos do

16: $\quad m \leftarrow m+\{q, \operatorname{seq}(q)\}$

17: end for

18: end if

19: enviar_multicast $(m)$

20: $\operatorname{seq}(p) \leftarrow \operatorname{seq}(p)+1$

21:

22: \{Tarefa 2: Recepção de heartbeats\}

23: Ao receber uma mensagem $m$ enviada por $q$ :

24: $r \leftarrow$ horario_recebimento $(m)$

25: visto $\left(q, s e q \_q \_e m \_m, r\right)\left\{s e q \_q \_e m \_m\right.$ corresponde à sequência de $q$ na mensagem $\left.m\right\}$

26: for all detector $z \in m-\{q\}$ do

27: $\quad \operatorname{visto}\left(z, s e q \_z \_e m \_m, r\right)\left\{s e q \_z \_e m \_m\right.$ corresponde à sequência de $z$ na mensagem $m\}$

28: end for

29:

30: $\{$ Tarefa 3: Verificação de timeouts\}

31: Em ult_visto $(q)+\Delta_{t o}, \forall q \in$ vizinhos - suspeitos:

32: $\quad$ suspeitos $\leftarrow$ suspeitos $+\{q\}$

33: notificar_falha $(q)$

34: Em ult_visto $(q)+\Delta_{c l}, \forall q \in$ suspeitos - parados:

35: $\quad$ parados $\leftarrow$ parados $+\{q\}$

36: $\quad \operatorname{seq}(q) \leftarrow 0$

Figura 4.7 - Estrutura básica do detector multicast. 


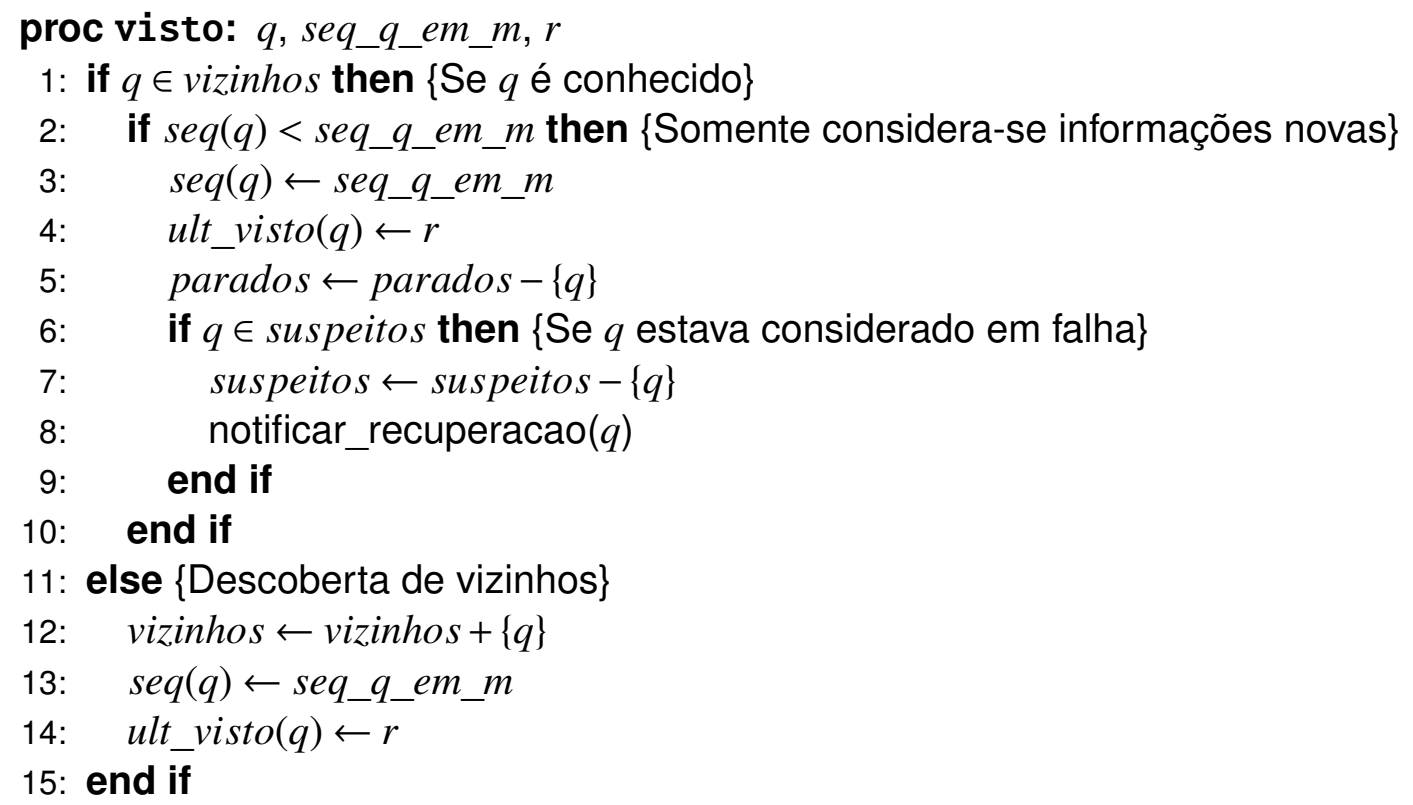

Figura 4.8 - Procedimento visto para o detector multicast simples.

permite que o intervalo de timeout seja reduzido e se aproxime do intervalo de envio das mensagens heartbeat $\Delta_{i}$, desta forma permitindo aos detectores que identifiquem falhas com maior rapidez. Em momentos em que a rede se apresenta gradualmente mais congestionada, $\Delta_{t o}$ se torna maior, evitando que detecções incorretas sejam causadas por flutuações no desempenho da rede.

A utilização do conceito de gossip payload para detectores multicast pode ser transportada para um detector adaptativo simples com algumas modificações. A Tarefa 2 deve ser alterada para que seja passado um parâmetro extra ao procedimento visto. Este parâmetro deve informar se a chamada está sendo realizada com referência ao detector que originou a mensagem sendo processada ou se o detector referenciado foi encontrado na lista de detectores trazida na mensagem. Um detector adaptativo que utiliza o intervalo de tempo entre informações recebidas para a estimação do intervalo de timeout $\Delta_{t o}$ não deve considerar informações recebidas de terceiros para a estimação, já que não há relação entre o intervalo de tempo entre recepções de forma direta e indireta. A Figura 4.9 mostra o procedimento visto modificado para funcionamento em um detector multicast adaptativo. Caso a informação recebida seja proveniente de uma fonte direta, a diferença entre o horário de recepção da informação e a última recepção do vizinho é utilizada para o cálculo da estimativa de horário de próxima recepção. O procedimento alimenta_funcao_avaliadora é responsável por alimentar a função que realiza este cálculo, e pode seguir o algoritmo detalhado no item 2.2.3. Este procedimento mantém a média histórica de in- 
proc visto: $q$, seq_q_em_m, $r$, direta

1: if $q \in$ vizinhos then $\{$ Se $q$ é conhecido\}

2: $\quad$ if $\operatorname{seq}(q)<s e q \_q \_e m \_m \vee$ direta then $\{$ São consideradas informações novas ou diretas\}

3: $\quad$ if direta $\wedge \exists$ ult_visto $(q)$ then $\{$ Se a informação é direta e há recepção anterior\}

4: $\quad \Delta_{t o}(q) \leftarrow$ alimenta_funcao_avaliadora $\left(q, r-u l t \_v i s t o(q)\right)$

5: $\quad$ end if

6: $\quad s e q(q) \leftarrow s e q \_q \_e m \_m$

7: $\quad$ ult_visto $(q) \leftarrow r$

8: $\quad$ parados $\leftarrow$ parados $-\{q\}$

9: $\quad$ if $q \in$ suspeitos then $\{\mathrm{Se} q$ estava considerado em falha\}

10: $\quad$ suspeitos $\leftarrow$ suspeitos $-\{q\}$

11: $\quad$ notificar_recuperacao $(q)$

12: $\quad$ end if

13: end if

14: else $\{$ Descoberta de vizinhos\}

15: $\quad$ vizinhos $\leftarrow$ vizinhos $+\{q\}$

16: $\quad s e q(q) \leftarrow s e q \_q \_e m \_m$

17: $\quad$ ult_visto $(q) \leftarrow r$

18: end if

Figura 4.9 - Procedimento visto para o detector multicast adaptativo.

tervalos de recepção e retorna uma estimativa para o intervalo entre o horário atual e o horário da próxima recepção de mensagem heartbeat do detector em questão.

No detector adaptativo descrito neste trabalho, o intervalo de timeout $\Delta_{t o}$ pode exceder o intervalo de limpeza $\Delta_{c l}$ caso haja uma grande variação nos intervalos entre o recebimento de mensagens heartbeat. Quando isso acontece, um detector passa a considerar seus vizinhos parados e reinicializa seu número de sequência para 0 , aceitando posteriormente mensagens potencialmente desatualizadas de terceiros. Para evitar este problema, o detector adaptativo não deve considerar parados os detectores que já não estejam considerados em falha.

\subsection{Detectores de falhas locais}

Detectores de falhas locais são monitores de processos do sistema operacional. Para utilizar a funcionalidade de detecção de falhas locais prevista na arquitetura GFDA, é necessário que a aplicação seja adaptada. Os processos da aplicação devem ser ligados a uma das bibliotecas de detecção de falhas locais fornecidas pela arquitetura. Estes processos devem também notificar o monitor local sobre sua terminação normal através de uma API. Em tempo de execução, caso os processos da aplicação sejam terminados sem 
que notifiquem o monitor sobre sua terminação normal, o detector passará a identificar sua terminação como anormal e notificações de falhas referentes aos processos serão geradas.

A arquitetura proposta permite a criação de diferentes estratégias de monitoração de processos locais, que podem ser empregadas através da utilização de distintas bibliotecas fornecidas na implementação da arquitetura. Isso permite a escolha de estratégias de monitoração mais apropriadas às características das diferentes aplicações.

\subsection{Gerenciadores de falhas}

Os gerenciadores de falhas são responsáveis por três tarefas distintas. É de sua responsabilidade o transporte das notificações de falha e recuperação geradas por detectores de falhas de infraestrutura e detectores locais. Em casos em que parte dos nós não possui conectividade com o gerenciador de falhas central, como para nós sem acesso ao restante da grade, a transmissão das notificações para além do domínio de monitoração não pode acontecer diretamente. É necessário que os nós encaminhem as notificações em nível de aplicação por meio dos nós integrantes do domínio que têm conectividade externa, estabelecendo através destes um caminho ao destino da notificação. Na arquitetura proposta, este encaminhador toma a forma do gerenciador de falhas distribuído. Também é de responsabilidade de um gerenciador de falhas central o envio das notificações de falha e recuperação e toda informação associada a um consumidor final destas informações. E, finalmente, é de sua responsabilidade a realização do processamento das notificações de falhas recebidas diretamente de detectores de falhas de infraestrutura, visando otimizar a qualidade de serviço de detecção de falhas. O gerenciador de falhas, portanto, fica encarregado em encaminhar as notificações e amenizar o efeito das notificações contraditórias, causadas por flutuações na performance da rede ou de processamento, ou inconsistentes, causadas por visões distintas do estado do domínio de monitoração entre os nós.

Em sua maioria, grades computacionais apresentam uma estrutura hierárquica em que recursos estão localizados em redes sem endereçamento público, como no caso de nós de processamento de um cluster que integra a grade (PAULA, 2009). Estes clusters de computadores recebem tarefas registradas em seus nós de entrada. Tradicionalmente, estes nós de entrada também são o único canal de comunicação dos nós computacionais com o restante da grade. É razoável exigir maior disponibilidade de serviço de um nó de entrada já existente, por exemplo, já que se trata de uma peça chave na infraestrutura do cluster. Propõe-se a utilização dos nós de entrada para realizar um processamento 
de notificações de falha e recuperação emitidas pelos detectores de falhas distribuídos. Este processamento visa reduzir o número de enganos produzidos pelos detectores, se utilizando das informações recebidas de todo o conjunto de detectores.

A utilização de dois métodos de processamento distintos é proposta. Um dos métodos é a filtragem de notificações conflitantes, realizada com a manutenção de cada notificação em espera por um período de tempo determinado. Caso neste período seja recebida uma notificação que contradiga uma informação armazenada anteriormente, o processamento de notificações descarta as informações em conflito imediatamente. Após esta espera, as notificações que ainda se encontrem armazenadas são consideradas válidas e podem ser repassadas a um mecanismo de registro ou recuperação de falhas, conforme apropriado. Este método é superior a estratégias como aumentar o intervalo de timeout $\Delta_{t o}$ dos detectores de falhas distribuídos, já que o processamento de falhas opera com base em informações provenientes de todos os detectores no domínio, promovendo uma filtragem com maior precisão.

O segundo método para o processamento de notificações utiliza um local de armazenamento temporário para exigir um quórum de notificações. As notificações são mantidas neste local de armazenamento até que uma parcela dos detectores de falhas distribuídos envie notificações compatíveis, estabelecendo o quórum mínimo para que a notificação passe a ser aceita. De maneira similar, assim que as notificações são consideradas válidas, estas podem ser repassadas a um sistema de registro ou recuperação. A exigência de quórum confere ao sistema maior resistência com relação a notificações incorretas, já que é necessário que um número de detectores igual ou superior ao exigido pelo quórum apresente as mesmas informações. Esta funcionalidade também protege o sistema contra o comportamento de detectores incorretos ou maliciosos.

Os gerenciadores de falhas também acumulam informações sobre a disposição dos recursos monitorados na topologia da rede. Em intervalos regulares, os detectores de falha de infraestrutura anunciam sua presença ao gerenciador de falhas configurado para o domínio de monitoração em que se situam. Esta comunicação é realizada através de um canal ponto a ponto. Os gerenciadores de falhas distribuídos, por sua vez, anunciam sua presença de maneira similar, comunicando-se com o próximo gerenciador de falhas na cadeia. Os gerenciadores de falhas também publicam informações sobre os detectores conectados diretamente a eles. Esta comunicação é ilustrada na Figura 4.10. As setas correspondem ao fluxo de informação para o estabelecimento do conhecimento sobre a topologia da grade. 


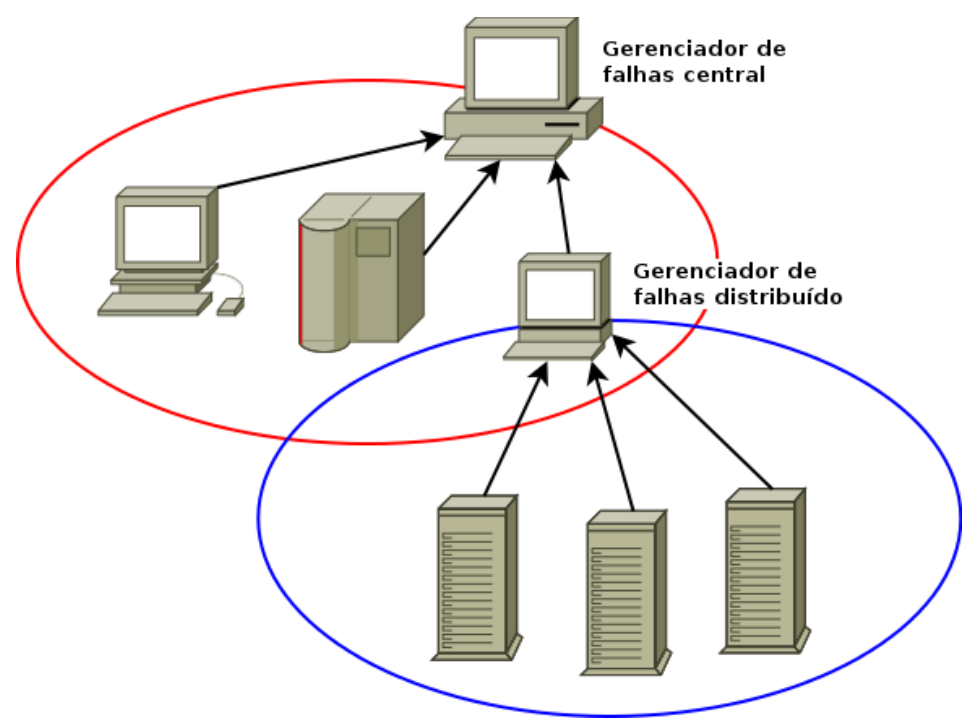

Figura 4.10 - Comunicação para estabelecimento da visão da topologia.

O gerenciador de falhas mantém, dessa forma, uma representação da estrutura hierárquica de dependências entre recursos computacionais. Na ocasião de uma falha de infraestrutura, o gerenciador de falhas central pode informar sobre a indisponibilidade de todos os recursos afetados pelo evento. No exemplo da Figura 4.10, o servidor executando o gerenciador de falhas distribuído para o domínio de monitoração representado pelo círculo azul também faz parte do domínio de monitoração representado pelo círculo vermelho, ou seja, tem um detector de falhas de infraestrutura instalado e configurado para este domínio. Caso este gerenciador de falhas distribuído se torne indisponível, os recursos do domínio de monitoração azul, como os nós computacionais representados neste domínio, também serão considerados indisponíveis pelo gerenciador de falhas central.

Adicionalmente, é possível cadastrar tarefas associadas a nós computacionais junto ao gerenciador de falhas central em tempo de execução. Quando este cadastramento é realizado, a informação repassada ao consumidor final é incrementada com informações sobre as tarefas afetadas. Ou seja, se um nó computacional ou processo monitorado falha, a arquitetura GFDA relata o conjunto exato de nós afetados como consequência, assim como o conjunto de tarefas afetadas. As tarefas podem ser afetadas por falhas nos nós computacionais que executam algum de seus processos, ou devido a falhas diretamente em um de seus processos. Os dados provenientes dos agendamentos realizados por um meta-escalonador na grade podem ser utilizados para alimentar o gerenciador de falhas com as informações necessárias. Esta funcionalidade permite uma integração simples com meta-escalonadores existentes. 
A utilização de gerenciadores de falhas introduz um ponto de falha. Caso um gerenciador de falhas venha a ficar indisponível, todos os detectores de falhas de infraestrutura em seu domínio de monitoração serão considerados em falha. Em grades computacionais hierárquicas, este ponto de falha já existe, já que os nós de um cluster de computadores ou supercomputador estão normalmente acessíveis apenas através de uma máquina de entrada. É exatamente neste nó que os gerenciadores de falha devem ser instalados, visando não introduzir um ponto de falha adicional.

Gerenciadores de falhas permitem, portanto:

a) A realização da transmissão de dados obtidos em domínios de monitoração sem acesso ao restante da grade;

b) A melhoria da qualidade do serviço de detecção de falhas através do processamento de notificações de falha e recuperação recebidos;

c) A integração da arquitetura de detecção de falhas com sistemas externos, como sistemas de recuperação automatizada integrados a meta-escalonadores.

\subsection{Considerações sobre a arquitetura proposta}

Conforme descrito nos itens anteriores, a arquitetura GFDA, proposta neste trabalho, reúne diversas técnicas de detecção de falhas e ferramentas adicionais para proporcionar melhor qualidade de serviço. Com isso, a arquitetura busca estabelecer uma plataforma sobre a qual novas estratégias de detecção de falhas possam ser implementadas. A arquitetura também é posicionada de forma a não depender de middlewares ou meta-escalonadores específicos, sendo facilmente interoperável com as ferramentas instaladas na grade.

A arquitetura proposta pode servir de base para a construção de um sistema de tolerância a falhas para grades computacionais. Por este motivo, foram tomadas decisões que priorizam a qualidade de serviço de detecção de falhas em condições adversas, como as encontradas em grades computacionais que conectam organizações virtuais através de redes de longa distância. A possibilidade de utilização de algoritmos com características distintas na mesma grade computacional, comportando grande heterogeneidade na composição das redes que ligam a grade e os recursos nela disponibilizados, também é considerada uma prioridade. As decisões favorecem a viabilização de detecção de falhas em ambientes com restrições de conectividade entre os nós computacionais. 
Os protocolos de detectores de falhas de infraestrutura que utilizam o gossip payload apresentam um tamanho maior das mensagens heartbeat transmitidas. O tamanho das mensagens é incrementado linearmente de acordo com o número de detectores no mesmo domínio de monitoração. Este tamanho adicional, porém, é aceitável ao levar em consideração o ganho em qualidade de serviço obtido através da utilização da técnica. A arquitetura GFDA também permite a segmentação das redes em domínios de monitoração menores, desta forma reduzindo significativamente o tamanho das mensagens heartbeat transmitidas pelos detectores. A arquitetura proposta permite que seja utilizado um detector que não utiliza técnicas de redundância adicionais em domínios de monitoração onde estas técnicas não resultam em melhoria na qualidade de serviço de detecção, ou caso as consequências negativas trazidas pela transmissão de mensagens de maior tamanho sejam superiores ao seu benefício para o domínio. 


\section{IMPLEMENTAÇÃO}

A arquitetura GFDA foi implementada visando realizar uma avaliação das estratégias propostas. A implementação foi realizada de maneira direta, sem a utilização de simuladores. A arquitetura foi implementada na linguagem $\mathrm{C}_{++}$para plataformas Linux, e uma suíte de testes foi desenvolvida para avaliar a implementação e verificar as funcionalidades projetadas. A estrutura da implementação facilita o desenvolvimento de novos detectores e gerenciadores de falhas. Este capítulo apresenta os detalhes da implementação realizada.

\subsection{Detectores de falhas de infraestrutura}

Os detectores de falhas de infraestrutura funcionam através do envio de mensagens heartbeat UDP. As mensagens são codificadas utilizando protocol buffers (PROTOCOL BUFFERS, 2012), com o propósito de minimizar o overhead de comunicação e processamento das mensagens de rede e simplificar a implementação. Para a comunicação assíncrona de rede em todos os componentes da arquitetura, a biblioteca Boost. Asio (KOHLHOFF, 2011) foi utilizada. A escolha pela utilização de comunicação assíncrona de rede permite que os detectores de falhas utilizem uma única thread de processamento, reduzindo o consumo de recursos, e desta forma o impacto causado pela utilização da arquitetura. Esta otimização é importante, já que o detector de falhas não deve influenciar negativamente o desempenho da plataforma computacional.

O diagrama de classes da Figura 5.1 mostra um modelo simplificado da organização das classes que compõem os detectores de falhas de infraestrutura. Esta organização visa maximizar o reuso de código para agilizar a implementação de diferentes estratégias de detecção. Foram implementados três detectores de falhas de infraestrutura: multicast simples (MulticastDetector), multicast adaptativo (MulticastAdaptiveDetector) e gossip tradicional (GossipDetector). Durante a construção da arquitetura, é formado um executável para cada detector. Com exceção do detector gossip, os detectores podem ter a técnica gossip payload, proposta neste trabalho, habilitada através de um argumento de linha de comando. O canal de comunicação (UDP unicast ou multicast) é abstraído na forma de communicators (UdpCommunicator e MulticastCommunicator). Grande parte da lógica responsável pela temporização do envio e recebimento das mensagens heartbeat é abstraída na classe HeartbeatController, enquanto o armazenamento do estado dos detectores vizinhos é unificado nas classes PeerMap e AdaptivePeerMap, permitindo 


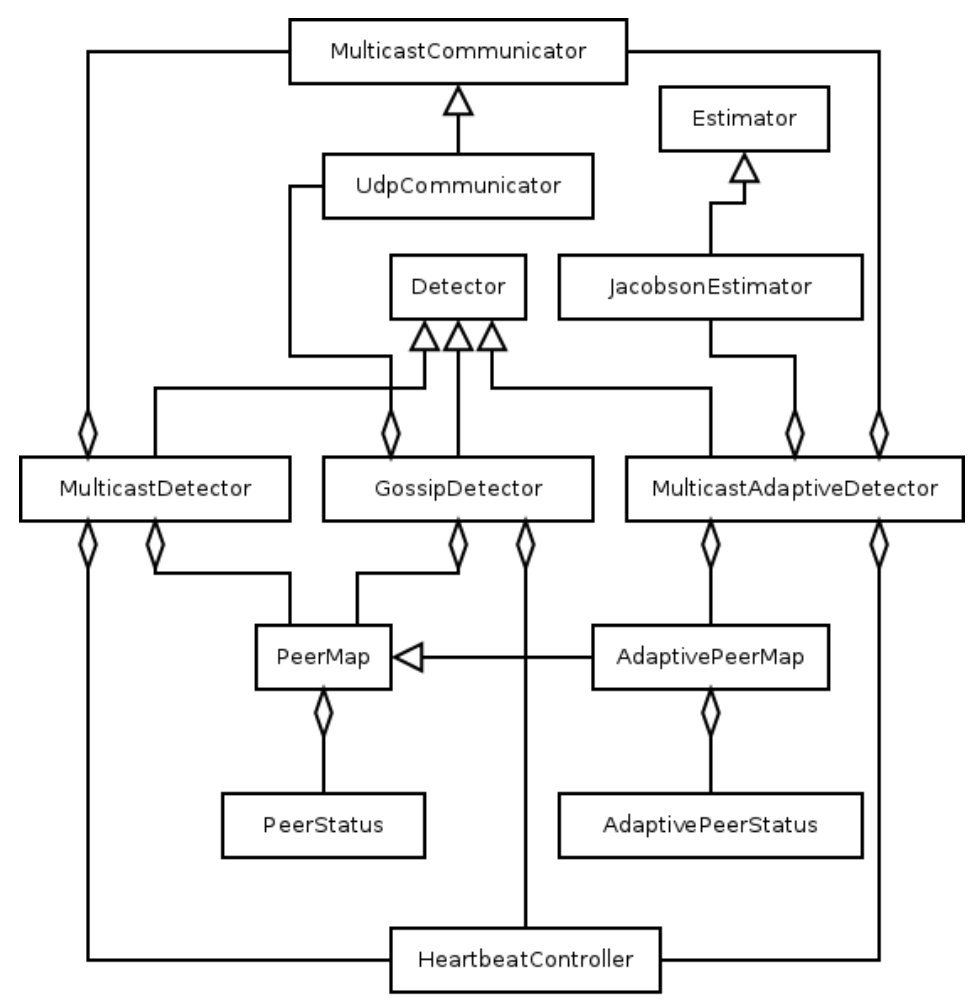

Figura 5.1 - Diagrama de classes dos detectores de falhas de infraestrutura.

que novos detectores sejam criados com facilidade. Algoritmos de estimação de timeouts também estão generalizados na forma da classe Estimator, permitindo a experimentação com algoritmos alternativos.

A Figura 5.2 mostra a estrutura de uma mensagem heartbeat. As informações referentes ao remetente, especificando o identificador do domínio, identificador do nó em que o detector está em execução e último número de sequência gerado pelo detector, estão presentes em todas as mensagens. Para cada nó vizinho conhecido, caso o gossip payload esteja habilitado, são transmitidos seu identificador e o último número de sequência recebido do nó. Para o detector gossip tradicional, a comunicação é ponto a ponto (unicast), e portanto o endereço de rede de cada nó vizinho também precisa ser informado para que os nós possam ser descobertos automaticamente, ou seja, sem configuração prévia realizada pelo administrador. Esta descoberta automática em detectores gossip é importante para sua implantação em grande escala. Nos outros detectores, como a comunicação se dá através de um canal multicast, não é necessário transportar estas informações nas mensagens heartbeat.

A implementação da arquitetura GFDA realizada utiliza o nome completo (FQDN) do computador em que a arquitetura é instalada como o identificador do nó. Alternativamente, o administrador pode configurar os componentes da arquitetura para utilizar outro identi- 


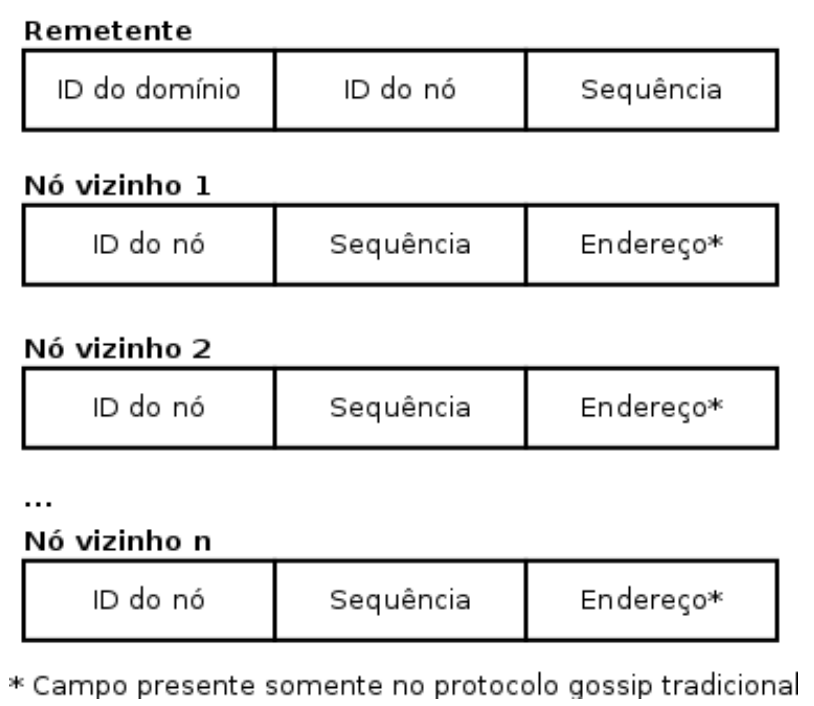

Figura 5.2 - Estrutura de uma mensagem heartbeat.

ficador. O tamanho das mensagens heartbeat enviadas é influenciado pelo tamanho do identificador escolhido. Caso o nome do computador seja grande demais, é recomendado que o administrador utilize identificadores mais curtos caso seja desejável reduzir a utilização da rede, especialmente se o gossip payload estiver habilitado. A Figura 5.3 apresenta uma comparação dos tamanhos das mensagens heartbeat geradas pelo detector multicast configurado com o gossip payload e pelo detector gossip implementado, considerando identificadores de nós com o tamanho de 20 bytes. É possível perceber que o tamanho das mensagens cresce linearmente com o aumento no número de vizinhos no domínio de monitoração. As mensagens transmitidas por multicast não contém o endereço dos nós, e portanto são menores. Com este detector, assumindo um MTU (Maximum Transmission Unit) de 1500 bytes, mensagens heartbeat podem ser transmitidas em um único pacote de rede com até cerca de 60 vizinhos no domínio de monitoração.

Os detectores são configurados no momento de sua invocação através de parâmetros da linha de comando. Para sua execução, é necessário informar o endereço do gerenciador de falhas responsável para o domínio em que o detector se encontra. Entre as diversas configurações disponíveis, é possível configurar todos os parâmetros de timeouts ou associados à função de estimação do protocolo adaptativo.

\subsection{Detectores de falhas locais}

Os detectores de falhas locais expõem uma interface simples em linguagem $\mathrm{C}$ para integração com aplicações que devem ser monitoradas localmente. O detector local é inicializado através da chamada pmon_init. Esta chamada recebe como parâmetros os argumentos 


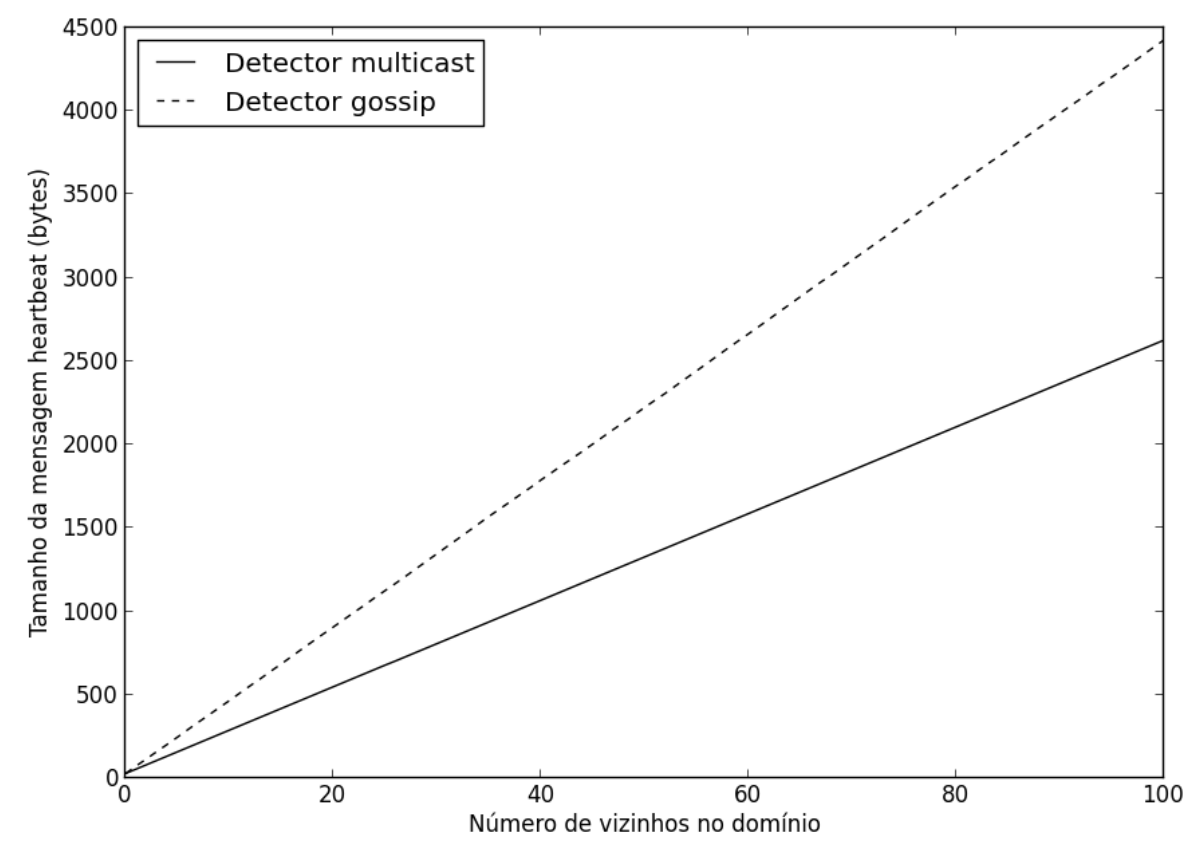

Figura 5.3 - Tamanho das mensagens heartbeat enviadas pelos detectores implementados.

de linha de comando enviados originalmente à aplicação. A chamada interpreta os argumentos destinados ao detector e os remove da lista de argumentos que é devolvida à aplicação. Desta forma, é possível configurar o detector e a aplicação através de argumentos de linha de comando. Os argumentos modificados e devolvidos à aplicação devem ser liberados após seu processamento com a chamada pmon_free_args. Ao final da execução com sucesso, a aplicação deve executar a chamada pmon_finalize com o argumento PMON_SUCCESS para evitar que o processo de aplicação tenha sua terminação considerada anormal.

Duas bibliotecas distintas de interface entre detectores de falhas locais e aplicações foram criadas. A grande maioria das aplicações, cujas instâncias distribuídas possuem ciclo de vida idêntico ao ciclo de vida dos processos lançados nos nós computacionais, pode ser atendida pelo detector que utiliza chamadas simples do sistema operacional para a monitoração de processos como a chamada de sistema waitpid. Já aplicações distribuídas cujos processos não podem ser monitorados desta forma, tais como aplicações que realizam a desconexão do terminal (daemonization) ou operam com múltiplos processos com ciclos de vidas distintos, podem ser monitoradas pelo detector de falhas libgfda-pmon-cgroups. Este detector de falhas locais utiliza a funcionalidade de cgroups (MENAGE; JACKSON; LAMETER, 2012), disponível em sistemas com kernel Linux recente, para monitorar múltiplos processos organizados em hierarquia. 
De maneira similar à invocação dos detectores de falhas de infraestrutura, o endereço do gerenciador de falhas responsável para o domínio em que o detector se encontra deve ser especificado através da linha de comando.

\subsection{Gerenciadores de falhas}

Os gerenciadores de falhas implementam um canal de comunicação TCP. Através deste canal, um protocolo baseado em texto, que pode ser operado através de ferramentas como telnet, pode ser utilizado para registrar ou alterar tarefas (jobs), obter informações sobre o estado do gerenciador, e notificar falhas ou presença (advertisements). O Apêndice A enumera os comandos disponíveis para este protocolo. Ao tomar ações referentes a uma notificação de falha de infraestrutura ou local já processadas, o gerenciador de falhas central utiliza um protocolo também baseado em texto para comunicar a um consumidor final o evento de falha. Este protocolo está descrito no Apêndice B.

Para representar as dependências entre os recursos computacionais, o gerenciador de falhas central utiliza um mapa associativo entre dependências e dependentes, implementado como uma árvore binária. Ao receber novas informações de dependência de recursos, provenientes da publicação de presença de outros gerenciadores de falhas e detectores de falhas de infraestruturas, as informações antigas referente aos recursos são eliminadas, e as informações novas são adicionadas ao mapa. Em um segundo passo, laços de dependência do tipo $A \rightarrow B \rightarrow A$ ou mais complexas, como por exemplo $A \rightarrow B \rightarrow C \rightarrow A$, são encontrados e eliminados. A disposição dos dados em uma árvore binária permite o rápido lookup de dependentes, visando não causar atraso no processamento de notificações de falha.

As informações mantidas por um gerenciador de falhas sobre os trabalhos e nós conhecidos são periodicamente escritas em disco. Estas informações também são escritas em disco antes da terminação normal dos gerenciadores de falhas. Desta maneira, é possível preservar grande parte destas informações em situações em que há a necessidade dos processos dos gerenciadores de falhas serem temporariamente interrompidos, como reinicializações do sistema, procedimentos de manutenção de hardware ou defeitos na implementação dos gerenciadores.

O sistema de construção da arquitetura GFDA gera executáveis para o gerenciador de falhas distribuído e o gerenciador de falhas central. A configuração dos gerenciadores de falhas é realizada através de parâmetros na linha de comando. Entre as diversas 
configurações disponíveis, é possível configurar os parâmetros que coordenam a utilização de técnicas de processamento adicional de notificações de falha e recuperação. Para os gerenciadores de falhas distribuídos, é necessário informar o endereço do próximo gerenciador de falhas na cadeia formada até o gerenciador central. Um terceiro executável criado pelo sistema de construção da arquitetura GFDA é um cliente que se conecta a um gerenciador de falhas para o envio de comandos administrativos. Este comando pode ser utilizado por um administrador ou por ferramentas automatizadas de integração da arquitetura GFDA com sistemas externos.

\subsection{Comunicação criptografada}

A implementação da arquitetura GFDA se utiliza de criptografia na transmissão de mensagens, visando evitar ataques com detectores de falhas não autorizados que causam a disrupção do serviço que a grade computacional proporciona. As mensagens trocadas através de canais TCP, como o envio de notificações de falha e recuperação, notificações de presença, transmissão de dados de topologia e configuração em tempo de execução, são encapsuladas em uma sessão TLS (Transport Layer Security). A sessão é mutualmente autenticada, ou seja, ao término da negociação para abertura da sessão, tanto o cliente quanto o servidor possuem garantias criptográficas sobre a identidade do agente no lado oposto da conexão. Caso os certificados e chaves necessários não sejam informados através da linha de comando, a implementação dos componentes da arquitetura GFDA busca por estes arquivos nos diretórios onde o toolkit Globus os armazena. Desta forma, os componentes da arquitetura se integram com facilidade em ambientes que utilizam este popular middleware para grades computacionais.

Já para os detectores de falhas de infraestrutura, que realizam a transmissão de mensagens heartbeat através do protocolo UDP, a utilização do TLS não é possível, já que este depende do estabelecimento de uma conexão e o UDP não oferece esta capacidade. Os pacotes contendo mensagens heartbeat não são, portanto, encriptados. Estes pacotes são, porém, assinados através de uma técnica conhecida como HMAC (Hash-based Message Authentication Code). Com esta técnica, é possível que um detector possa verificar a autenticidade de uma mensagem enviada desde que a mensagem tenha sido assinada com uma chave criptográfica de seu conhecimento. A chave compartilhada é armazenada junto ao gerenciador de falhas do domínio. Em sua inicialização, os detectores consultam o gerenciador de falhas para a obtenção da chave compartilhada. A função de hashing SHA-1 (Secure Hash Algorithm 1) é utilizada na implementação da arquitetura GFDA. Este 


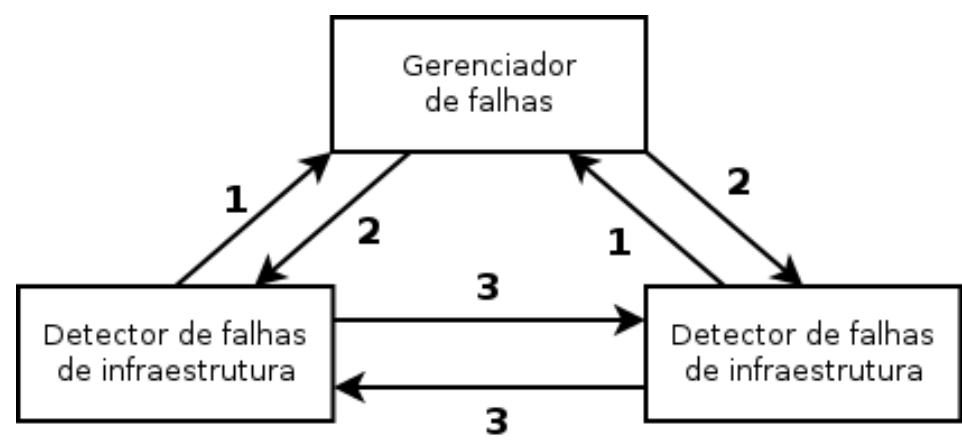

1: Requisiçåo de chave (TLS)

2: Chave criptográfica (TLS)

3: Mensagem heartbeat (HMAC-SHA-1)

Figura 5.4 - Procedimento para a obtenção da chave criptográfica utilizada na assinatura de mensagens heartbeat.

procedimento é ilustrado na Figura 5.4. As operações 1 e 2 são realizadas através da sessão TLS previamente estabelecida. A operação 3, referente à transmissão de mensagens heartbeat, passa a ser realizada a partir da obtenção da chave criptográfica. A utilização da assinatura das mensagens heartbeat é opcional, mas recomendada. Os detectores que obtiverem a chave criptográfica com sucesso ignoram as mensagens heartbeat enviadas sem uma assinatura válida.

\subsection{Replicação dos gerenciadores de falhas}

Visando evitar condições onde a introdução de um gerenciador de falhas está associada à introdução de um ponto único de falha, os gerenciadores de falhas implementados na arquitetura GFDA suportam uma forma primitiva de replicação das informações. Cada instância de processo gerenciador de falhas é marcado como mestre ou escravo em sua inicialização, dependendo dos parâmetros de linha de comando especificados em seu lançamento. Um gerenciador de falhas mestre aceita notificações e comandos como a criação de tarefas normalmente. Já um gerenciador de falhas escravo recusa comandos e notificações que alterem seu estado, com a exceção do comando que o torna o gerenciador mestre.

Os gerenciadores de falhas são configurados com uma lista dos endereços de todos os gerenciadores de falhas, mestres e escravos, em seu domínio de monitoração. O gerenciador de falhas mestre sincroniza seu estado interno com os gerenciadores escravos ao ser iniciado e em intervalos regulares. Nesta sincronização, o gerenciador mestre serializa o estado de suas estruturas internas que contém informações sobre os nós conhecidos, tarefas cadastradas, e notificações nos locais de armazenamento temporário para o pro- 
cessamento de notificações. Estas informações serializadas são enviadas aos escravos, que as incorporam ao seu próprio estado. Na ocasião de falha de um gerenciador de faIhas mestre, um gerenciador escravo pode assumir o controle ao receber uma mensagem que o torna o gerenciador mestre para o domínio. Este gerenciador passa então a enviar informações de sincronização aos demais gerenciadores escravos. Todas as informações de sincronização são enviadas através da sessão encriptada criada com o protocolo TLS, conforme descrito na Seção 5.4 .

Não há failover automático, ou seja, o procedimento de troca do gerenciador de faIhas mestre não é realizado de forma automática na arquitetura GFDA. Os componentes da arquitetura GFDA se conectam a um endereço específico do gerenciador de falhas. Um failover automático, portanto, depende também da troca de endereços na camada de rede. Diversas soluções para o problema já existem, tais como o VRRP (IETF NETWORK WORKING GROUP, 2004) e CARP (OPENBSD TEAM, 2012) e Linux-HA (HAAS, 2010). Estas soluções podem ser integradas com o cliente para administração dos gerenciadores de falhas construído com a arquitetura GFDA para implementar o failover de forma automática. 


\section{TESTES E RESULTADOS}

Os testes realizados com a arquitetura implementada e os resultados obtidos nestes testes são apresentados e discutidos neste capítulo. Uma suíte de testes foi elaborada para avaliar o comportamento dos componentes implementados. Um modelo de adversidades foi criado para simular um ambiente justo para a comparação entre diferentes estratégias para a detecção de falhas de infraestrutura. Os detectores de falhas de infraestrutura são então executados em máquinas virtuais que representam um sistema distribuído. A suíte de testes estrutura os componentes da arquitetura proposta em uma hierarquia de recursos para permitir a avaliação do seu funcionamento correto nesta disposição. Esta hierarquia simula situações encontradas em grades computacionais em que alguns recursos computacionais não podem ser contatados diretamente devido a restrições de conectividade entre estes. As seções seguintes descrevem em detalhes a suíte de testes e o ambiente de testes utilizado para as execuções dos detectores de falhas de infraestrutura. Os resultados obtidos são então apresentados e analisados, e uma discussão destes se segue.

\subsection{Suíte de testes}

A implementação da arquitetura GFDA foi acompanhada da elaboração de uma suíte de testes constituída de scripts de shell. A suíte é composta por 8 casos de teste, descritos na Tabela 6.1. A suíte de testes abrange a base de código fonte comum, compartilhada por todos os componentes da arquitetura, assim como o código dos gerenciadores de falhas e detectores de falhas locais. Os detectores de falhas de infraestrutura são testados no ambiente detalhado nas seções seguintes.

Os dados de cobertura da suíte de testes apresentados na Tabela 6.2 puderam ser extraídos através da ferramenta gcov (FREE SOFTWARE FOUNDATION, 2010). A cobertura da suíte de testes revela a abrangência dos testes realizados, mostrando a proporção de linhas de código, funções, métodos e condicionais que foram exercitados ao menos uma vez durante a execução da suíte de testes. Como é possível perceber, apenas uma pequena parcela do código não é exercitada pela suíte de testes. Uma análise cuidadosa destes dados permite entender que a parcela do código que não é exercitada corresponde à verificação de erros de sintaxe dos protocolos e à funcionalidade na base comum de código que não é utilizada pelos componentes ativados pela suíte de testes. Todas as 
Tabela 6.1 - Operações exercitadas pela suíte de testes.

\begin{tabular}{|c|c|}
\hline Caso de teste & Operações exercitadas \\
\hline FmanCommands & $\begin{array}{l}\text { Criação, alteração e remoção de tarefas em um gerenci- } \\
\text { ador de falhas central. Obtenção da chave HMAC-SHA-1 } \\
\text { para os detectores de falhas de infraestrutura. }\end{array}$ \\
\hline FmanNotifications & $\begin{array}{l}\text { Recepção de notificações de falha e recuperação válidas } \\
\text { e inválidas. Testes de ambos os métodos de processa- } \\
\text { mento de notificações e consulta do estado dos locais } \\
\text { de armazenamento temporário para processamento de } \\
\text { notificações. }\end{array}$ \\
\hline FmanProxy & $\begin{array}{l}\text { Retransmissão de mensagens entre dois gerenciadores } \\
\text { de falhas. Transmissão de notificações entre gerencia- } \\
\text { dores de falhas. Testes dos métodos de processamento } \\
\text { de notificações em uma cadeia de gerenciadores de fa- } \\
\text { lhas. }\end{array}$ \\
\hline FmanDepends & $\begin{array}{l}\text { Estabelecimento e manutenção de dependências entre } \\
\text { recursos. Verificação das consequências das dependên- } \\
\text { cias estabelecidas em eventos de falha. Resolução de } \\
\text { dependências circulares entre recursos. }\end{array}$ \\
\hline FmanProxyDepends & $\begin{array}{l}\text { Propagação de dependências em uma cadeia de geren- } \\
\text { ciadores de falhas através de notificações de presença. }\end{array}$ \\
\hline FmanReplication & $\begin{array}{l}\text { Serialização, desserialização e persistência de informa- } \\
\text { ções dos gerenciadores de falhas. Replicação de dados } \\
\text { serializados a gerenciadores escravos. Troca do geren- } \\
\text { ciador mestre em simulações de falha. }\end{array}$ \\
\hline PmonWaitpid & $\begin{array}{l}\text { Detecção de falhas locais utilizando o monitorador } \\
\text { libgfda-pmon-waitpid. Retransmissão de notifica- } \\
\text { ções de falhas locais. }\end{array}$ \\
\hline PmonCgroups & $\begin{array}{l}\text { Detecção de falhas locais utilizando o monitorador } \\
\text { libgfda-pmon-cgroups. Retransmissão de notifica- } \\
\text { ções de falhas locais. }\end{array}$ \\
\hline
\end{tabular}

Tabela 6.2 - Resultados da análise de cobertura da suíte de testes.

\begin{tabular}{|r||r|r|r|}
\hline Métrica & Exercitados & Total & Cobertura \\
\hline \hline Linhas de instrução & 2221 & 2502 & $88,8 \%$ \\
\hline Funções e métodos & 380 & 392 & $96,9 \%$ \\
\hline Condicionais & 4620 & 10892 & $42,4 \%$ \\
\hline
\end{tabular}


funcionalidades providas pelos gerenciadores de falhas e detectores de falhas locais são exercitadas.

\subsection{Modelo de adversidades}

O modelo de adversidades simula uma rede congestionada conectando detectores de faIhas de infraestrutura instalados em nós sujeitos a falhas. O objetivo do modelo é a reprodução das condições adversas de rede encontradas em grades computacionais integrando organizações virtuais conectadas por enlaces de longa distância. Os seguintes conceitos são recriados no modelo de adversidades:

- Perda de pacotes

- Atraso de rede

- Falha dos detectores

Perda de pacotes se refere a eventos em que um pacote de rede não alcança o destinatário. Na prática, a perda de pacotes tipicamente resulta da degradação do sinal no meio da rede, de equipamentos de rede defeituosos ou de congestionamento na rede. No modelo de adversidades, a perda de pacotes é configurada como uma probabilidade de que qualquer pacote de rede seja perdido antes do seu processamento pelo destinatário. A probabilidade de perda de pacotes é verificada em duas situações: enquanto o pacote se encontra na fila de envio e enquanto o pacote se encontra na fila de recepção, anterior ao seu processamento.

Atraso de rede é o atraso médio na rede em que se encontram os nós e pode resultar da utilização de conexões de longa distância ou de retransmissões causadas pela perda de pacotes. No modelo de adversidades, o atraso é especificado como um intervalo de tempo fixo e uma variação aleatória limitada a uma margem. Este atraso é aplicado nas filas de recebimento e envio de pacotes no sistema operacional de cada nó.

O modelo pode ser configurado para simular perda de pacotes e atraso de rede em rajadas. Com rajadas, a probabilidade de perda de um pacote depende parcialmente da probabilidade obtida para os eventos anteriores. De maneira similar, a variação no atraso da rede depende parcialmente da variação do atraso empregada anteriormente. No modelo, rajadas são configuradas como uma porcentagem indicando a importância dada a valores escolhidos anteriormente para a obtenção de novos valores aleatórios. Perda de 
pacotes e atraso de rede são simulados utilizando o software netem, parte da suíte de software iproute2 para Linux. O Intermediate Functional Block é utilizado para aplicar os efeitos de rede também à fila de recebimento de pacotes.

O modelo de adversidades simula também falhas que levam à terminação dos detectores. Estas falhas simuladas buscam se assemelhar a falhas ocorridas devido a problemas no software detector de falhas, como situações levando a terminação anormal dos programas, ou falhas relacionadas ao ambiente em que os detectores de falhas executam, como falhas do hardware ou sistema operacional. A cada 25 segundos, o modelo reconsidera se cada detector que está em execução deve ser terminado e se cada detector anteriormente interrompido deve ser recuperado. Um detector pode ser recuperado apenas se este foi terminado há um intervalo de tempo superior ou igual ao intervalo de limpeza $\Delta_{c l}$. Probabilidades de falha e recuperação de detectores são configuráveis.

O gerador de números pseudoaleatórios utilizado para determinar a ocorrência de faIhas e recuperação de nós é inicializado com uma semente fixa para prover um ambiente justo para as comparações entre os diferentes detectores. Já o gerador de números pseudoaleatórios utilizado para determinar os parâmetros de perda de pacotes e atraso na rede não utiliza uma semente fixa, o que significa que estes parâmetros variam ao acaso, restritos às margens impostas pelo modelo de adversidades. Todos os testes são executados múltiplas vezes para contabilizar esta variação.

Quatro diferentes configurações são utilizadas para simular diferentes níveis de carga (stress) na infraestrutura da rede simulada. Estas configurações estão detalhadas na Tabela 6.3. Uma das configurações representa um ambiente estável, sem perda de pacotes de rede, com pouco atraso e alta correlação entre o histórico de atraso de pacotes e futuras determinações de atraso. Esta configuração permite a avaliação do comportamento dos detectores em situações próximas do ideal, permitindo a verificação de seu funcionamento.

\subsection{Ambiente de testes}

Os resultados dos testes experimentais foram obtidos pela comparação entre as notificações de falha e recuperação enviadas pelos detectores de falhas e a informação real do estado dos detectores. Os testes foram conduzidos em uma rede de 8 máquinas virtuais utilizando sistema operacional Debian 6.0.2 com kernel Linux 2.6.32. As notificações de falha e recuperação são enviadas a um gerenciador de falhas instalado no sistema hospedeiro. Cada máquina virtual é configurada com duas interfaces de rede. Uma destas 
Tabela 6.3 - Configurações do modelo de adversidades.

\begin{tabular}{|l|l|l|}
\hline Configuração & Parâmetros & Valores \\
\hline \hline \multirow{5}{*}{ Baixo stress } & Probabilidade de perda de pacotes & $5 \%$ \\
\cline { 2 - 3 } & Rajada na perda de pacotes & Não há \\
\cline { 2 - 3 } & Atraso da rede & $15 \mathrm{~ms} \pm 5 \mathrm{~ms}$ \\
\cline { 2 - 3 } & Rajada no atraso da rede & Não há \\
\cline { 2 - 3 } & Probabilidade de falha do detector & $5 \%$ \\
\cline { 2 - 3 } & Probabilidade de recuperação do detector & $70 \%$ \\
\hline \hline \multirow{5}{*}{ Aédio stress } & Probabilidade de perda de pacotes & $10 \%$ \\
\cline { 2 - 3 } & Rajada na perda de pacotes & $10 \%$ \\
\cline { 2 - 3 } & Atraso da rede & $50 \mathrm{~ms} \pm 15 \mathrm{~ms}$ \\
\cline { 2 - 3 } & Rajada no atraso da rede & $5 \%$ \\
\cline { 2 - 3 } & Probabilidade de falha do detector & $7 \%$ \\
\cline { 2 - 3 } & Probabilidade de recuperação do detector & $65 \%$ \\
\hline \hline \multirow{5}{*}{ Ambiente estável } & Probabilidade de perda de pacotes & $20 \%$ \\
\cline { 2 - 3 } & Rajada na perda de pacotes & $15 \%$ \\
\cline { 2 - 3 } & Atraso da rede & $100 \mathrm{~ms} \pm 25 \mathrm{~ms}$ \\
\cline { 2 - 3 } & Rajada no atraso da rede & $10 \%$ \\
\cline { 2 - 3 } & Probabilidade de falha do detector & $10 \%$ \\
\cline { 2 - 3 } & Probabilidade de recuperação do detector & $60 \%$ \\
\cline { 2 - 3 } & Rajada no atraso da rede & Não há \\
\cline { 2 - 3 } & Rajada na perda de pacotes & $50 \%$ \\
\hline \multirow{n}{*}{} & Probabilidade de falha do detector & $5 \%$ \\
\cline { 2 - 3 } & Probabilidade de recuperação do detector & $70 \%$ \\
\hline
\end{tabular}

interfaces permite à máquina comunicar-se com o sistema hospedeiro, enquanto a outra conecta a máquina a uma rede virtual compartilhada entre todas as máquinas virtuais. Apenas a interface conectada à rede virtual é afetada pelo modelo de adversidades. Todas as notificações de falhas e recuperação são enviadas para processamento e registro do hospedeiro através da interface de rede que não é afetada pelo modelo de adversidades. Desta forma, as métricas podem ser coletadas sem interferência.

Para a obtenção dos resultados, os detectores multicast, configurados ou não para a utilização do gossip payload, são configurados da seguinte maneira. O intervalo entre o envio de mensagens heartbeat $\left(\Delta_{i}\right)$ é configurado para $5 \mathrm{~s}$, e o intervalo de timeout $\left(\Delta_{t o}\right)$ é configurado para $10 \mathrm{~s}$. O intervalo de limpeza $\left(\Delta_{c l}\right)$ é configurado em $30 \mathrm{~s}$. Para os detectores adaptativos, a função para a estimação do intervalo de timeout descrita no Item 2.2.3 é configurada com os parâmetros $\frac{1}{8}$ para o ganho da média $(\alpha), \frac{1}{4}$ para o ganho do desvio de média $(\beta)$ e 4 para a influência do desvio $(\gamma)$. Estes parâmetros são os mesmos utilizados para a implementação original do timeout de retransmissão TCP (JACOBSON, 1988). 
Tabela 6.4 - Cenários considerados para a execução dos testes.

\begin{tabular}{|l|l|l|}
\hline Cenário & Parâmetros & Valores \\
\hline \hline \multirow{4}{*}{ 1: Nenhum processamento } & $\begin{array}{l}\text { Tempo no buffer para filtragem de notifica- } \\
\text { ções conflitantes }\end{array}$ & - \\
\cline { 2 - 3 } & Exigência de quórum & Não há \\
\cline { 2 - 3 } & Tempo no buffer para exigência de quórum & - \\
\hline \hline \multirow{4}{*}{ 2: Filtragem de conflitos } & $\begin{array}{l}\text { Tempo no buffer para filtragem de notifica- } \\
\text { ções conflitantes }\end{array}$ & $10 s$ \\
\cline { 2 - 3 } & Exigência de quórum & Não há \\
\cline { 2 - 3 } & Tempo no buffer para exigência de quórum & - \\
\hline \hline \multirow{4}{*}{ 3: Exigência de quórum } & $\begin{array}{l}\text { Tempo no buffer para filtragem de notifica- } \\
\text { ções conflitantes }\end{array}$ & - \\
\cline { 2 - 3 } & Exigência de quórum & 4 nós \\
\cline { 2 - 3 } & Tempo no buffer para exigência de quórum & $10 s$ \\
\hline \hline \multirow{3}{*}{ 4: Ambas as técnicas } & $\begin{array}{l}\text { Tempo no buffer para filtragem de notifica- } \\
\text { ções conflitantes }\end{array}$ & $2 s$ \\
\cline { 2 - 3 } & Exigência de quórum & 3 nós \\
\cline { 2 - 3 } & Tempo no buffer para exigência de quórum & $7 s$ \\
\hline
\end{tabular}

Para o detector gossip, o intervalo entre o envio de mensagens heartbeat é configurado para $5 s$, enquanto o intervalo de timeout é ajustado em $12 s$. O intervalo de limpeza é mantido em 30 s, o mesmo intervalo configurado para os detectores multicast. A razão para a utilização destes valores é compensar a fragilidade dos detectores gossip em decorrência da propagação menos eficiente de informações na rede em comparação aos detectores multicast. Nos testes realizados com o detector gossip, a lista de detectores vizinhos é informada a todos os detectores no momento de sua inicialização. Desta maneira, um detector começa a enviar mensagens do protocolo imediatamente após ser iniciado, eliminando da comparação o atraso da descoberta automática de vizinhos e permitindo uma comparação mais justa.

Para cada detector, dez ciclos de testes com duração de dez minutos são executados. Das medições de cada métrica são extraídos a média e o desvio padrão acima e abaixo da média, que são apresentados nos gráficos que se seguem. Medições com diferença em relação a média excedendo 3 vezes o desvio padrão são considerados outliers e excluídas dos resultados. No máximo 2 medições são excluídas em cada conjunto de medições. São considerados quatro cenários com variações das técnicas de processamento de notificações apresentadas neste trabalho. Os cenários estão detalhados na Tabela 6.4.

Nos cenários que empregam o processamento de notificações através da filtragem de notificações conflitantes, as notificações são armazenadas em um local de armazena- 
mento temporário (buffer) por um breve período de tempo. Durante este período, caso uma notificação conflitante venha a ser recebida, ambas as notificações são descartadas. Caso isso não aconteça durante este intervalo, a notificação é considerada válida. Já nos cenários que exigem um quórum de notificações de falhas, as notificações também são armazenadas por um breve período de tempo. Então, com uma exigência de quórum de $n$ detectores, caso um número $n-1$ de notificações compatíveis provenientes de outros detectores sejam recebidas durante este intervalo, a notificação original será considerada válida. Se este número de notificações não for recebido durante o intervalo considerado, as notificações compatíveis armazenadas são descartadas.

No cenário com ambas as técnicas habilitadas, as notificações são primeiramente processadas através da exigência de quórum. Caso a notificação atenda aos requisitos de quórum, esta é então submetida ao processamento de filtragem de notificações conflitantes. A notificação é considerada válida somente após esta segunda filtragem. Neste cenário, são escolhidos parâmetros diferentes para as técnicas de processamento, visando otimizar a qualidade de serviço com base no conhecimento adquirido na análise dos resultados obtidos nos outros cenários. O tempo de permanência de notificações no buffer para a filtragem de conflitos foi reduzido para apenas $2 s$, enquanto a exigência de quórum e tempo de permanência das notificações para análise de quórum são ambas reduzidas a 3 nós e $7 s$, respectivamente.

\subsection{Métricas}

O sistema hospedeiro executa um gerenciador de falhas que recebe e armazena as notificações de falha e recuperação dos detectores em execução nos nós de processamento simulados nas máquinas virtuais. Um registro do modelo de adversidades também é armazenado durante a execução de um teste. Estas informações podem então ser cruzadas para derivar métricas sobre o desempenho do sistema de detecção. As seguintes métricas são coletadas:

\section{Número de enganos}

Número de ocorrências em que um detector $p$ passa a suspeitar da falha de outro detector $q$ em um momento em que $q$ não esteja em falha.

\section{Duração média de enganos}

Intervalo médio de tempo entre um engano e o recebimento de uma notificação que o retifica. 


\section{Atraso médio das detecções}

Média do intervalo de tempo entre uma falha e sua correspondente detecção.

\section{Atraso médio das detecções na metade final dos testes}

Média do intervalo de tempo entre uma falha e sua correspondente detecção, considerando-se somente os eventos ocorridos na metade final de cada teste.

\section{Detecções por falha}

Média do quociente entre o número de notificações de falhas correspondentes a falhas reais e o número de falhas reais, medindo a eficiência do detector em notificar falhas que aconteceram.

\subsection{Análise dos resultados}

Os testes foram realizados com cinco diferentes configurações de detectores de falhas:

\section{Multicast simples}

Detector com comunicação via multicast simples.

\section{Multicast simples com gossip payload}

Detector comunicação via multicast simples utilizando a técnica gossip payload para distribuição de informações.

\section{Multicast adaptativo}

Detector com comunicação via multicast com adaptação do intervalo de timeout $\left(\Delta_{t o}\right)$ de acordo com flutuações no histórico de recepções das mensagens heartbeat.

Multicast adaptativo com gossip payload Detector com comunicação via multicast com adaptação e utilizando a técnica gossip payload para distribuição de informações.

Gossip com nós pré-carregados Detector gossip previamente configurado com uma lista de seus vizinhos.

Considerando-se todas as baterias de testes, totalizando quatro configurações do modelo de adversidades, em quatro cenários diferentes, com cinco configurações de detectores e dez ciclos de testes com duração de dez minutos cada, o tempo gasto com a execução dos testes experimentais é superior a 130 horas. 


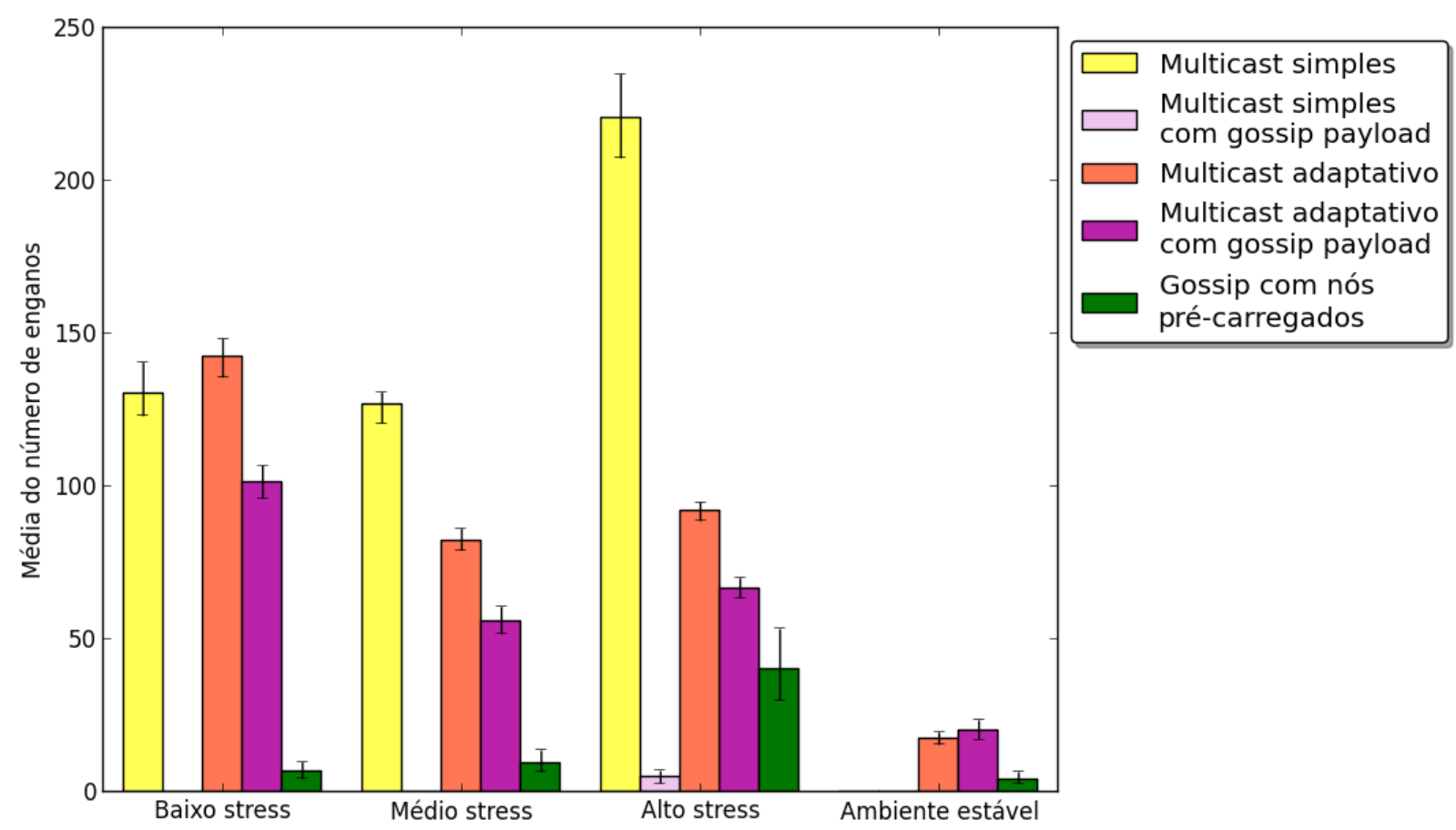

Figura 6.1 - Número de enganos no cenário 1.

\subsection{Resultados do cenário 1 (nenhum processamento)}

Neste cenário, nenhum processamento de notificações de falha e recuperação é realizado pelo gerenciador de falhas. As notificações recebidas pelo gerenciador de falhas em execução no sistema hospedeiro são imediatamente consideradas e registradas para análise.

A Figura 6.1 apresenta o número de enganos cometidos pelos detectores. Como é possível perceber, o número de enganos é inequivocamente reduzido com a utilização da técnica gossip payload para os detectores multicast. O detector multicast simples com a técnica gossip payload comete enganos apenas na configuração de alto stress. Isso se justifica pela redundância adicional que a técnica oferece ao distribuir informações a cada troca de mensagens, desta forma reduzindo a probabilidade de enganos em decorrência da perda de informações causada pelo modelo de adversidades.

O comportamento dos detectores multicast adaptativo em relação à flutuação nas características da rede se mostra superior comparado ao detector multicast simples, especialmente em configurações com maior flutuação. Nestas configurações, um detector adaptativo aumenta o intervalo de timeout $\Delta_{t o}$ em resposta a variações no intervalo entre o recebimento de mensagens heartbeat, reduzindo assim a possibilidade de uma detecção incorreta. Já na configuração estável, o intervalo de timeout é reduzido ao mínimo, o que acaba aumentando a possibilidade de detecções incorretas. Em todas as demais configu- 
rações, o detector adaptativo que utiliza o gossip payload também apresenta desempenho superior comparado ao detector que não utiliza esta técnica.

O detector gossip tradicional apresenta bons resultados. Em todas as configurações, o número de enganos cometidos por este detector somente é superior ao número de enganos cometidos pelo detector multicast que utiliza o gossip payload. A exceção é a configuração estável, na qual o detector multicast simples apresenta desempenho superior mesmo sem o gossip payload. O protocolo gossip implementado depende da existência de nós em execução para a propagação de mensagens, já que esta propagação é realizada ponto a ponto. Quando há detectores em falha, há a perda de informações e os detectores gossip acabam por cometer enganos mesmo caso as condições de rede sejam favoráveis. Este é o caso da configuração estável, o que explica este fenômeno.

A Figura 6.2 mostra a duração média de enganos neste cenário. O desempenho do detector multicast com a técnica gossip payload novamente se apresenta superior ao desempenho de todos os demais detectores, já que não foram detectados enganos. Para todos os detectores multicast, o atraso das correções é inferior ou próximo ao intervalo de transmissão de mensagens heartbeat $\Delta_{i}=5 \mathrm{~s}$. Para o detector gossip, cujo intervalo $\Delta_{i}$ é de apenas $2 s$, a escolha aleatória de destinatários não garante o envio de informações em todos os turnos a um nó que tenha cometido um engano. Desta forma, múltiplos turnos podem ser necessários para que o detector que tenha cometido o engano possa receber as informações necessárias para realizar a correção do engano, o que explica o maior atraso e a grande variação.

O detector adaptativo com a técnica gossip payload proporciona resultados superiores em comparação aos detectores gossip e multicast simples em algumas configurações. Com a agressividade da adaptação do intervalo de timeout $\Delta_{t o}$ realizada pelos detectores adaptativos, este intervalo é reduzido e se aproxima do intervalo entre a transmissão de mensagens heartbeat $\Delta_{i}$. Pequenas variações no atraso na rede causam, no entanto, pequenas diferenças entre o momento esperado da recepção de uma mensagem e o momento de sua atual recepção, que por sua vez levam a enganos que são rapidamente corrigidos. Devido à redundância proporcionada pelo gossip payload, estes enganos são então corrigidos com o recebimento de qualquer mensagem que contenha a informação necessária, o que explica o melhor desempenho do detector adaptativo que utiliza a técnica.

Com o detector gossip tradicional, o algoritmo realiza a escolha aleatória do destinatário das mensagens heartbeat, e portanto esta métrica apresenta grande variação. Como 


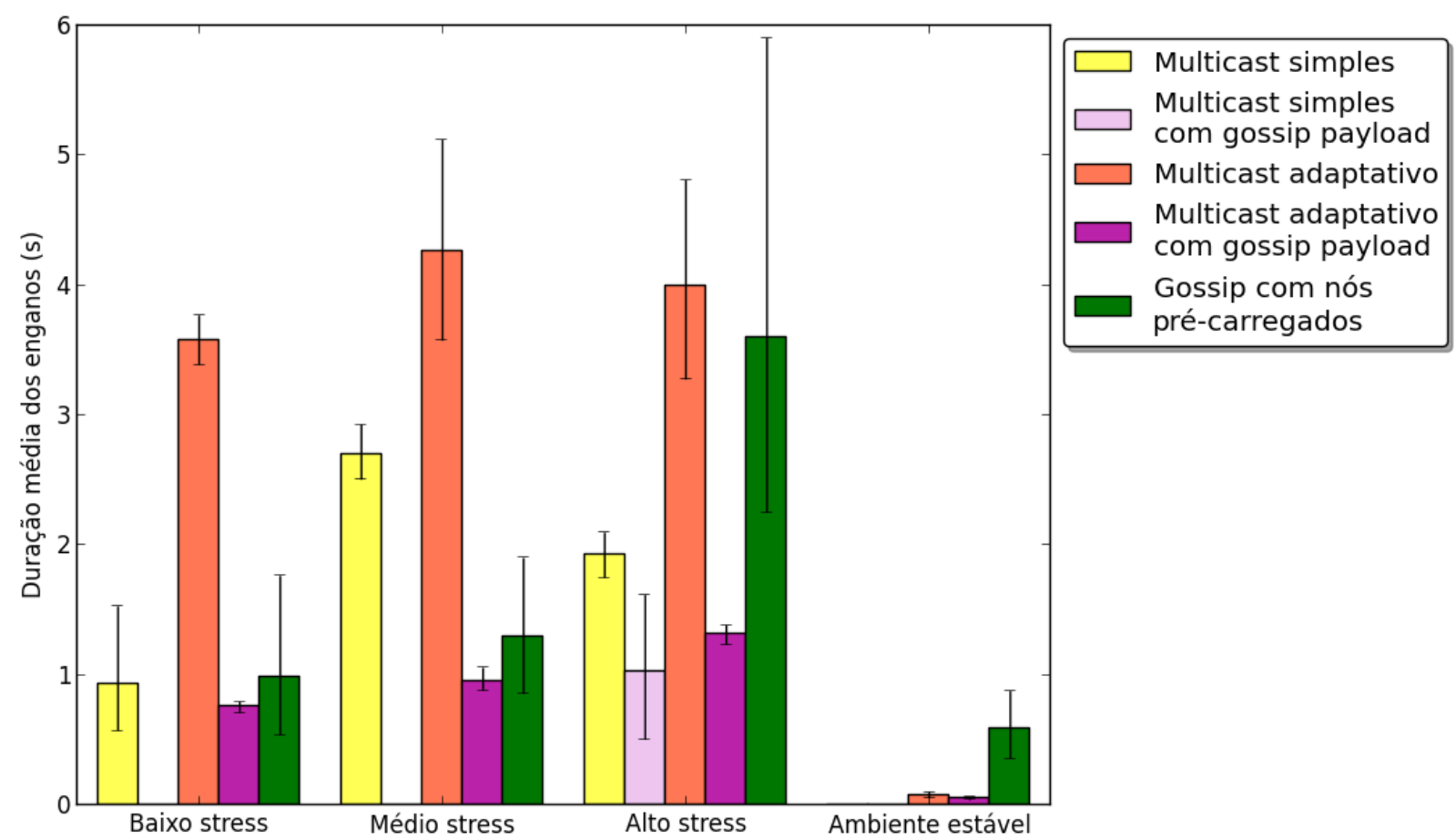

Figura 6.2 - Duração média dos enganos no cenário 1.

os dados são transmitidos ponto a ponto ao longo de diversos turnos, existe uma demora adicional na identificação de falhas que é dependente do algoritmo de seleção de destinatários para as mensagens heartbeat enviadas pelo protocolo.

A Figura 6.3 apresenta a proporção de detecções, ou seja, notificações de falhas reconhecidas corretamente, por falhas que realmente foram causadas pelo modelo de adversidades. Idealmente, esta métrica se aproxima de 1, o que significaria que todas as falhas ocorridas foram detectadas com sucesso. Todos os detectores apresentam valor 1 , o que significa que as diferentes características dos detectores não influenciam diretamente a probabilidade de que ao menos um dos detectores instalados nas máquinas virtuais consiga identificar uma falha causada pelo modelo de adversidades. Como não há o processamento das notificações de falha e recuperação, o recebimento de qualquer notificação de falha é imediatamente considerado, mesmo que notificações conflitantes sejam recebidas pelo gerenciador de falhas.

A Figura 6.4 mostra o tempo médio entre uma falha e sua detecção para cada detector neste cenário. De maneira geral, para os detectores multicast que não utilizam protocolos adaptativos, esta métrica se mantém inferior ao intervalo de timeout $\Delta_{t o}$. Isto se justifica pelo funcionamento destes detectores. Uma falha é considerada apenas após este intervalo, contando a partir da última recepção de mensagem heartbeat. O valor específico medido também depende da relação entre o intervalo de envio de mensagens heartbeat 


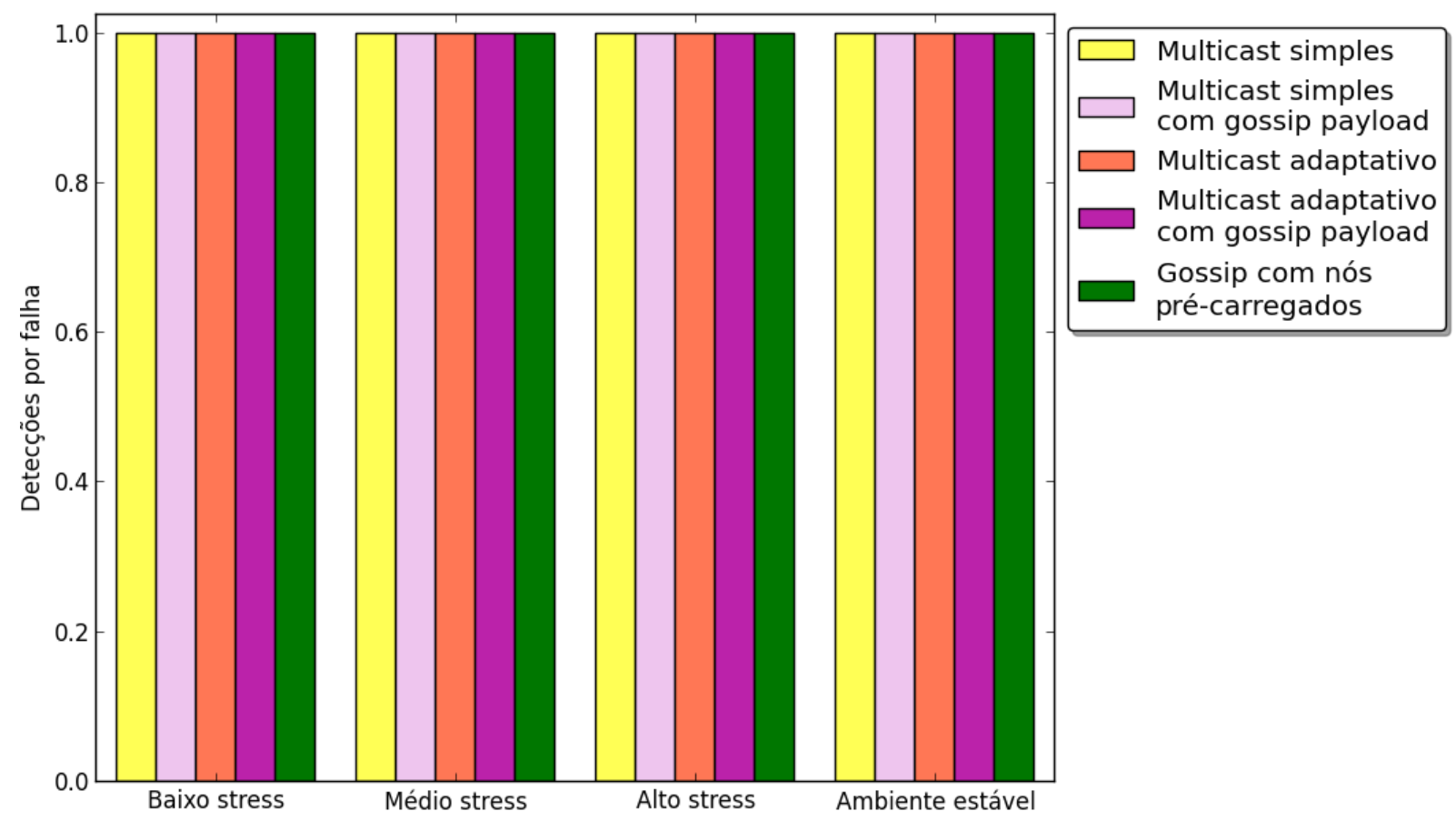

Figura 6.3 - Média de detecções por falha no cenário 1.

$\Delta_{i}$ e a frequência de geração de falhas do modelo de adversidades. Em outras palavras, esta métrica também depende da relação entre o intervalo de tempo entre a falha de um detector e o horário esperado do recebimento de sua próxima mensagem heartbeat.

Esta métrica permite avaliar o papel de protocolos adaptativos na detecção de falhas. É possível perceber uma redução no atraso médio das detecções no caso dos detectores adaptativos em relação aos detectores de mesmas características, mas que não utilizam a adaptação do intervalo de timeout. A adaptação traz resultados melhores em situações de baixo stress, já que a estimação de recebimentos futuros se torna mais conservadora na ocasião de perdas de pacote ou variações intensas no atraso médio da rede. Estas condições adversas implicam em uma variação na medição do intervalo entre as mensagens heartbeat recebidas, o que faz que o algoritmo de adaptação aumente o intervalo de timeout em resposta. A Figura 6.5 ilustra o fenômeno. No momento em que a amostra 45 é coletada, por exemplo, a mensagem heartbeat é recebida com um atraso superior a 10 segundos, o que indica que houve a perda de um pacote que deveria ter sido recebido há 5 segundos. Esta grande variação no intervalo medido leva há uma resposta do algoritmo de adaptação, que é vista como um dos picos do gráfico. Nas amostras seguintes, até a amostra de número 63, o intervalo medido segue com pouca variação, e por isso o intervalo $\Delta_{t o}$ estimado é reduzido, se aproximando do intervalo medido. Conforme o intervalo $\Delta_{t o}$ é reduzido, o atraso da detecção também é reduzido. 


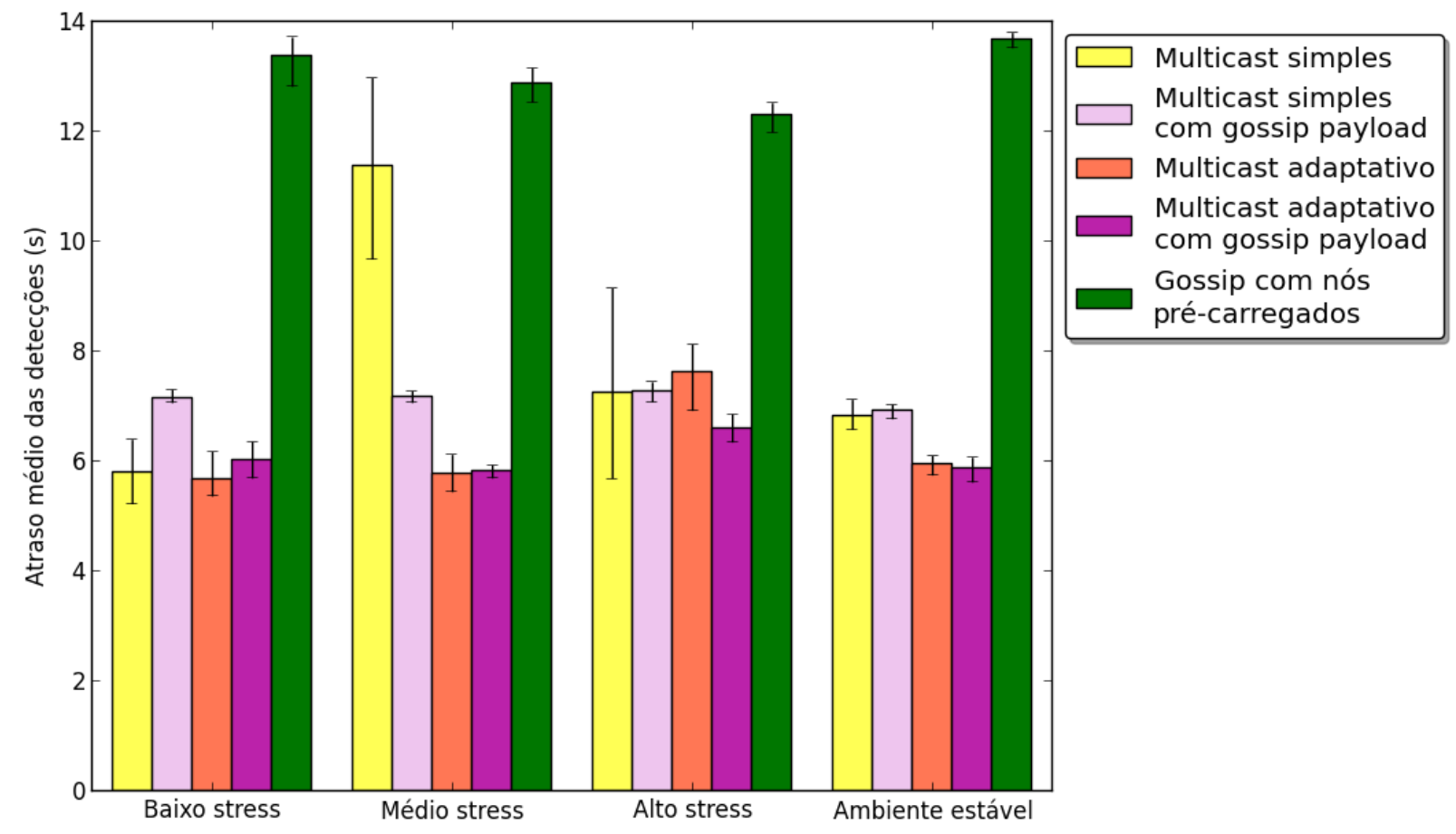

Figura 6.4 - Atraso médio das detecções no cenário 1.

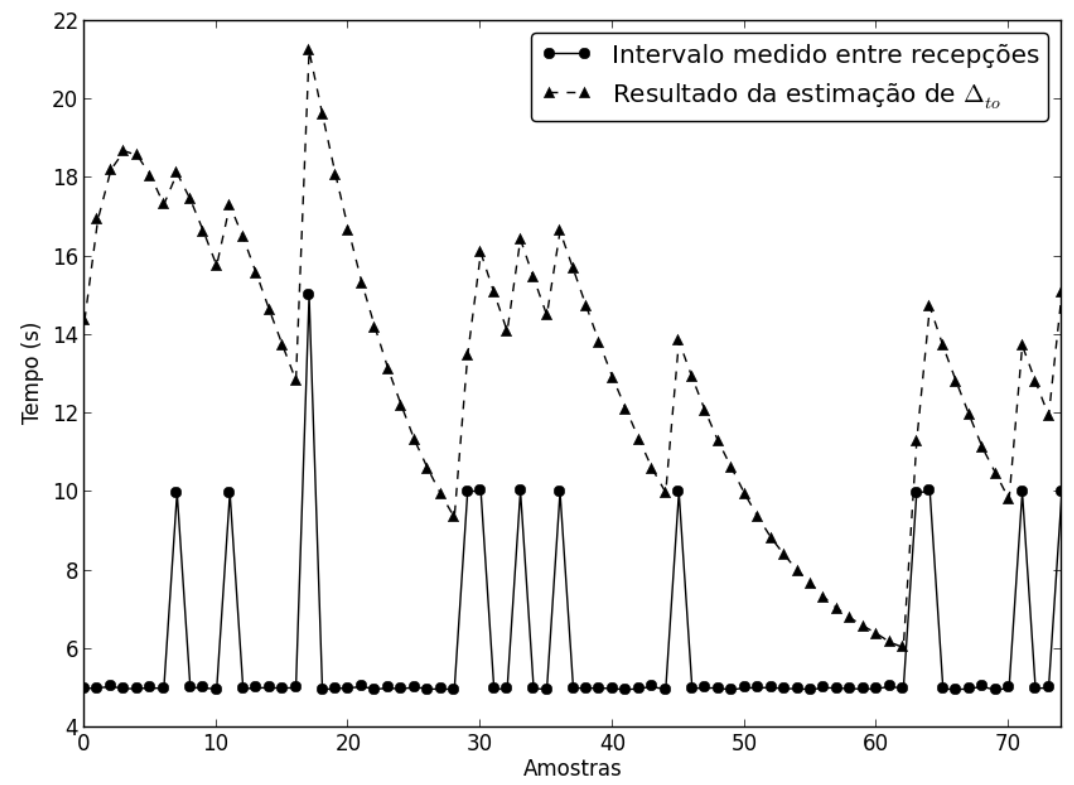

Figura 6.5 - Efeito na estimação do horário de recepções futuras de mensagens heartbeat causado por variações nas condições de rede, perdas de pacotes e falhas de detectores. 


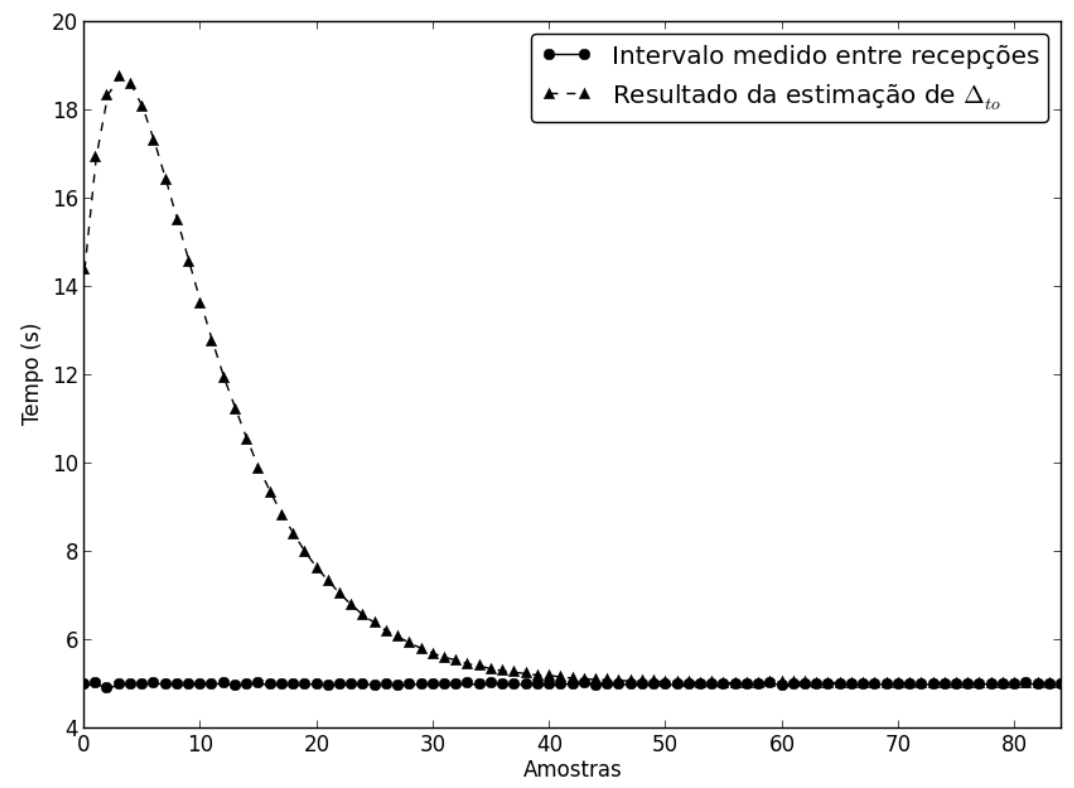

Figura 6.6 - Estimação do horário de recepções futuras de mensagens heartbeat em condições de rede favoráveis.

Em comparação, como é possível perceber na Figura 6.6, quando as condições de rede são favoráveis, a função de estimação utilizada reduz o intervalo de timeout $\Delta_{t o}$, chegando a aproximá-lo do intervalo entre o envio de mensagens heartbeat $\Delta_{i}$, e o mantendo constante. Esta Figura ilustra como a qualidade do serviço de detecção de falhas, no que diz respeito à redução do intervalo entre uma falha e sua detecção, pode ser beneficiada pela utilização de um algoritmo adaptativo. Também é possível perceber como esta métrica evolui de acordo com as flutuações da rede ao longo do tempo. No início da simulação, é possível perceber que o intervalo $\Delta_{t o}$ estimado apresenta valores altos, o que se traduz em um maior atraso de detecção. No entanto, conforme as amostras seguem sendo recebidas regularmente, ao final do gráfico é possível perceber que o intervalo $\Delta_{t o}$ é reduzido, se aproximando do intervalo $\Delta_{i}$, e promovendo uma detecção mais ágil.

Em uma execução de longa duração, um algoritmo adaptativo gradualmente aumenta sua rapidez na detecção ao ajustar o intervalo de timeout após sucessivas recepções de mensagens heartbeat em intervalos regulares. A Figura 6.7 apresenta o tempo médio entre uma falha e sua detecção, mas considerando apenas a metade final do intervalo de testes. Ou seja, todos os eventos com ocorrência anterior à metade final do intervalo são descartados para o cálculo do atraso. Desta maneira, durante o período considerado, o intervalo $\Delta_{t o}$ está reduzido. Através desta Figura é possível perceber claramente uma grande redução no atraso médio das detecções com a utilização do protocolo adaptativo. 


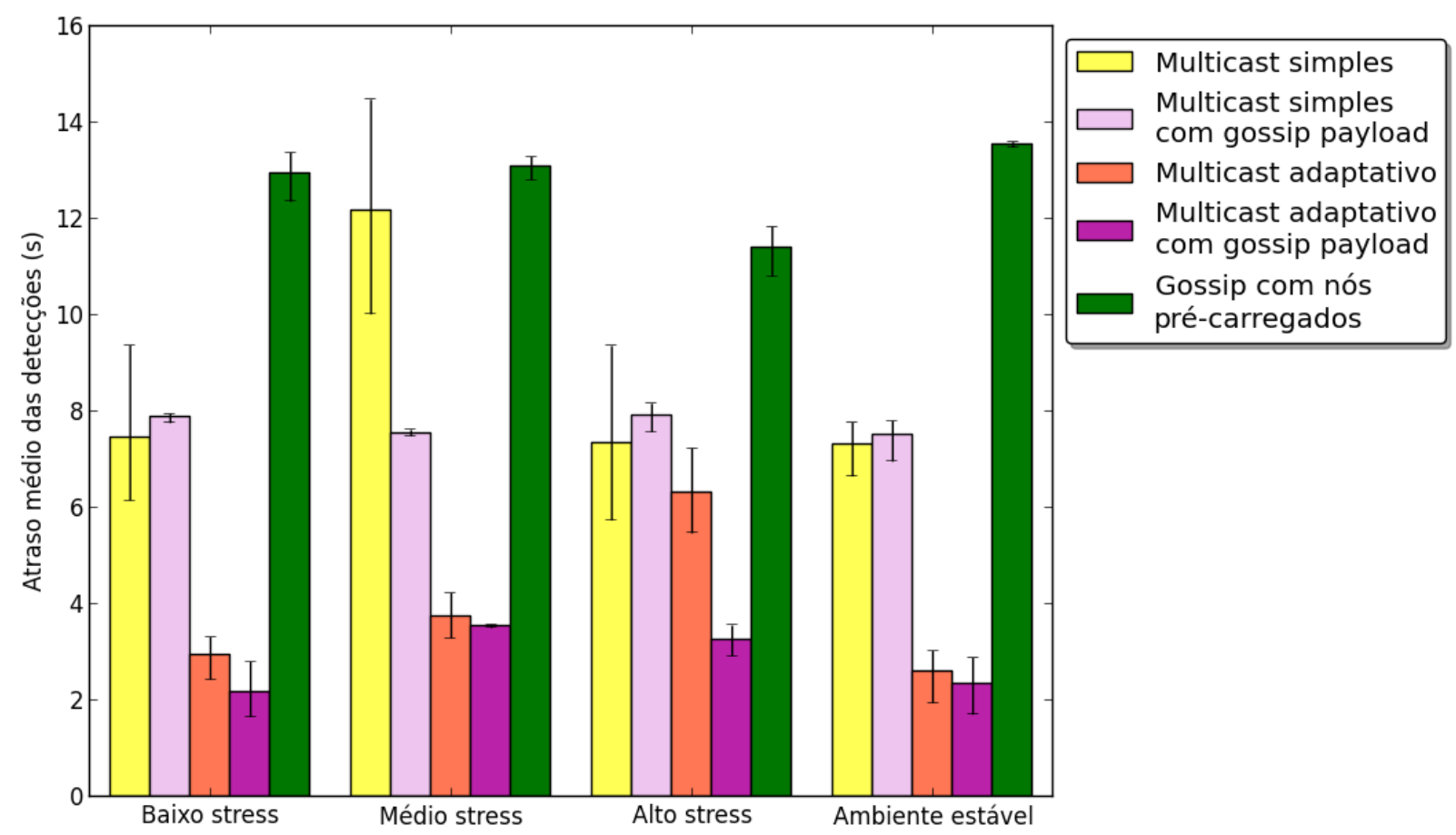

Figura 6.7 - Atraso médio das detecções na metade final do intervalo de testes no cenário 1.

\subsection{Resultados do cenário 2 (filtragem de conflitos)}

Neste cenário, o gerenciador de falhas em execução no sistema hospedeiro realiza o processamento das notificações de falha e recuperação através da manutenção das notificações por um intervalo de tempo. Caso uma notificação conflitante seja recebida neste período, ambas as notificações são descartadas. As notificações são registradas para análise somente após este processamento.

Como é possível visualizar na Figura 6.8, a utilização desta filtragem traz uma redução significativa no número de enganos contabilizados. Todos os detectores são beneficiados com a utilização desta técnica. O detector multicast que utiliza a técnica gossip payload, que já havia apresentado poucos enganos no cenário sem processamento de notificações, não apresenta nenhum engano após a filtragem de conflitos. Na configuração estável, a filtragem é suficiente para eliminar totalmente os enganos com qualquer detector. De maneira geral, o desempenho dos detectores se deteriora de acordo com as condições de rede.

O pior desempenho é encontrado com os detectores que não utilizam a técnica gossip payload. O detector multicast simples, apesar de não contar com a técnica gossip payload, consegue atingir um desempenho satisfatório quando o nível de stress na rede é 


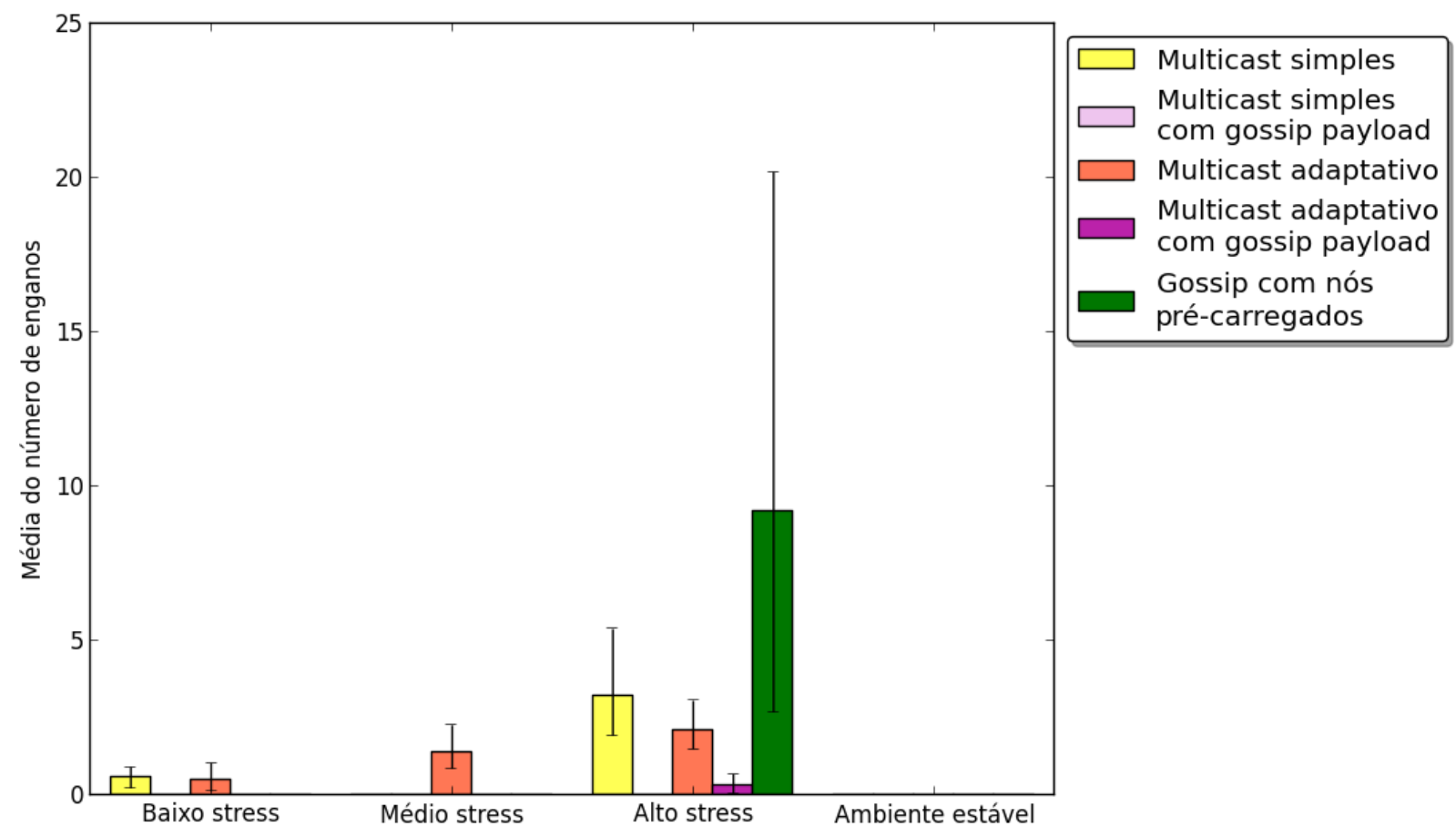

Figura 6.8 - Número de enganos no cenário 2.

baixo. O processamento de notificações garante que poucas notificações incorretas sejam consideradas.

A informação adicional sobre detectores vizinhos encontrada nas mensagens heartbeat do detector gossip não é suficiente para garantir um bom desempenho na configuração de alto stress. Nesta configuração, as rajadas fazem com que seja mais provável que uma quantidade maior de mensagens heartbeat consecutivas sejam perdidas. Estas rajadas podem, portanto, evitar que existam divergências entre os detectores em uma situação de engano, reduzindo a eficiência do processamento das notificações.

Os detectores adaptativos conseguem desempenho adequado embora estimem agressivamente o horário de recepção de novas mensagens heartbeat, o que normalmente levaria a detecções incorretas caso a filtragem de notificações em conflito não estivesse em uso. As alterações nas condições de rede causam detecções espúrias, corrigidas rapidamente com o recebimento da mensagem heartbeat esperada. Estes enganos temporários e de curta duração são facilmente identificados e anulados através da filtragem de conflitos.

A Figura 6.9 mostra a duração média de enganos neste cenário. Nas medições nais quais não foram detectados enganos, esta métrica é apresentada com valor zero. As medições exibidas mostram um valor muito superior aos valores encontrados na medição no cenário 2, apresentados na Figura 6.2. Esta diferença e a enorme variação observada nas medições são consequência direta do processamento de notificações. Este processa- 


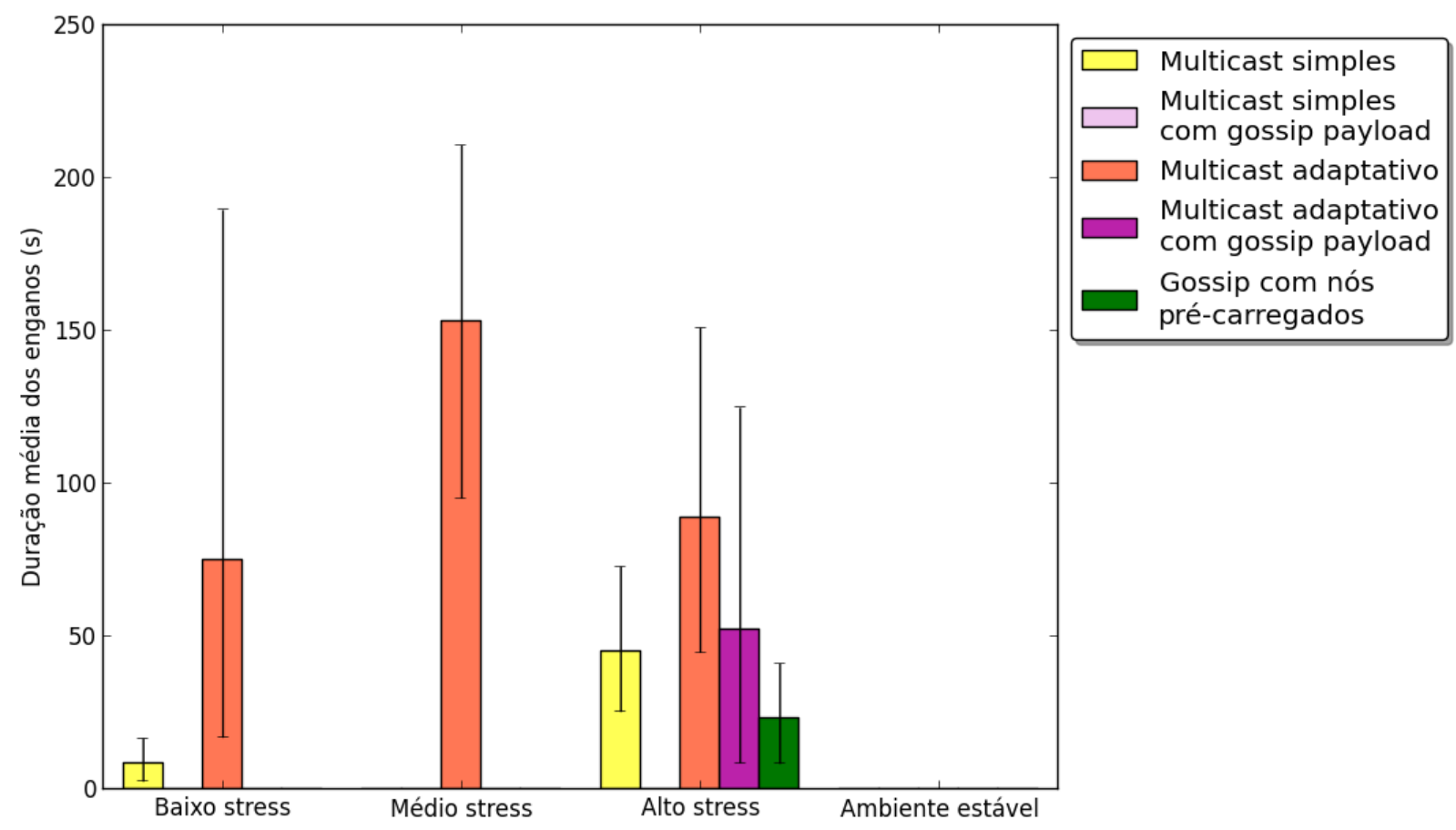

Figura 6.9 - Duração média dos enganos no cenário 2.

mento impõe restrições à consideração de notificações de falha, visando reduzir a probabilidade de situações em que detectores em desacordo alteram a visão do gerenciador de falhas sobre o estado dos detectores. Enquanto previne o reconhecimento de notificações incorretas, o processamento também impõe dificuldades aos detectores que buscam enviar notificações de recuperação. Isso significa que algumas correções de enganos podem não ser aceitas pelo gerenciador de falhas caso não atendam às exigências da filtragem de notificações. Estas notificações só passam a ser corrigidas após uma segunda falha e posterior recuperação aceita pela filtragem de notificações. O efeito destas situações é uma grade duração média dos enganos, que em conjunto com enganos corrigidos rapidamente sem notificações conflitantes resulta em grande variação para a métrica.

O detector multicast adaptativo sem a utilização da técnica gossip payload é o mais afetado pelo efeito do processamento de notificações de falha sobre a duração dos enganos. Com o processamento de notificações, os frequentes enganos de curta duração causados pela estimação agressiva do intervalo de timeout não são aceitos pelo gerenciador de falhas. Os enganos detectados são causados pela perda de pacotes em rajadas, que causam detecções incorretas de maior duração, pois não são corrigidas até a próxima transmissão de mensagem heartbeat do nó equivocadamente considerado em falha. $O$ protocolo adaptativo que utiliza a técnica gossip payload não é tão afetado por este problema, já que os detectores podem receber informações indiretas para rapidamente efetuar a correção ou até mesmo prevenir o engano. 


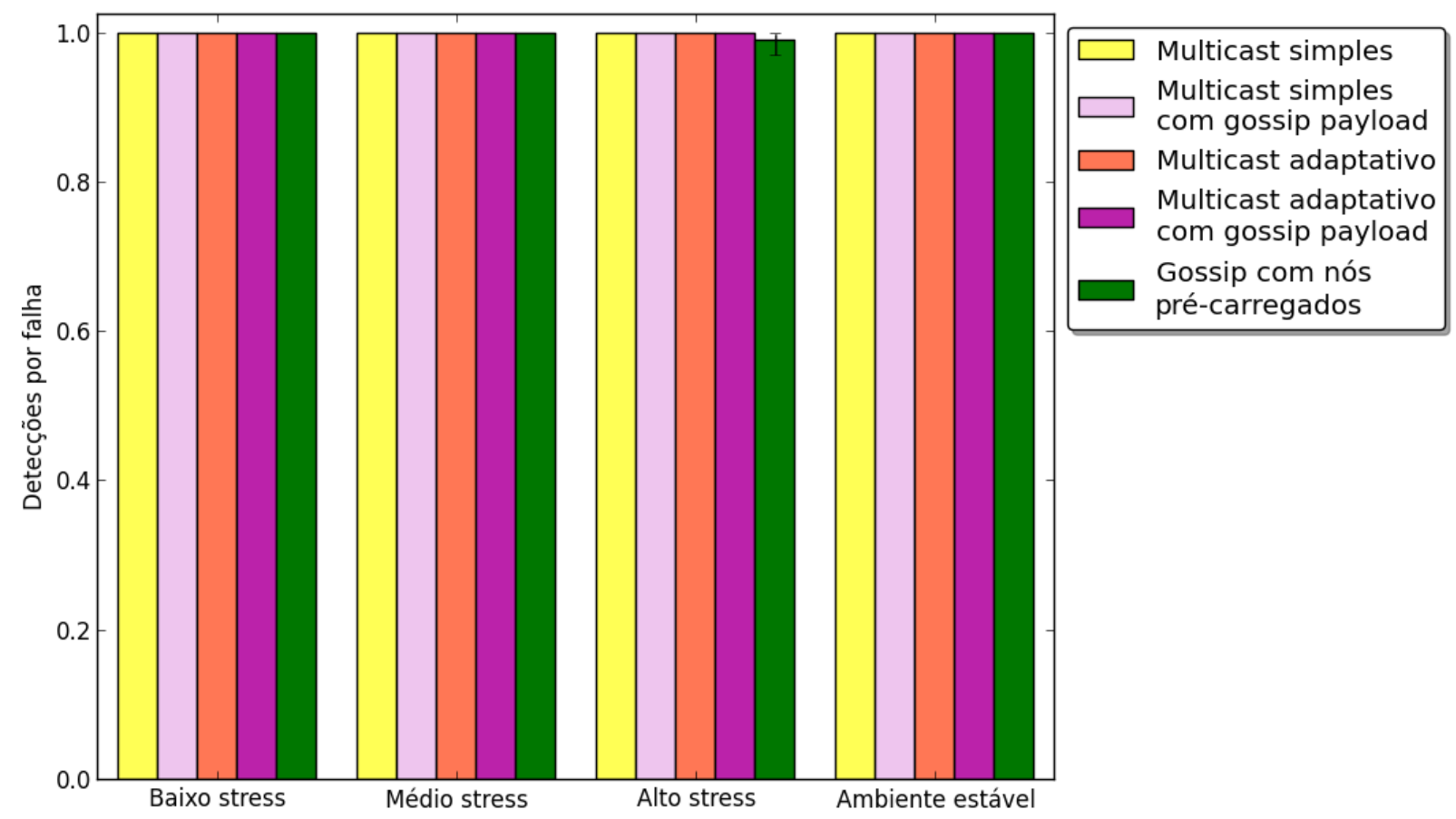

Figura 6.10 - Média de detecções por falha no cenário 2.

A Figura 6.10 apresenta a média do número de detecções de falhas por cada falha. Como é possível perceber, não há variação em relação aos valores apresentados na Figura 6.3. O processamento de notificações de falha através da filtragem de notificações conflitantes não causa efeito negativo sobre a eficiência na detecção de falhas de forma geral. O detector gossip apresenta pequena variação pontual devido à perda de informações causada pela falha de detectores na configuração de alto stress sobre a infraestrutura.

As Figuras 6.11 e 6.12 apresentam o intervalo médio entre uma falha e sua detecção em todo o período de testes e apenas em sua metade final, respectivamente. Esta distinção é feita porque a estimação do intervalo de timeout $\Delta_{t o}$ se comporta de maneira ideal após o recebimento de várias mensagens heartbeat em intervalos regulares. É possível perceber que as proporções observadas no cenário 1 apresentadas nas Figuras 6.4 e 6.7 são mantidas, mas o intervalo é atrasado em aproximadamente $10 \mathrm{~s}$. Este atraso é proveniente do período em que as notificações são mantidas no buffer com a finalidade de identificação de conflitos. Observando estas métricas, é possível perceber que a utilização da filtragem de conflitos reduz a qualidade do serviço de detecção de falhas no que diz respeito ao atraso na detecção.

A redução do atraso com a utilização da estimação adaptativa ao longo do tempo de execução dos detectores também é percebida neste cenário. O limite inferior para o atraso 


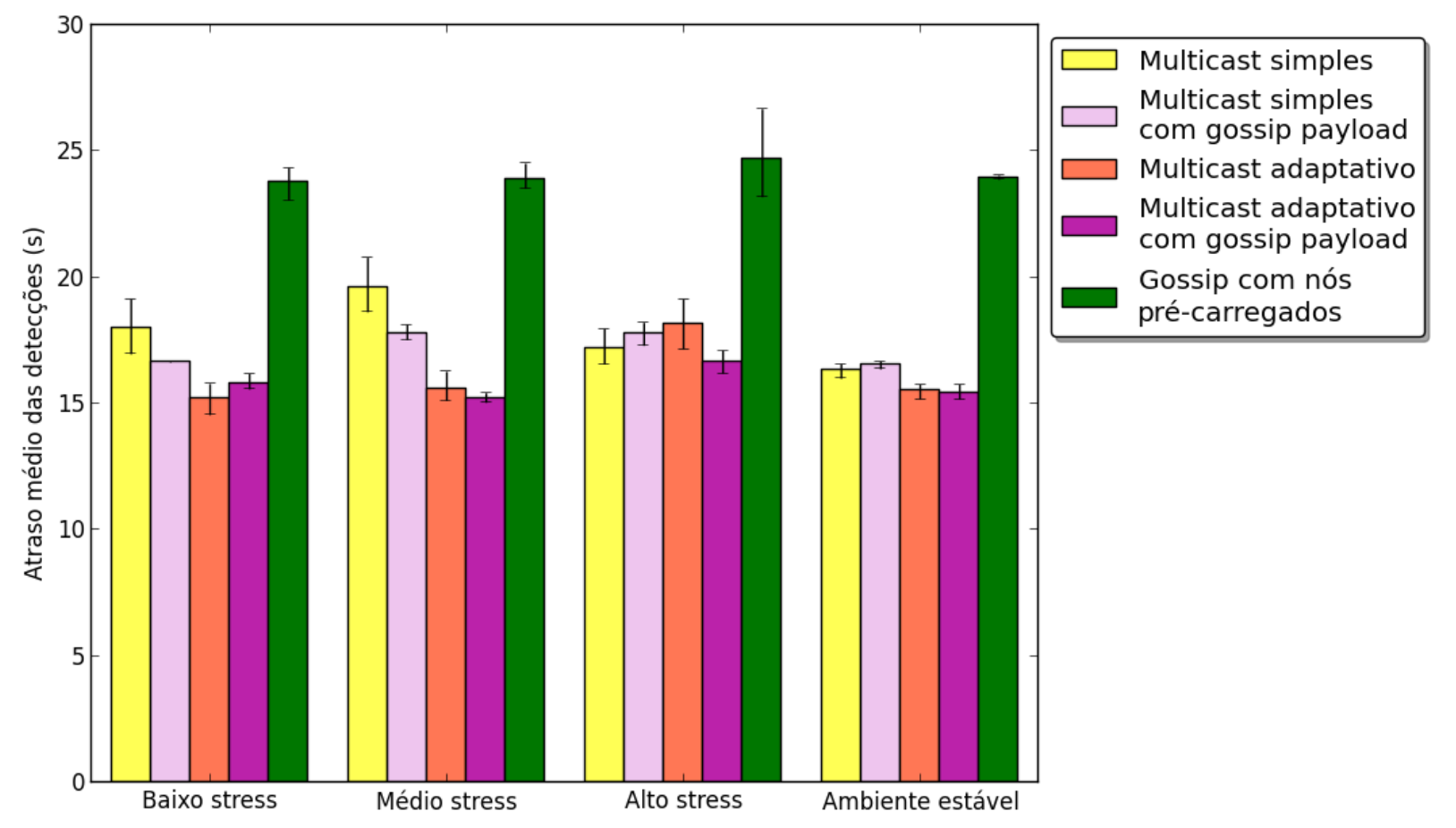

Figura 6.11 - Atraso médio das detecções no cenário 2.

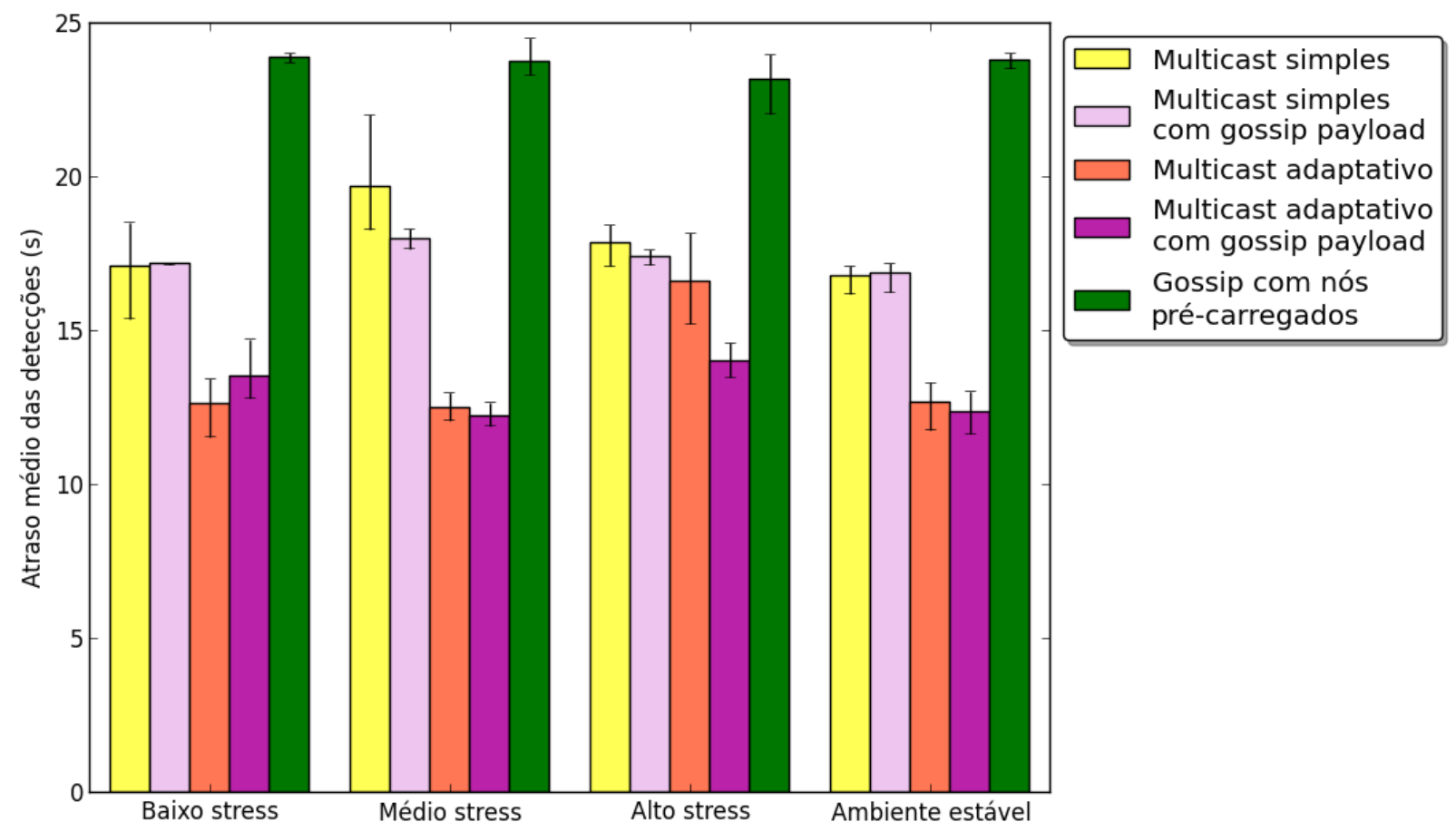

Figura 6.12 - Atraso médio das detecções na metade final do intervalo de testes no cenário 2. 


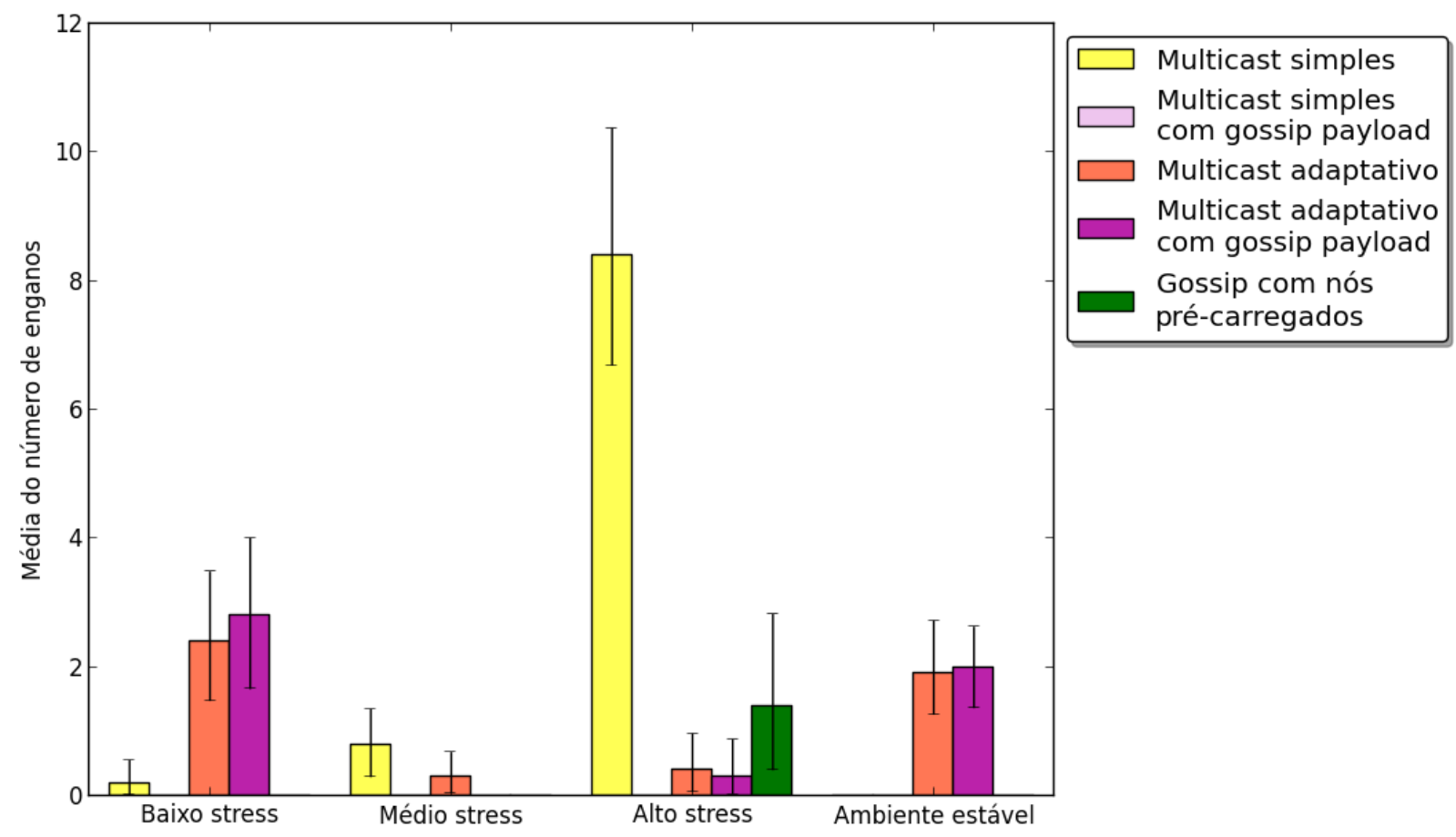

Figura 6.13 - Número de enganos no cenário 3.

é, porém, a soma do intervalo entre os envios de mensagens heartbeat $\Delta_{i}$ acrescido do período de tempo em que as notificações são mantidas no buffer para filtragem de conflitos.

\subsection{Resultados do cenário 3 (quórum)}

Neste cenário, o gerenciador de falhas em execução no sistema hospedeiro realiza o processamento das notificações de falha e recuperação através da exigência de um quórum. As notificações recebidas pelo gerenciador de falhas são consideradas e registradas para análise somente após a recepção de quatro mensagens confirmando a notificação, sendo todas estas geradas por detectores diferentes.

A Figura 6.13 apresenta o número de enganos cometidos pelos detectores. Estes valores são significantemente inferiores aos obtidos no cenário 1 (Figura 6.1), e comparáveis aos resultados apresentados no cenário 2 (Figura 6.8). Assim como nos resultados dos cenário apresentados anteriormente, o comportamento do detector multicast com a técnica gossip payload apresenta os melhores resultados. Isso se justifica pela redundância adicional que a técnica oferece, que reduz a probabilidade de situações em que um número de detectores cometendo o mesmo engano satisfaça o quórum exigido. De maneira geral, todos os detectores são beneficiados pela exigência de quórum quanto ao número de enganos. 
Na Figura 6.8, referente ao cenário 2, o detector gossip apresentou uma grande quantidade de enganos na configuração de alto stress. Em comparação, na Figura 6.13, o detector multicast simples mostra uma maior quantidade de enganos nesta configuração. No caso do processamento com exigência de quórum, é necessário que diversos detectores se manifestem para que uma notificação seja considerada. Com a utilização de um detector gossip ou multicast com a técnica gossip payload, a redundância contida nas mensagens heartbeat reduz a probabilidade de que diversos detectores se manifestem de maneira incorreta no intervalo de tempo de consideração do quórum. Já os detectores multicast sem o gossip payload estão mais vulneráveis a apresentar enganos em conjunto na ocasião de perda de pacotes.

Os detectores adaptativos apresentam resultado superior conforme as condições de rede se tornam mais adversas. Em condições mais estáveis, os detectores passam a estimar agressivamente os horários de recepção de mensagens heartbeat, e pequenas flutuações no atraso são responsáveis por enganos cometidos por um grande número de detectores simultaneamente. Portanto, mesmo sem a redundância adicional do gossip payload, os protocolos adaptativos apresentam pequeno número de enganos em condições adversas.

A Figura 6.14 apresenta a média do número de detecções de falhas por falha neste cenário. É possível identificar um grande impacto na eficiência dos detectores em configurações de médio e alto stress. No entanto, os detectores que utilizam a técnica gossip payload continuam apresentando resultados muito próximos a 1 em todas as configurações. Nos outros detectores, com a exigência de quórum, a falta de redundância distribuída em mensagens heartbeat promove uma possibilidade alta de que um número insuficiente de detectores enviem notificações compatíveis. Com isso, algumas notificações corretas são descartadas no momento de seu processamento. Ao contrário do processamento realizado com a filtragem de notificações, cujos resultados são apresentados na Figura 6.10, o processamento de notificações através de exigência de quórum apresenta um efeito negativo na detecção de falhas em configurações com maior perda de pacotes e com a utilização de detectores multicast sem a técnica gossip payload.

A duração média de enganos neste cenário é apresentada na Figura 6.15. Os valores encontrados são muito superiores aos apresentados na Figura 6.1, correspondente ao cenário 1. De maneira similar ao constatado no cenário 2 (Figura 6.9), a mesma filtragem que exige coerência na visão dos detectores para a aceitação de uma notificação de falha também dificulta a correção de um engano através de notificações de recuperação, já que o 


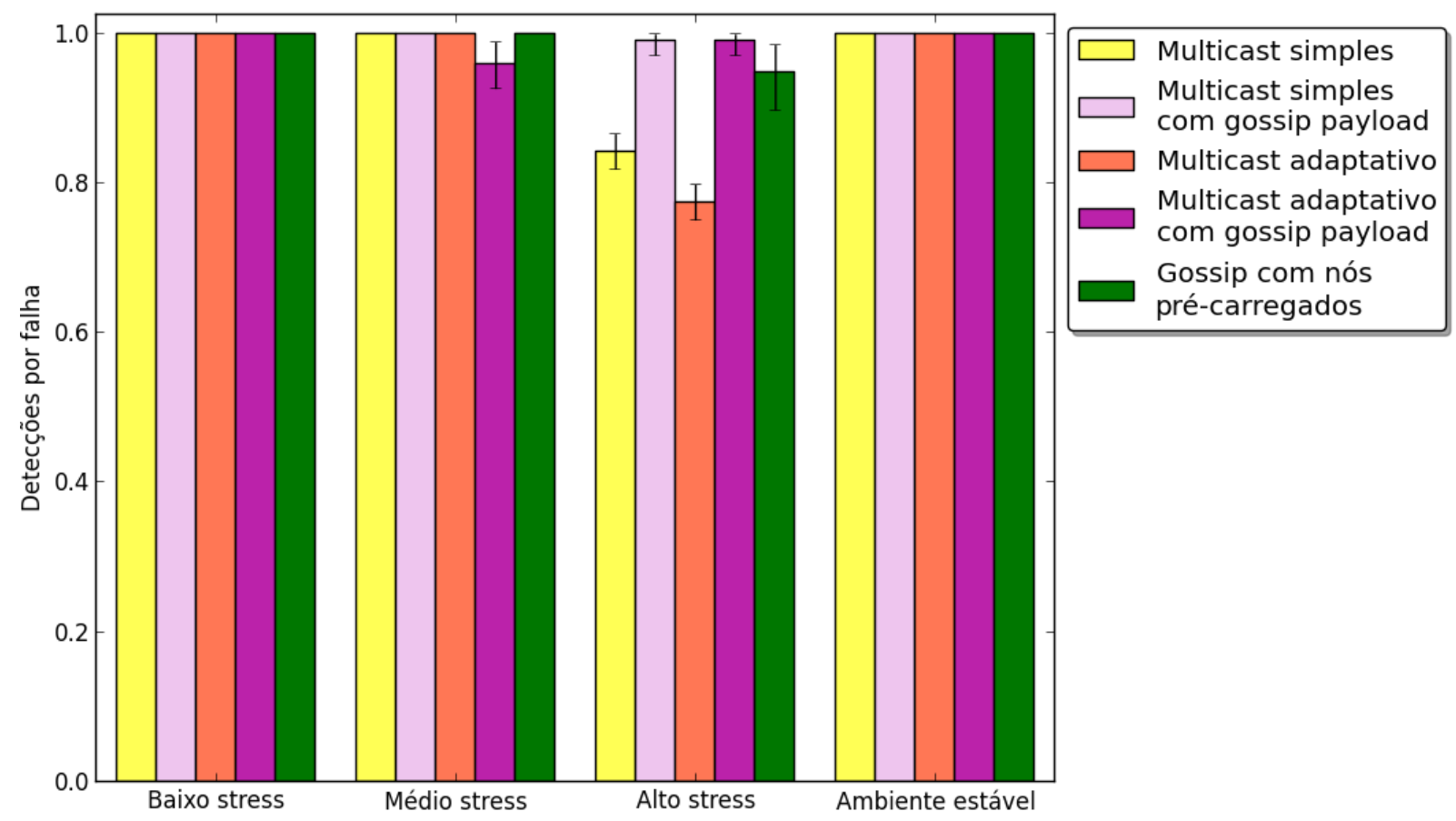

Figura 6.14 - Média de detecções por falha no cenário 3.

quórum é exigido em ambas as situações. Por esse motivo, algumas correções de engano não são aceitas.

A Figura 6.15 mostra um bom desempenho para o detector adaptativo que utiliza 0 gossip payload. A redundância oferecida pela técnica faz com que enganos possam ser corrigidos rapidamente através do recebimento de informações indiretas, causando um menor intervalo de tempo entre o engano e sua correção. O melhor desempenho nas configurações de maior adversidade reflete a característica reativa do protocolo adaptativo. A estimação do horário de recepção de próximas mensagens heartbeat se torna mais conservadora conforme as condições da rede se tornam adversas, ampliando o intervalo de timeout $\Delta_{t o}$ e assim reduzindo a probabilidade do acontecimento de enganos. Os enganos remanescentes são de curta duração, como resultado da estimação do intervalo de timeout.

A Figura 6.16 mostra a média do intervalo de tempo entre uma falha e sua detecção. Como é possível perceber, a exigência de quórum não influencia de maneira significativa o atraso na detecção de falhas, apesar da utilização do armazenamento temporário das notificações recebidas. Isso pode ser explicado pelo fato de que o buffer de notificações não as armazena por um período fixo de tempo. As notificações são removidas do buffer tão logo quanto o quórum é atendido. Portanto, o atraso causado por este processamento só 


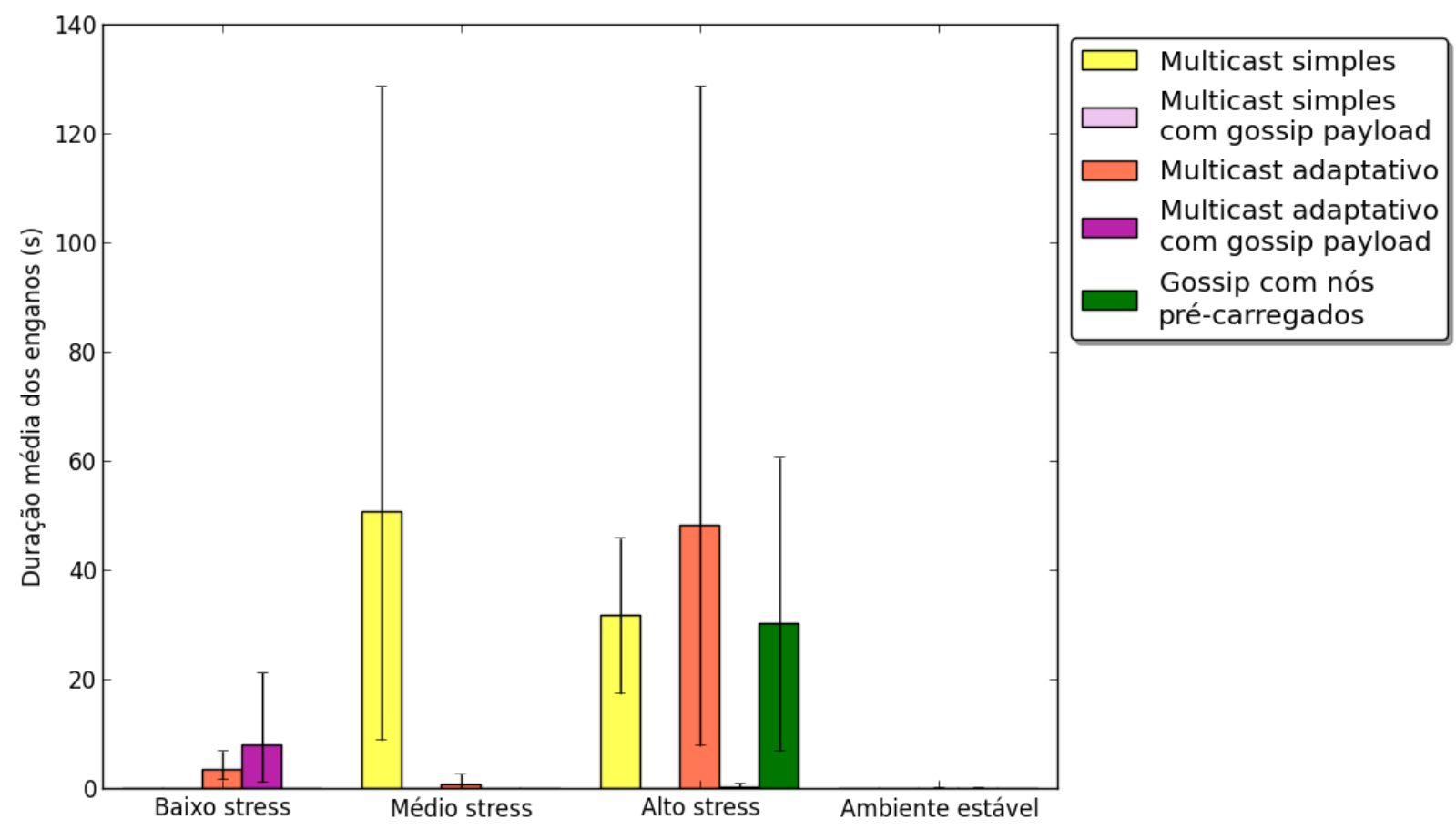

Figura 6.15 - Duração média dos enganos no cenário 3.

está associado à demora no recebimento de um número de notificações de falha suficiente para atender o quórum exigido.

As proporções entre os diferentes detectores e configurações se mantém próximas das proporções identificadas na Figura 6.4, que mostra a mesma métrica no cenário 1. Os detectores multicast simples e gossip apresentam atraso proporcional ao intervalo de timeout. Os detectores multicast adaptativos apresentam resultado inferior, com atraso maior em relação aos detectores multicast simples. Os detectores adaptativos enviam mensagens de detecção em momentos diferentes, já que utilizam intervalos de timeout diferentes entre si, de acordo com o histórico de recepção de mensagens individual a cada detector. Desta maneira, com um detector adaptativo, a exigência de quórum das notificações tende aumentar o atraso na detecção.

Já a Figura 6.17 mostra a média do atraso das detecções, considerando apenas a metade final dos testes. Esta métrica permite identificar a influência da estimação adaptativa do intervalo de timeout após o recebimento de diversas mensagens heartbeat. Assim como constatado na análise das Figuras 6.7 e 6.12, referentes aos cenários 1 e 2, respectivamente, há uma grande redução no atraso com a utilização de protocolos adaptativos. A redução no atraso observada para os detectores adaptativos na metade final dos testes é mais expressiva do que o atraso gerado pela combinação entre a utilização destes detectores e a exigência de quórum. 


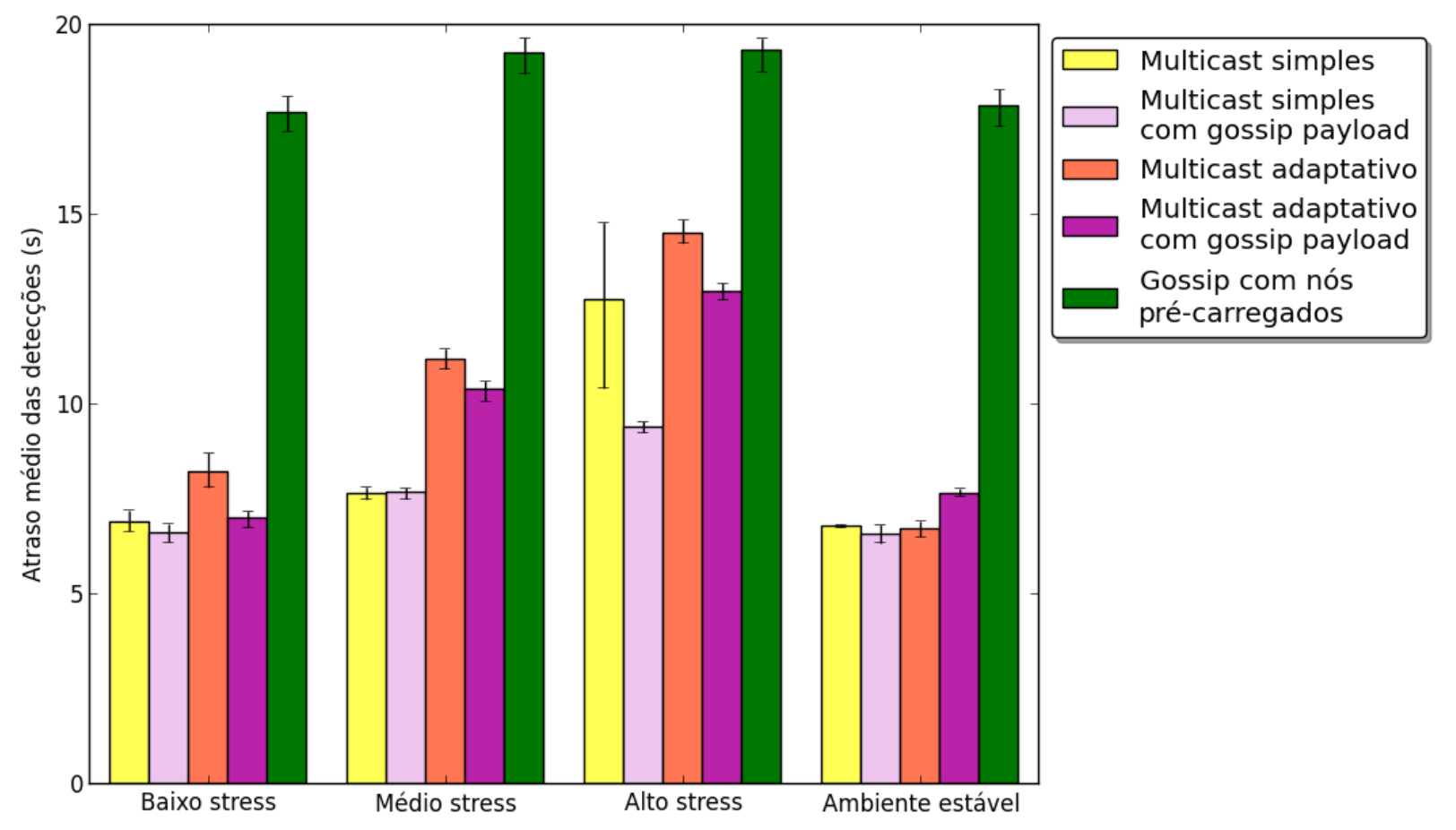

Figura 6.16 - Atraso médio das detecções no cenário 3.

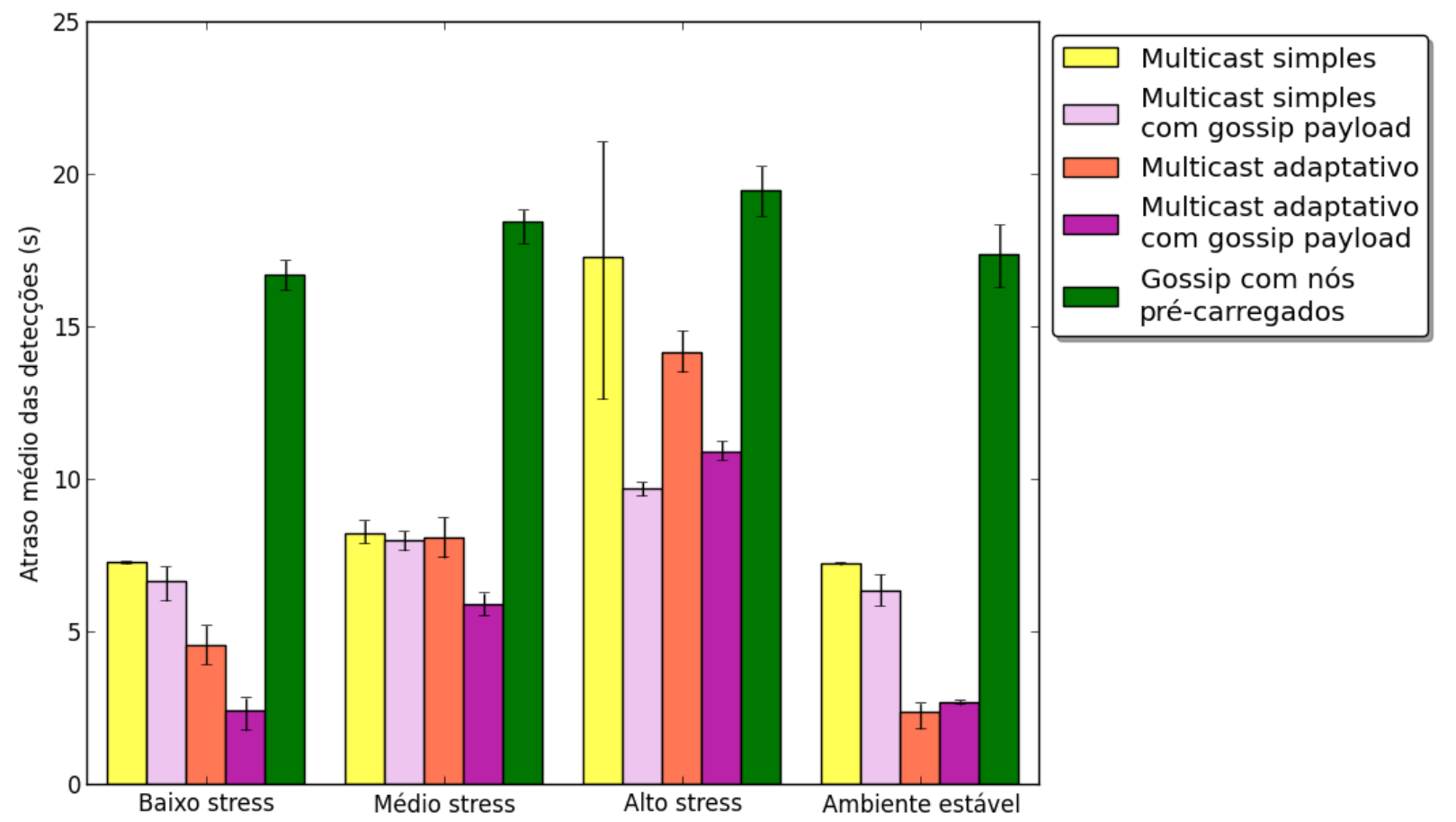

Figura 6.17 - Atraso médio das detecções na metade final do intervalo de testes no cenário 3. 

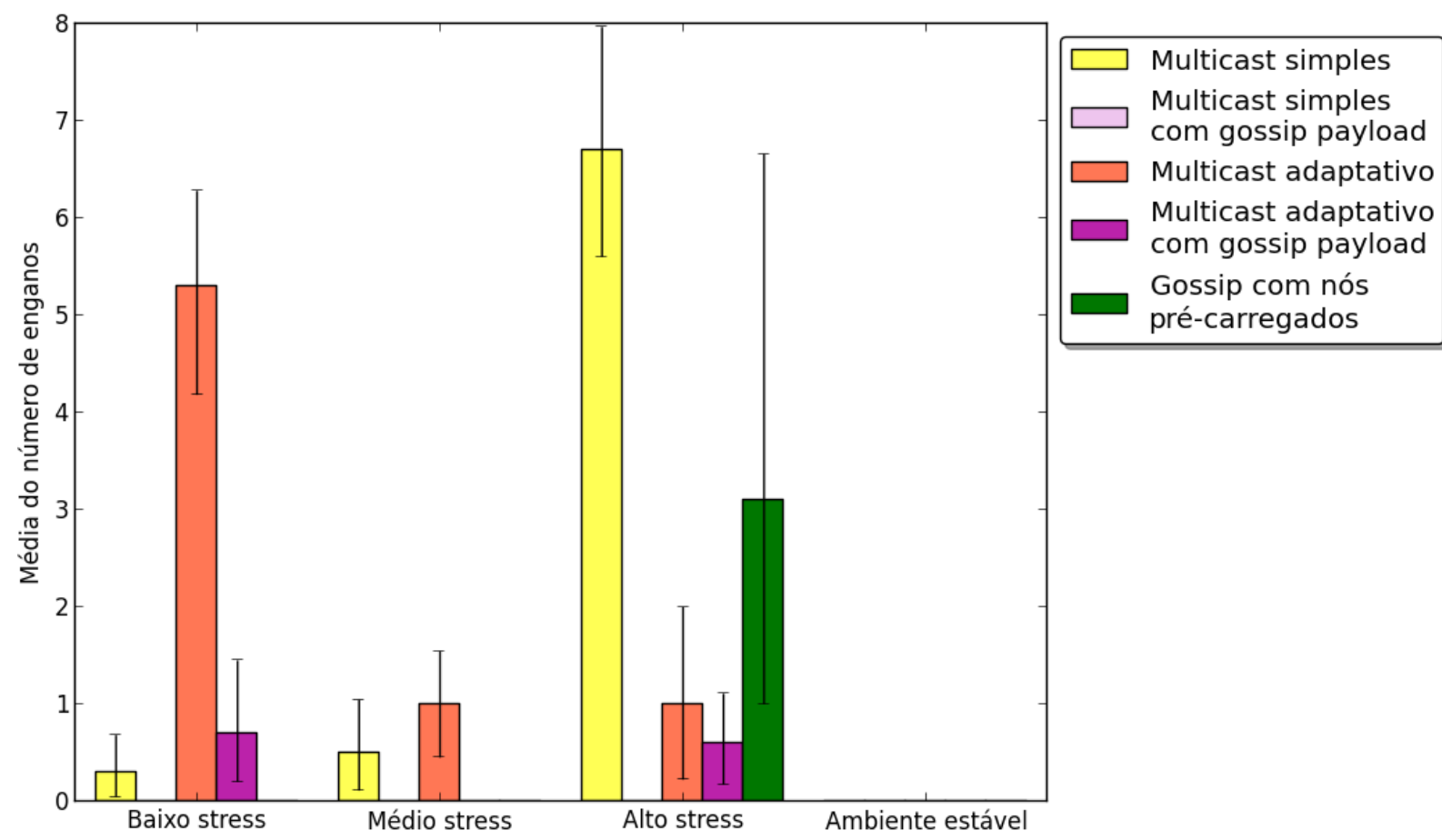

Figura 6.18 - Número de enganos no cenário 4.

\subsection{Resultados do cenário 4 (filtragem de notificações e exigência de quórum)}

Neste cenário, o processamento das notificações de falhas é realizado por uma combinação das técnicas descritas anteriormente: a filtragem de notificações conflitantes e a exigência de quórum de notificações. As notificações são armazenadas em um local de armazenamento temporário para a exigência de quórum. Caso o quórum seja atendido, as notificações são armazenadas em um outro local de armazenamento, desta vez para a identificação de notificações conflitantes. Os valores dos parâmetros foram escolhidos após análise dos resultados obtidos com a utilização das técnicas em separado, buscando atingir uma configuração otimizada.

O número de enganos é apresentado na Figura 6.18. Como é possível perceber, o resultado é comparável ao resultado apresentado nas Figuras 6.8 e 6.13, referentes à mesma métrica nos cenários com processamento de notificações apresentados anteriormente. Apesar da redução do número de notificações compatíveis exigidas pelo quórum, a combinação com a filtragem de conflitos permitiu que o número de enganos se mantivesse baixo.

A média de duração de enganos no cenário 4 é apresentada na Figura 6.19. É possível perceber que os resultados são comparáveis aos obtidos com o processamento de notificações com exigência de quórum, apresentados na Figura 6.15. A exigência de um 


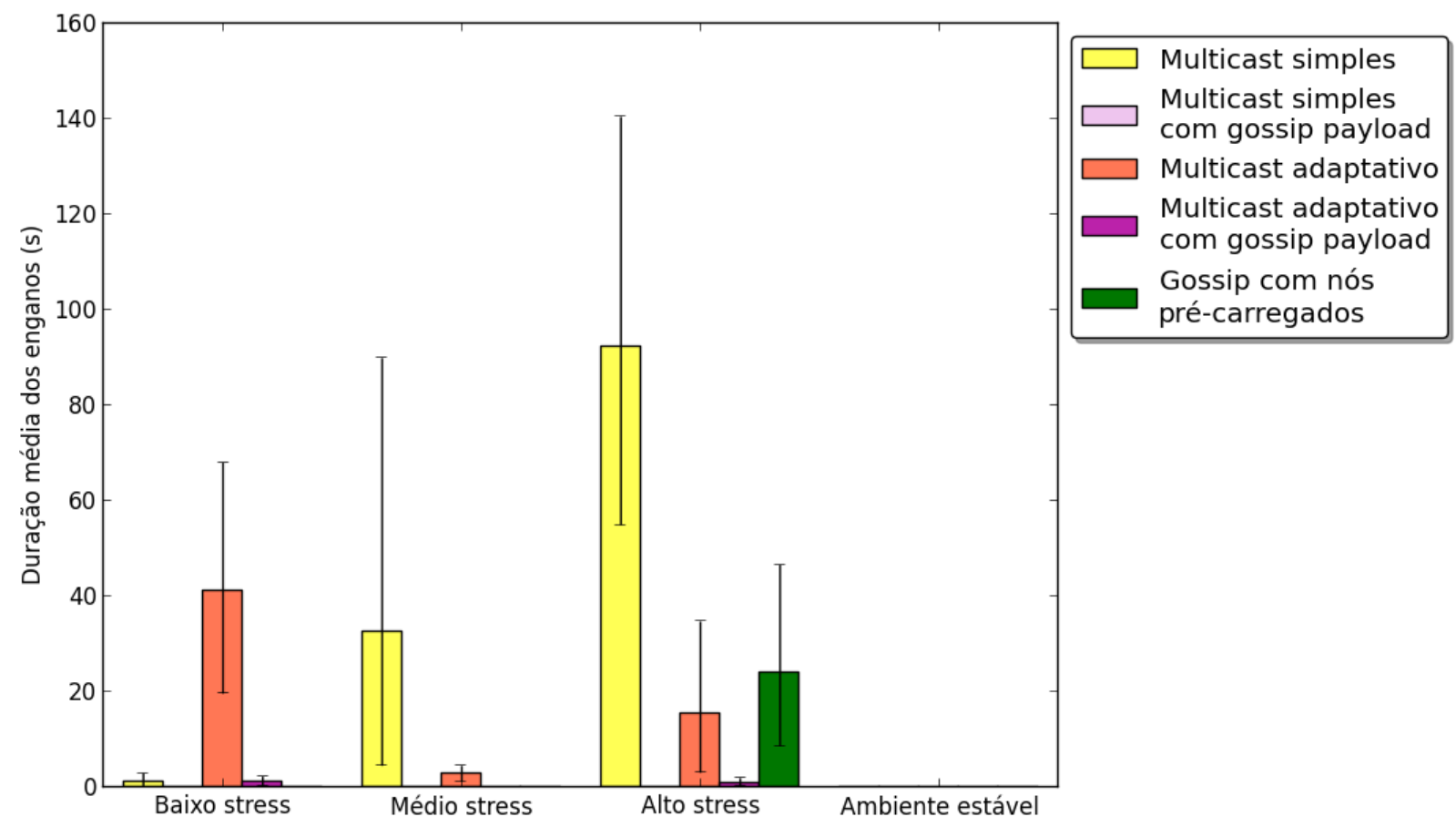

Figura 6.19 - Duração média dos enganos no cenário 4.

menor número de detectores para estabelecimento de quórum é responsável pela melhoria apresentada nesta métrica, já que os enganos podem ser corrigidos com mais facilidade através do envio de notificações de recuperação.

A média de detecções por falha é apresentada na Figura 6.20. Os resultados são inferiores aos obtidos com o processamento de notificações com filtragem de conflitos (Figura 6.10) em virtude da utilização conjunta da exigência de quórum. Os resultados são, porém, superiores aos obtidos com o processamento de notificações através da exigência de quórum (Figura 6.14), em razão da flexibilização da exigência de quórum.

As Figuras 6.21 e 6.22 apresentam o atraso entre uma falha e sua detecção, considerando todo o intervalo de tempo da execução dos testes e somente a metade final deste intervalo, respectivamente. Estes resultados são ligeiramente inferiores aos resultados obtidos no cenário 3 somente com a utilização de quórum (Figuras 6.16 e 6.17). Isso se deve à utilização da filtragem de notificações conflitantes, que mantém as notificações armazenadas por um intervalo de tempo fixo. Os resultados são, porém, muito superiores aos apresentados no cenário 2 (Figuras 6.11 e 6.12). Apesar da utilização da filtragem de conflitos que armazena as notificações de falhas por um intervalo de tempo fixo, o atraso total é inferior em relação ao cenário 2 porque este intervalo de tempo fixo é menor. Este intervalo pôde ser reduzido sem a alteração significativa da qualidade de serviço porque a técnica de exigência de quórum está sendo usada em conjunto. 


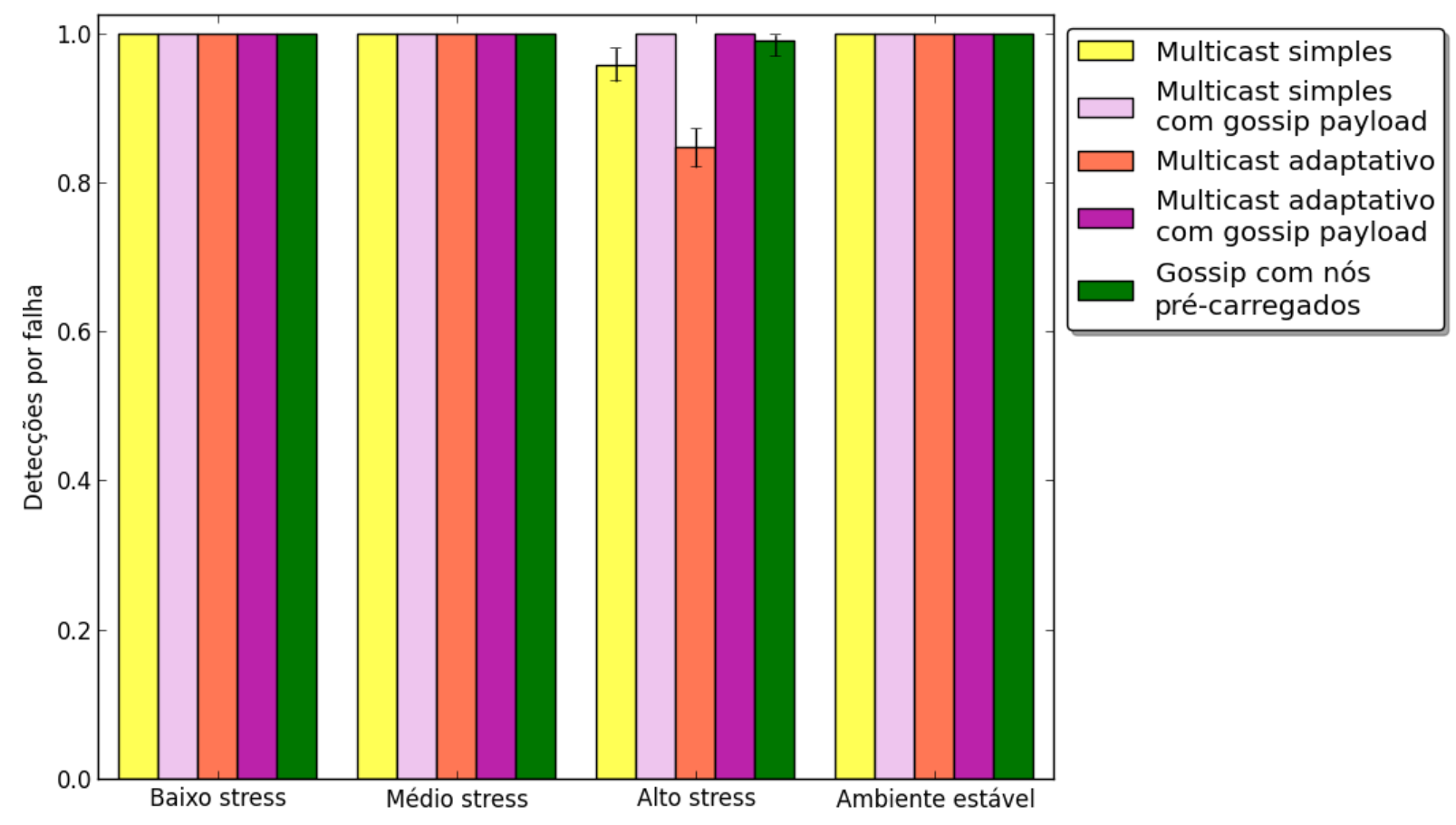

Figura 6.20 - Média de detecções por falha no cenário 4.

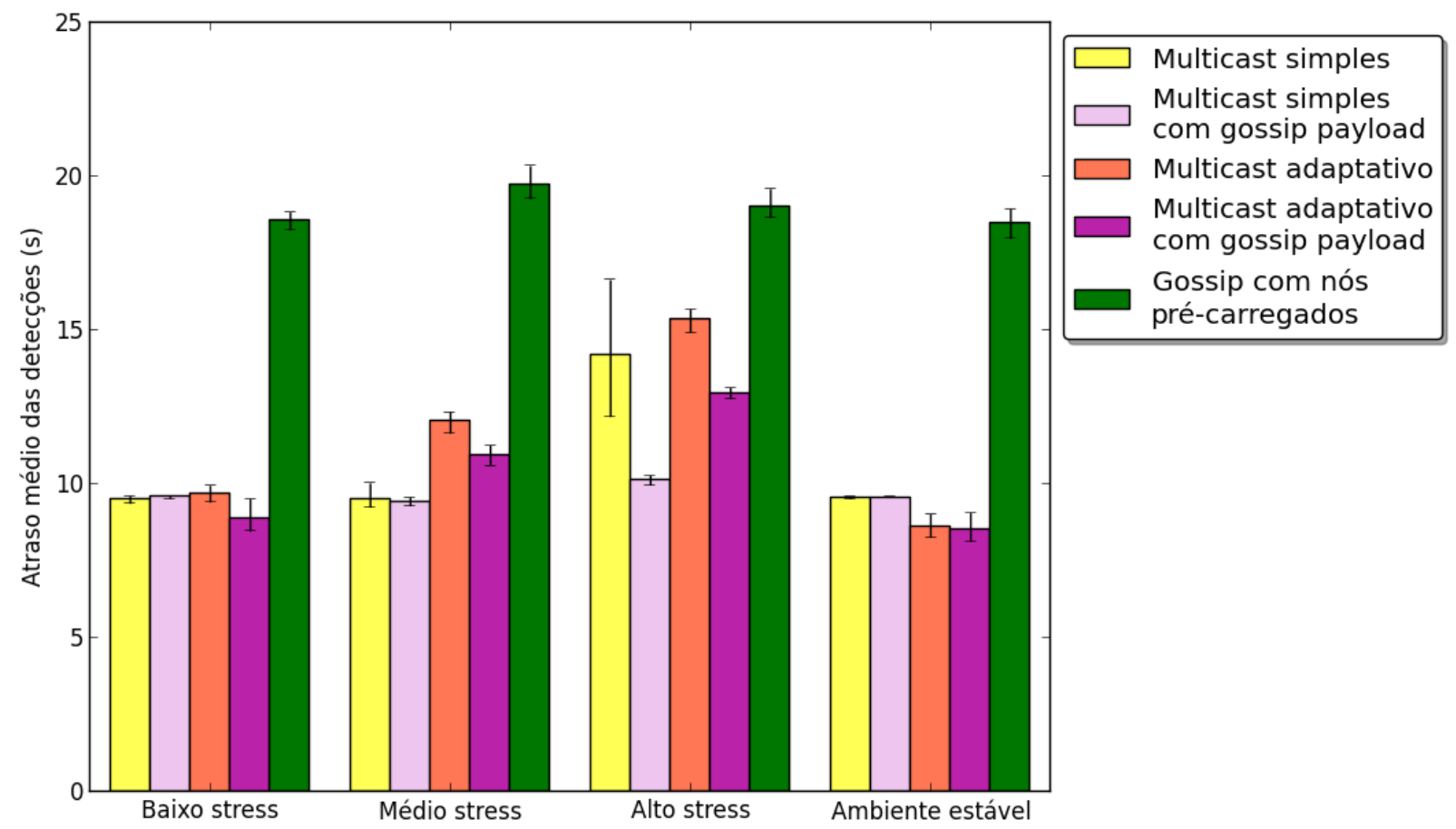

Figura 6.21 - Atraso médio das detecções no cenário 4. 


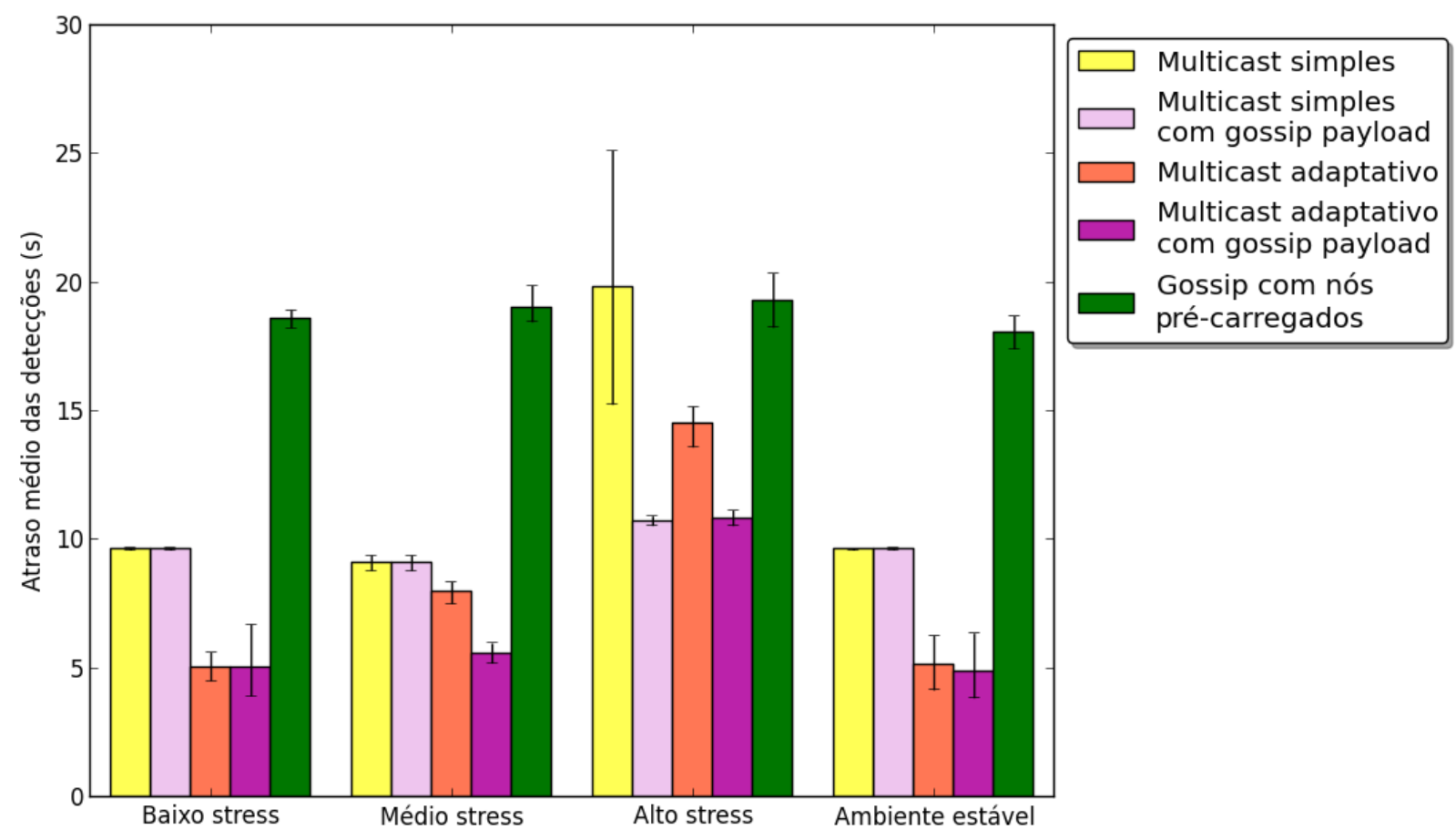

Figura 6.22 - Atraso médio das detecções na metade final do intervalo de testes no cenário 4.

\subsection{Discussão}

Os resultados apresentados mostram a vantagem dos detectores que utilizam a técnica gossip payload em comparação aos detectores que não a utilizam. Com a utilização da técnica, a redundância adicional contida em cada mensagem heartbeat promove um menor número de enganos em todos os cenários. A redução no número de enganos é ainda mais expressiva com o detector multicast simples, sem a adaptação do intervalo de timeout. O detector multicast adaptativo com gossip payload apresenta redução, mas está sujeito a enganos causados por uma estimação muito agressiva do horário de recebimento de mensagens heartbeat. A utilização do gossip payload também promove melhores resultados quanto à duração média dos enganos, já que as informações são propagadas rapidamente, compensando a perda de informações associada à perda de pacotes e acelerando o envio de notificações de recuperação.

Os detector adaptativo obtém resultados satisfatórios quando utilizado em conjunção com a técnica gossip payload. O efeito da estimação adaptativa do intervalo de timeout $\Delta_{t o}$ é mais notável na metade final do intervalo de testes. Em condições estáveis, após diversas recepções de mensagens heartbeat, o valor estimado deste intervalo passa a se aproximar do intervalo de transmissão das mensagens heartbeat $\Delta_{i}$. É possível notar grande benefício de sua utilização quanto ao atraso de detecção, mas o benefício é reduzido conforme as condições de rede se tornam mais adversas. O efeito também é li- 
geiramente reduzido com a utilização da exigência de quórum de notificações. No entanto, sua utilização em ambientes sem técnicas de processamento das notificações é desencorajada, porque a estimação agressiva do intervalo de timeout traz enganos de curta duração, que são facilmente corrigidos com as técnicas de processamento.

Os resultados dos cenários que utilizam o processamento de notificações de falha e recuperação são positivos. As técnicas de filtragem de notificações conflitantes e exigência de quórum proporcionam grande redução no número de enganos à custa da imposição de uma maior resistência à correção de enganos. Isso porque o processamento de notificações estabelece critérios para a aceitação de notificações, que são aplicadas igualmente a notificações de falha e recuperação de nós. Uma possível otimização a ser estudada seria o envio de notificações de recuperação ao gerenciador de falhas diretamente pelos nós recuperados, e não mais enviado por seus vizinhos. Outra desvantagem da utilização de processamento de falhas é o aumento no atraso de detecção. Este atraso é muito inferior com a técnica de exigência de quórum, já que as notificações podem ser aceitas imediatamente assim que o quórum seja atingido. Outra possível otimização é o processamento simultâneo com as técnicas de exigência de quórum e filtragem de notificações conflitantes, com as notificações armazenadas em um único local de armazenamento temporário.

É possível perceber que a utilização de protocolos multicast com a técnica gossip payload é adequada a todos os cenários considerados. Recomenda-se sua utilização a menos que existam grandes restrições quanto ao tamanho dos pacotes de rede que podem ser emitidos pelos detectores de falhas de infraestrutura, ou caso as redes consideradas não possam suportar protocolos multicast. Não recomenda-se a utilização de protocolos adaptativos a menos que as condições da rede na qual os detectores são implantados se mantenham estáveis e que técnicas de processamento de notificações também sejam utilizadas. Recomenda-se a utilização das técnicas de filtragem de notificações conflitantes e exigência de quórum em todos os casos devido à grande eficiência na prevenção de enganos. A escolha dos parâmetros é uma decisão sobre as exigências de qualidade de serviço das aplicações em execução e as características das redes nas quais os detectores de falhas de infraestrutura são implantados. 


\section{CONCLUSÕES}

A arquitetura GFDA foi projetada e implementada para atender as necessidades de detecção de falhas em grades computacionais. De acordo com as funcionalidades apresentadas nos Capítulos 4 e 5, é possível constatar que a arquitetura possibilita a utilização de detectores falhas até mesmo em redes onde há restrições de conectividade direta entre os nós computacionais. A importância desta característica é possibilitar a detecção de falhas de infraestrutura e a propagação de notificações de falha e recuperação em grades computacionais onde os recursos estão disponibilizados em uma hierarquia de camadas. Através dos resultados apresentados e discutidos no Capítulo 6, também conclui-se que as técnicas projetadas para a arquitetura GFDA permitem a utilização de detectores de falhas em redes com alta perda de pacotes e atraso variável, reduzindo de maneira expressiva a quantidade de enganos. Nestas condições, o gossip payload e o processamento de notificações proporcionam uma qualidade de serviço de detecção de falhas adequada.

Diversos módulos de detecção de falhas locais e falhas de infraestrutura foram criados e comparações entre as técnicas de detecção de falhas de infraestrutura puderam ser realizadas. Os diferentes módulos de detecção de falhas de infraestrutura podem ser executados simultaneamente na mesma grade, em domínios de monitoração diferentes. Isso permite que um administrador escolha os módulos mais adequados a cada domínio, considerando as vantagens e desvantagens proporcionadas por cada detector. Os módulos gerenciadores de falhas também podem ter configurações distintas de acordo com o domínio de monitoração considerado, permitindo balancear a relação entre o atraso de detecção e a probabilidade de detecções falsas. Havendo a necessidade, novos protocolos de detecção de falhas de infraestrutura, novas técnicas de detecção local e processamento de falhas podem ser introduzidos à arquitetura.

A arquitetura GFDA provê as informações necessárias para a implementação de um sistema de recuperação de falhas integrado a plataformas como grades computacionais. As informações de detecção obtidas com a arquitetura implementada incluem informações sobre recursos e tarefas afetadas por cada evento de falha. A implementação da arquitetura também se preocupa com questões práticas como a autenticação das mensagens trocadas entre os componentes da arquitetura e a disponibilização de um software cliente para os gerenciadores de falhas que permite a execução de tarefas administrativas. Para os casos em que a utilização de um gerenciador de falhas levaria à introdução de um ponto único de falha, é possível configurar a replicação das informações dos gerenciadores de 
falhas para gerenciadores escravos. Em uma situação de falha do gerenciador mestre, um dos gerenciadores escravos pode então assumir a tarefa de mestre.

\subsection{Restrições}

O projeto da arquitetura apresenta o gerenciador central como um gargalo de escalabilidade. Enquanto a utilização da replicação passiva implementada na arquitetura pode reduzir a probabilidade de que o gerenciador central não esteja disponível em um dado momento, uma solução que removesse estes gargalos seria mais apropriada para uma plataforma distribuída escalável, mas dependeria de complexas técnicas para a distribuição de informações entre múltiplos gerenciadores em replicação ativa.

A utilização de detectores de falhas com a técnica gossip payload implica em um maior tamanho das mensagens heartbeat em comparação a protocolos multicast tradicionais, embora inferior ao consumo de banda de protocolos gossip onde os endereços dos nós são contidos nos pacotes. Há, portanto, uma exigência de capacidade mínima de transmissão de dados.

A comunicação multicast pode ser desabilitada em algumas redes que conectam recursos a serem monitorados. Em especial, provedores de acesso a Internet restringem a utilização direta de multicast. Nestes casos, os detectores multicast ainda podem funcionar através de protocolos de tunelamento tais como o GRE (Generic Routing Encapsulation) ou em uma rede overlay como uma VPN que exponha a capacidade multicast. Alternativamente, o administrador pode escolher um protocolo ponto a ponto como o protocolo gossip para a monitoração de recursos conectados através destas redes, mantendo a utilização de detectores multicast nas redes locais.

\subsection{Contribuições}

As principais contribuições deste trabalho são:

- Projeto e implementação de uma arquitetura que viabiliza a detecção de falhas em grades computacionais hierárquicas com restrições de conectividade entre os nós;

- Criação do gossip payload para disseminação de informações redundantes nas mensagens heartbeat, beneficiando a qualidade de serviço de detecção de falhas; 
- Desenvolvimento de técnicas de processamento de notificações para a redução da frequência de detecções falsas;

- Criação do modelo que recria adversidades encontradas em redes de computadores através da utilização de máquinas virtuais em um ambiente controlado;

- Comparação das diferentes estratégias para detecção distribuída de falhas.

Este trabalho contribui para a pesquisa sobre a melhoria da qualidade do serviço de detecção distribuída de falhas. Diferentemente das abordagens existentes, são apresentadas técnicas de detecção de falhas para ambientes que apresentam condições de rede adversas. Também de maneira diferente de muitas das publicações existentes, apresentamos uma arquitetura que é compatível com grades computacionais em que são encontrados recursos com restrições de conectividade direta. O conhecimento sobre as limitações de grades computacionais é explorado com a utilização de gerenciadores de falhas que realizam o processamento das notificações de falha, otimizando a qualidade de serviço de detecção em relação às abordagens encontradas na literatura.

\subsection{Trabalhos futuros}

A análise dos resultados apresentados no Capítulo 6 permitiu identificar áreas em que a qualidade do serviço de detecção de falhas de infraestrutura pode ser melhorada. As técnicas de processamento podem ser alteradas para reduzir as exigências no caso das notificações de recuperação, já que sua determinação é mais simples e menos sujeita a enganos. Isso garantiria uma menor possibilidade de que um nó previamente em faIha não seja reconhecido pelos gerenciadores de falhas ao retornar ao funcionamento, e também reduziria o intervalo de tempo necessário para a correção de enganos. Outra possível modificação para o processamento de notificações é a aplicação das técnicas de processamento simultaneamente. Na implementação atual, ao utilizar ambas as técnicas de processamento, as notificações são primeiramente submetidas à exigência de quórum, e então as notificações aceitas são sujeitas à filtragem de notificações conflitantes. Com a aplicação simultânea das técnicas, o atraso na detecção de falhas causado pelo processamento de notificações seria reduzido.

A assinatura criptográfica aplicada às mensagens heartbeat transmitidas entre os detectores de falhas de infraestrutura utiliza uma chave secreta que não é alterada durante o ciclo de vida dos componentes da arquitetura. Caso os gerenciadores de falhas possuam 
entropia suficiente para a rápida geração de chaves criptograficamente seguras, os detectores poderiam idealmente obter uma nova chave em intervalos periódicos, aumentando assim a segurança da solução.

A implementação da arquitetura GFDA realiza a replicação de informações entre múltiplos gerenciadores de falha, mas não realiza a troca de um gerenciador de falhas escravo para mestre de maneira automática. A troca automática sem a utilização de ferramentas externas seria possível com a especificação de múltiplos endereços de rede de gerenciadores de falhas em redundância para os componentes da arquitetura. Ao conectar-se em um gerenciador de falhas escravo, o componente seria informado sobre o gerenciador de falhas atualmente configurado como mestre. Ainda haveria a necessidade de que os gerenciadores de falhas fossem modificados de modo a realizar a troca de gerenciadores subordinados escravos para mestres. No caso de gerenciadores de falhas na última camada da cadeia de gerenciadores, esta troca teria de ser feita após o estabelecimento de consenso entre os gerenciadores sobreviventes.

A arquitetura GFDA fornece a funcionalidade básica necessária para a tomada de decisões no caso de eventos de falha e recuperação de recursos computacionais e falhas de processos de uma aplicação distribuída. A continuação natural do trabalho é o desenvolvimento de uma plataforma tolerante a falhas para a execução de tarefas em grades computacionais hierárquicas, integrando a arquitetura GFDA para a geração dos eventos de falha e recuperação. Esta plataforma tolerante a falhas poderia utilizar meta-escalonadores existentes ou criados especificamente para o agendamento tolerante a falhas. A utilização de técnicas como checkpointing ou message logging em grades computacionais hierárquicas traz diversos desafios a serem resolvidos.

\subsection{Publicações}

O protocolo de detecção de falhas multicast com a utilização da técnica gossip payload foi apresentado no 10th International Information and Telecommunication Technologies Symposium (I2TS 2011) e publicado na revista IEEE Latin America Transactions (LEMOS; SATO, 2012). Resultados preliminares obtidos com um subconjunto do ambiente descrito no Capítulo 6 foram apresentados no artigo. Uma versão revisada do protocolo de detecção de falhas multicast que utiliza o gossip payload e resultados atualizados que mostram a influência do processamento de notificações de falhas na qualidade de serviço de detecção serão publicados em artigo aceito para o XIII Simpósio em Sistemas Computacionais (WSCAD-SSC 2012). 


\section{REFERÊNCIAS}

ANDERSON, D. et al. SETI@home: an experiment in public-resource computing. Communications of the ACM, v. 45, n. 11, p. 56-61, 2002.

AVIZIENIS, A. et al. Basic concepts and taxonomy of dependable and secure computing. IEEE Transactions on Dependable and Secure Computing, v. 1, n. 1, p. 11-33, 2004.

BERTIER, M.; MARIN, O.; SENS, P. Implementation and performance evaluation of an adaptable failure detector. In: Proceedings of the International Conference on Dependable Systems and Networks. [S.I.]: IEEE Computer Society, 2002. p. 354-363.

BERTIER, M.; MARIN, O.; SENS, P. Performance analysis of a hierarchical failure detector. In: Proceedings of the International Conference on Dependable Systems and Networks. [S.I.]: IEEE Computer Society, 2003. p. 635-644.

BOLZE, R. et al. Grid'5000: a large scale and highly reconfigurable experimental grid testbed. International Journal of High Performance Computing Applications, v. 20, n. 4, p. 481-494, 2006.

BOSILCA, G. et al. MPICH-V: toward a scalable fault tolerant MPI for volatile nodes. In: Proceedings of the ACM/IEEE conference on Supercomputing. Los Alamitos, EUA: IEEE Computer Society, 2002. p. 1-18.

BOUTEILLER, A. et al. MPICH-V project: a multiprotocol automatic fault-tolerant MPI. International Journal of High Performance Computing Applications, v. 20, n. 3, p. 319-333, 2006.

CHANDRA, T.; TOUEG, S. Unreliable failure detectors for reliable distributed systems. Journal of the ACM, v. 43, n. 2, p. 225-267, 1996.

CHEN, W.; TOUEG, S.; AGUILERA, M. On the quality of service of failure detectors. IEEE Transactions on Computers, v. 51, n. 1, p. 13-32, 2002.

COOKE, A. et al. R-GMA: an information integration system for grid monitoring. In: MEERSMAN, R.; TARI, Z.; SCHMIDT, D. C. (Ed.). On The Move to Meaningful Internet Systems 2003: CoopIS, DOA, and ODBASE. Berlim: Springer-Verlag, 2003. v. 2888, p. 462-481.

COTI, C. et al. Blocking vs. non-blocking coordinated checkpointing for large-scale fault tolerant MPI. In: Proceedings of the ACM/IEEE conference on Supercomputing. Nova lorque: ACM, 2006.

CZAJKOWSKI, K. et al. Grid information services for distributed resource sharing. In: Proceedings of the International Symposium on High Performance Distributed Computing. [S.I.]: IEEE Computer Society, 2001. p. 181-194.

DÉFAGO, X.; HAYASHIBARA, N.; KATAYAMA, T. On the design of a failure detection service for large scale distributed systems. In: Proceedings of the International Symposium Towards Peta-Bit Ultra-Networks. [S.I.: s.n.], 2003. p. 88-95. 
FOSTER, I. Globus toolkit version 4: software for service-oriented systems. In: International Conference on Network and Parallel Computing. Berlim: Springer-Verlag, 2005. p. 2-13.

FOSTER, I.; KESSELMAN, C. The grid: blueprint for a new computing infrastructure. 1. ed. San Francisco, EUA: Morgan Kaufmann, 1999.

FOSTER, I.; KESSELMAN, C.; TUECKE, S. The anatomy of the grid: enabling scalable virtual organizations. International Journal of High Performance Computing Applications, v. 15, n. 3, p. 200-222, 2001.

FREE SOFTWARE FOUNDATION. gcov: a test coverage program. [S.I.], 2010. Disponível em: <http://gcc.gnu.org/onlinedocs/gcc/Gcov.htm>. Acesso em: 19 ago. 2012.

GENAUD, S.; JEANNOT, E.; RATTANAPOKA, C. Fault-management in P2P-MPI. International Journal of Parallel Programming, v. 37, n. 5, p. 433-461, 2009.

HAAS, F. The Linux-HA user's guide. [S.I.], 2010. Disponível em: <http://www.linuxha.org/doc/users-guide/users-guide.html>. Acesso em: 19 ago. 2012.

HAYASHIBARA, N.; CHERIF, A.; KATAYAMA, T. Failure detectors for large-scale distributed systems. In: Proceedings of the International Symposium on Reliable Distributed Systems. Washington: IEEE Computer Society, 2002. p. 404-409.

HURSEY, J. et al. The design and implementation of checkpoint/restart process fault tolerance for Open MPI. In: International Parallel and Distributed Processing Symposium. [S.I.]: IEEE Computer Society, 2007. p. 1-8.

HWANG, S.; KESSELMAN, C. Grid workflow: a flexible failure handling framework for the grid. In: Proceedings of the International Symposium on High Performance Distributed Computing. [S.I.]: IEEE Computer Society, 2003. p. 126-137.

IETF NETWORK WORKING GROUP. IETF RFC 3768: Virtual Router Redundancy Protocol. [S.I.], 2004. Disponível em: <http://www.ietf.org/rfc/rfc3768.txt>. Acesso em: 19 ago. 2012.

JACOBSON, V. Congestion avoidance and control. In: SIGCOMM Computer Communication Review. Nova lorque: ACM, 1988. v. 18, n. 4, p. 314-329.

JOHNSON, B. Design and analysis of fault-tolerant digital systems. Boston, EUA: Addison-Wesley, 1989.

JOHNSON, D.; ZWAENEPOEL, W. Sender-based message logging. In: Proceedings of the International Symposium on Fault-Tolerant Computing. [S.I.]: IEEE Computer Society, 1987. p. 14-19.

KOHLHOFF, C. Boost 1.46.0: Boost.Asio documentation. [S.I.], 2011. Disponível em: $<$ http://www.boost.org/doc/libs/1_46_0/doc/html/boost_asio.html>. Acesso em: 19 ago. 2012.

LEMOS, F. T. C.; SATO, L. M. Improving the robustness of distributed failure detectors in adverse conditions. IEEE Latin America Transactions, v. 10, n. 1, p. 1364-1369, 2012. 
LITZKOW, M.; LIVNY, M.; MUTKA, M. Condor - a hunter of idle workstations. In: International Conference on Distributed Computing Systems. [S.I.]: IEEE Computer Society, 1988. p. 104-111.

MARIANI, L. A fault taxonomy for component-based software. Electronic Notes in Theoretical Computer Science, v. 82, n. 6, p. 55-65, 2003.

MASSIE, M.; CHUN, B.; CULLER, D. The ganglia distributed monitoring system: design, implementation, and experience. Parallel Computing, v. 30, n. 7, p. 817-840, 2004.

MENAGE, P.; JACKSON, P.; LAMETER, C. CGROUPS documentation. [S.I.], 2012. Disponível em: <http://www.kernel.org/doc/Documentation/cgroups/cgroups.txt>. Acesso em: 19 ago. 2012.

OPENBSD TEAM. PF: firewall redundancy with CARP and pfsync. [S.I.], 2012. Disponível em: <http://www.openbsd.org/faq/pf/carp.html>. Acesso em: 19 ago. 2012.

PAULA, N. Um ambiente de monitoramento de recursos e escalonamento cooperativo de aplicações paralelas em grades computacionais. 2009. 191 p. Tese (Doutorado) - Escola Politécnica da Universidade de São Paulo, 2009.

PROTOCOL BUFFERS. Developer guide. [S.I.], 2012. Disponível em: $<$ http://developers.google.com/protocol-buffers/docs/overview>. Acesso em: 19 ago. 2012.

RANGANATHAN, S. et al. Gossip-style failure detection and distributed consensus for scalable heterogeneous clusters. Cluster Computing, v. 4, n. 3, p. 197-209, 2001.

RENESSE, R. van; MINSKY, Y.; HAYDEN, M. A gossip-based failure detection service. In: Proceedings of the International Conference on Distributed Systems Platforms and Open Distributed Processing. Londres: Springer-Verlag, 1998. p. 55-70.

SANKARAN, S. et al. The LAM/MPI checkpoint/restart framework: system-initiated checkpointing. International Journal of High Performance Computing Applications, v. 19, n. 4, p. 479-493, 2005.

STELLING, P. et al. A fault detection service for wide area distributed computations. Cluster Computing, v. 2, n. 2, p. 117-128, 1999.

STELLNER, G. CoCheck: checkpointing and process migration for MPI. In: Proceedings of the International Parallel Processing Symposium. [S.I.]: IEEE Computer Society, 1996. p. 526-531.

ZANIKOLAS, S.; SAKELLARIOU, R. A taxonomy of grid monitoring systems. Future Generation Computer Systems, v. 21, n. 1, p. 163-188, 2005. 


\section{APÊNDICE A - PROTOCOLO DE COMUNICAÇÃO COM O GERENCIADOR DE FALHAS}

Os gerenciadores de falhas utilizam um protocolo de comunicação próprio para administração, submissão de notificações de falha e recuperação, construção de uma visão da topologia e integração, distribuição de chaves criptográficas, comandos administrativos e de integração com meta-escalonadores. Este protocolo é baseado em texto e pode ser acessado através de ferramentas tais como telnet com suporte a TLS. Os comandos disponíveis estão apresentados na Tabela A.1.

A utilização dos comandos apresentados na Tabela A.1 é exemplificada através das Figuras A.1, A.2, A.3, A.4 e A.5. 
Tabela A.1 - Comandos disponíveis no protocolo de comunicação com gerenciadores de falhas.

\begin{tabular}{|c|c|c|c|}
\hline Comando & Descrição & Ger. cent. & Ger. dist. \\
\hline notify host & $\begin{array}{l}\text { Submissão de notificações de } \\
\text { falha e recuperação dos detec- } \\
\text { tores de falhas de infraestru- } \\
\text { tura }\end{array}$ & Sim & Sim \\
\hline notify job & $\begin{array}{l}\text { Submissão de notificações de } \\
\text { falhas dos detectores de falhas } \\
\text { locais }\end{array}$ & Sim & Sim \\
\hline advertise detector & $\begin{array}{l}\text { Publicação de presença de } \\
\text { uma detector de falhas de in- } \\
\text { fraestrutura }\end{array}$ & Sim & Sim \\
\hline advertise proxy & $\begin{array}{l}\text { Publicação de presença de um } \\
\text { gerenciador de falhas distri- } \\
\text { buído }\end{array}$ & Sim & Sim \\
\hline create job & $\begin{array}{l}\text { Cadastramento de tarefas em } \\
\text { execução na plataforma distri- } \\
\text { buída }\end{array}$ & Sim & Não \\
\hline remove job & $\begin{array}{l}\text { Remoção de uma tarefa previ- } \\
\text { amente cadastrada }\end{array}$ & Sim & Não \\
\hline alter job & $\begin{array}{l}\text { Alteração de uma tarefa previ- } \\
\text { amente cadastrada }\end{array}$ & Sim & Não \\
\hline query jobs & $\begin{array}{l}\text { Consulta das tarefas cadastra- } \\
\text { das }\end{array}$ & Sim & Não \\
\hline add depends & $\begin{array}{l}\text { Cadastro de dependências adi- } \\
\text { cionais entre recursos }\end{array}$ & Sim & Não \\
\hline remove depends & $\begin{array}{l}\text { Remoção de dependências en- } \\
\text { tre recursos }\end{array}$ & Sim & Não \\
\hline query depends & $\begin{array}{l}\text { Consulta das dependências } \\
\text { entre os recursos }\end{array}$ & Sim & Não \\
\hline $\begin{array}{l}\text { query intermittency_- } \\
\text { buffer }\end{array}$ & $\begin{array}{l}\text { Inspeção do buffer de intermi- } \\
\text { tência }\end{array}$ & Sim & Sim \\
\hline query quorum_buffer & Inspeção do buffer de quórum & Sim & Sim \\
\hline query dfd_hmac_key & $\begin{array}{l}\text { Consulta da chave HMAC para } \\
\text { criptografia entre os detectores }\end{array}$ & Sim & Sim \\
\hline replicate job_tracker & $\begin{array}{l}\text { Replicação do banco de tare- } \\
\text { fas (jobs) }\end{array}$ & Sim & Não \\
\hline $\begin{array}{l}\text { replicate host_- } \\
\text { dependency_tracker }\end{array}$ & $\begin{array}{l}\text { Replicação do banco de de- } \\
\text { pendências entre estações }\end{array}$ & Sim & Sim \\
\hline $\begin{array}{l}\text { replicate } \\
\text { intermittency_buffer }\end{array}$ & $\begin{array}{l}\text { Replicação buffer de intermi- } \\
\text { tência }\end{array}$ & Sim & Sim \\
\hline $\begin{array}{l}\text { replicate quorum_- } \\
\text { buffer }\end{array}$ & Replicação buffer de quórum & Sim & Sim \\
\hline
\end{tabular}




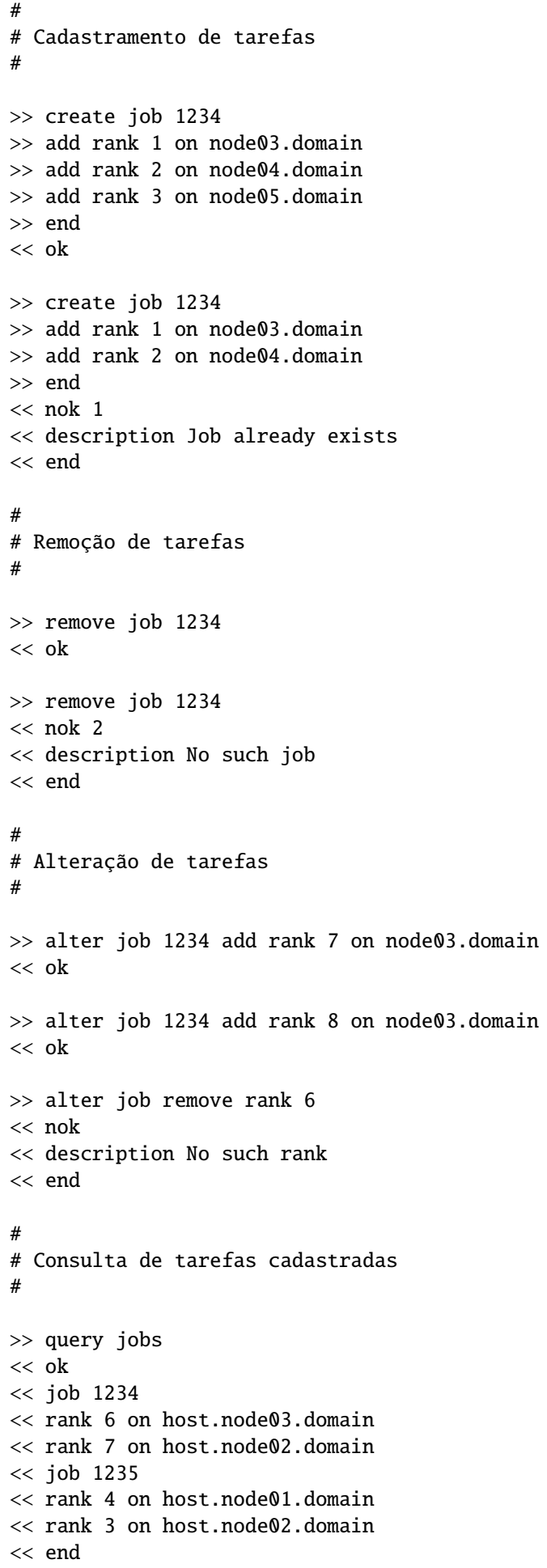

Figura A.1 - Exemplo dos comandos do gerenciador de falhas que tratam de tarefas. 


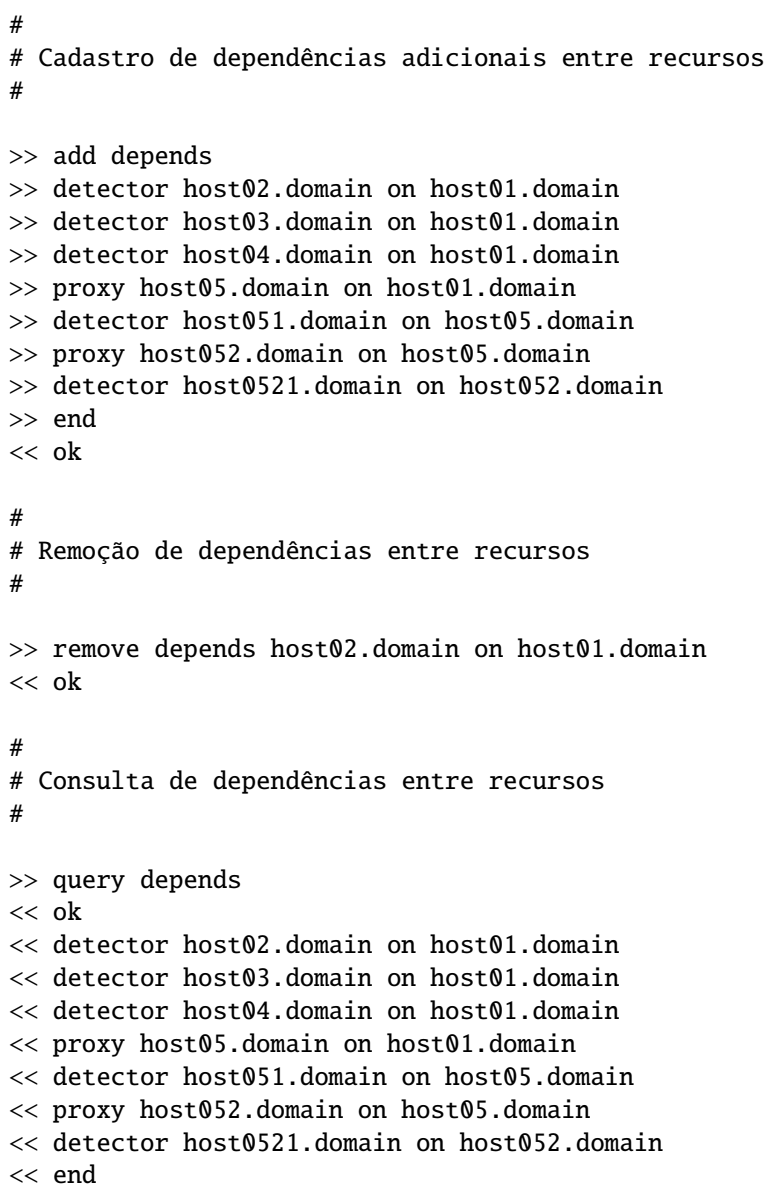

Figura A.2 - Exemplo dos comandos do gerenciador de falhas que tratam de dependências entre os recursos. 


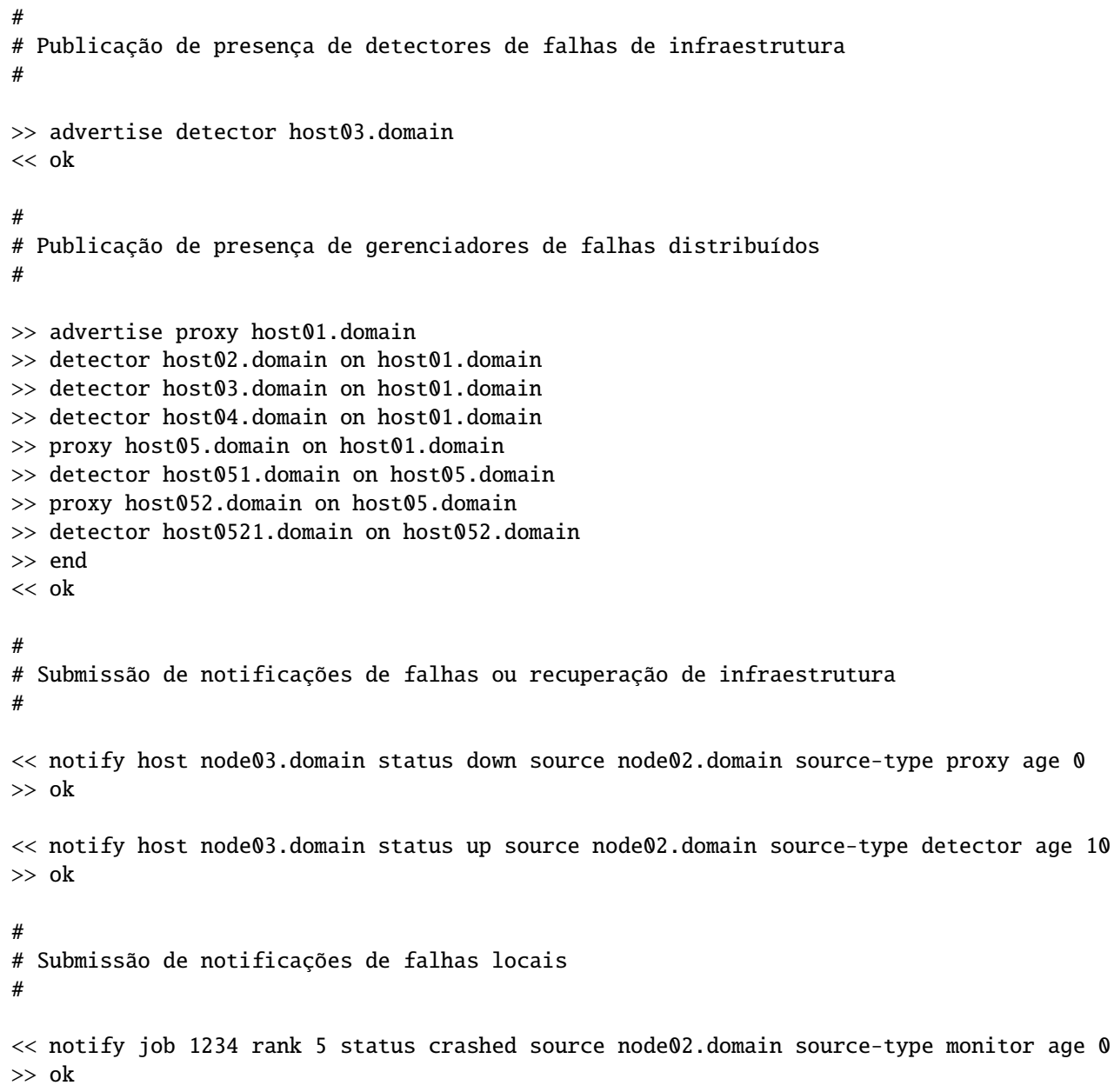

Figura A.3 - Exemplo dos comandos do gerenciador de falhas que tratam de publicação de presença e notificações de falha e recuperação. 


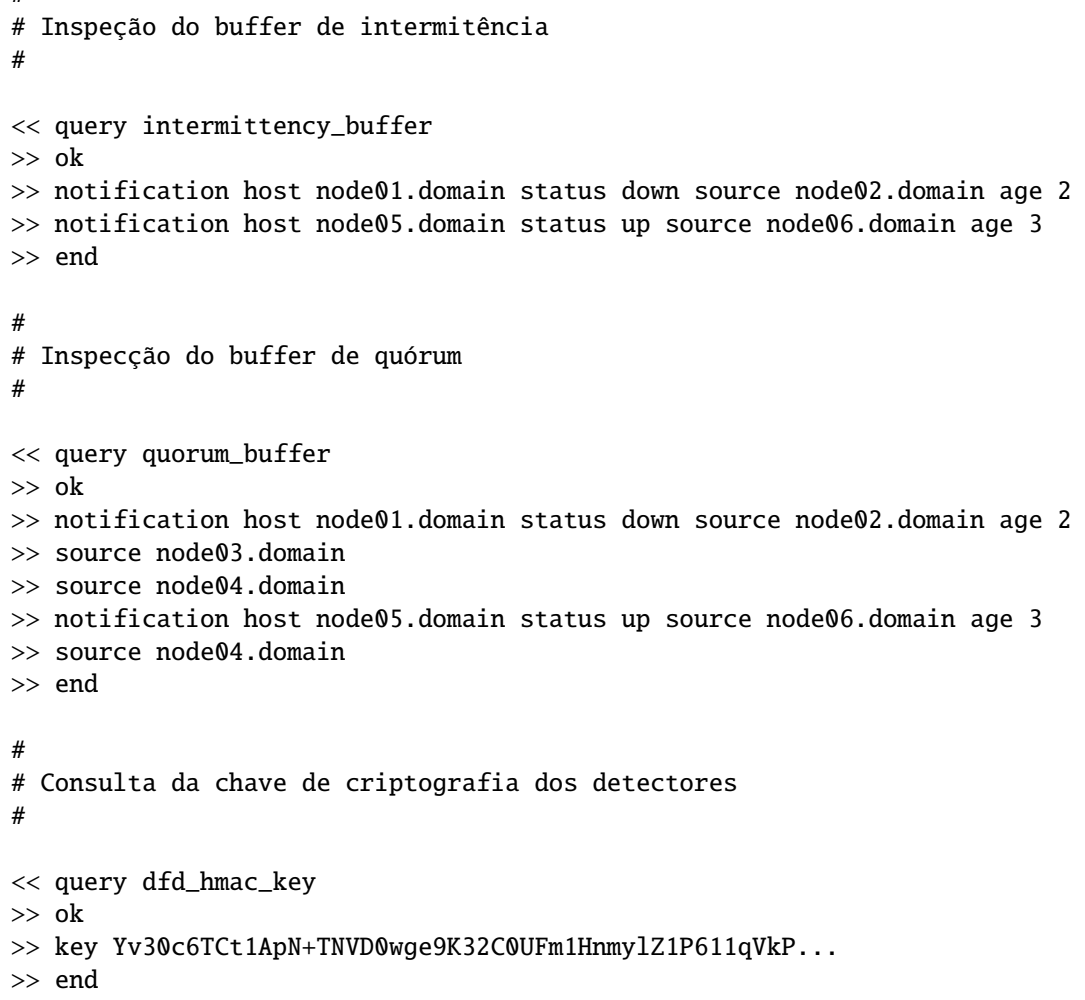

Figura A.4 - Exemplo dos comandos do gerenciador de falhas para observação do estado do processamento de notificações e da chave de criptografia usada pelos detectores. 


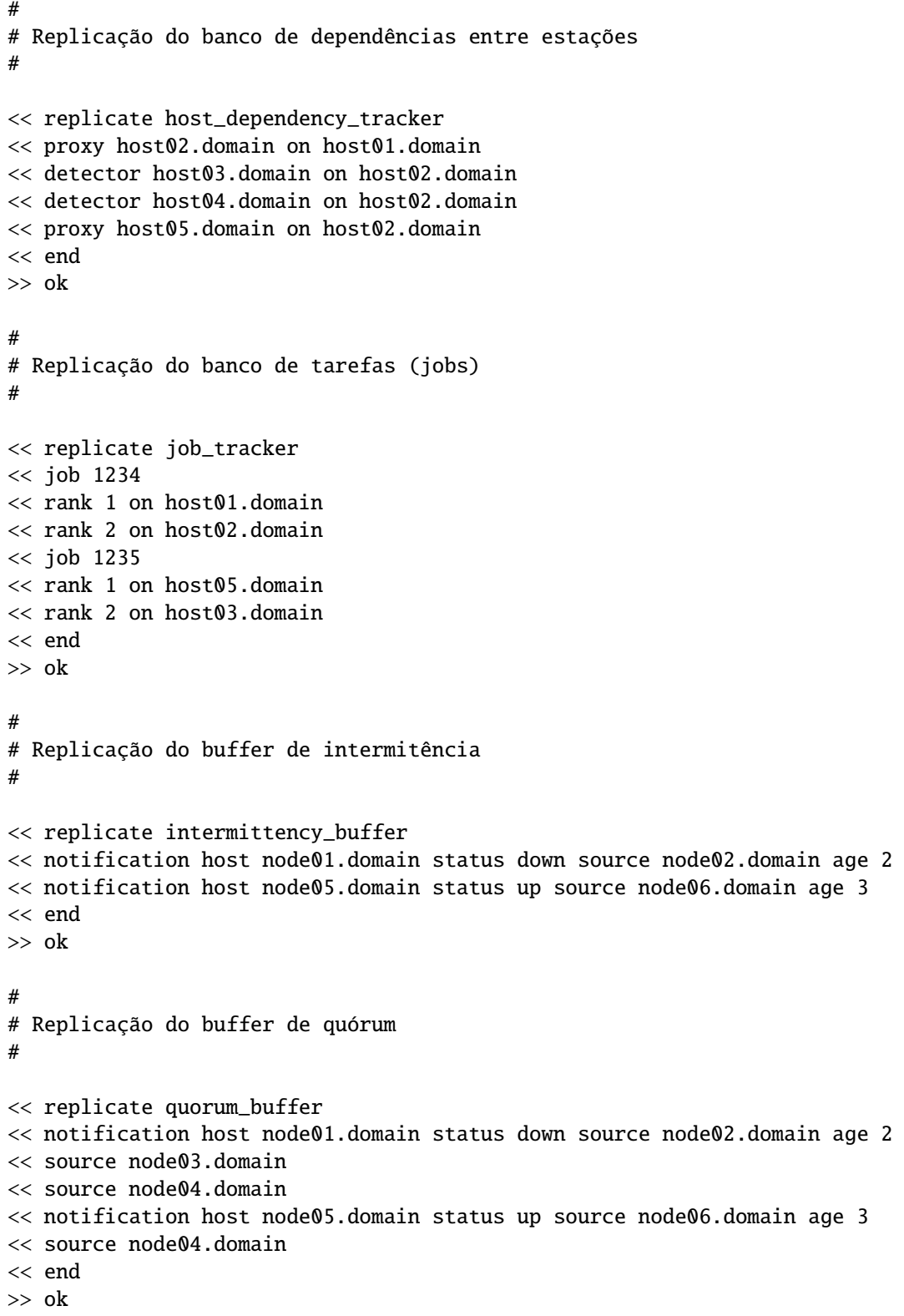

Figura A.5 - Exemplo dos comandos do gerenciador de falhas para transmissão de mensagens de replicação. 


\section{APÊNDICE B - PROTOCOLO DE INTEGRAÇÃO COM O GERENCIADOR DE FALHAS}

Os gerenciadores de falhas centrais utilizam um protocolo de comunicação específico para o envio de informações de eventos de falha e recuperação ao consumidor final. Este protocolo é baseado em texto e é repassado através da entrada padrão (standard input) do processo lançado para a transmissão das notificações. A comunicação entre os gerenciadores de falhas centrais e o consumidor final é demonstrada pela Figura B.1.

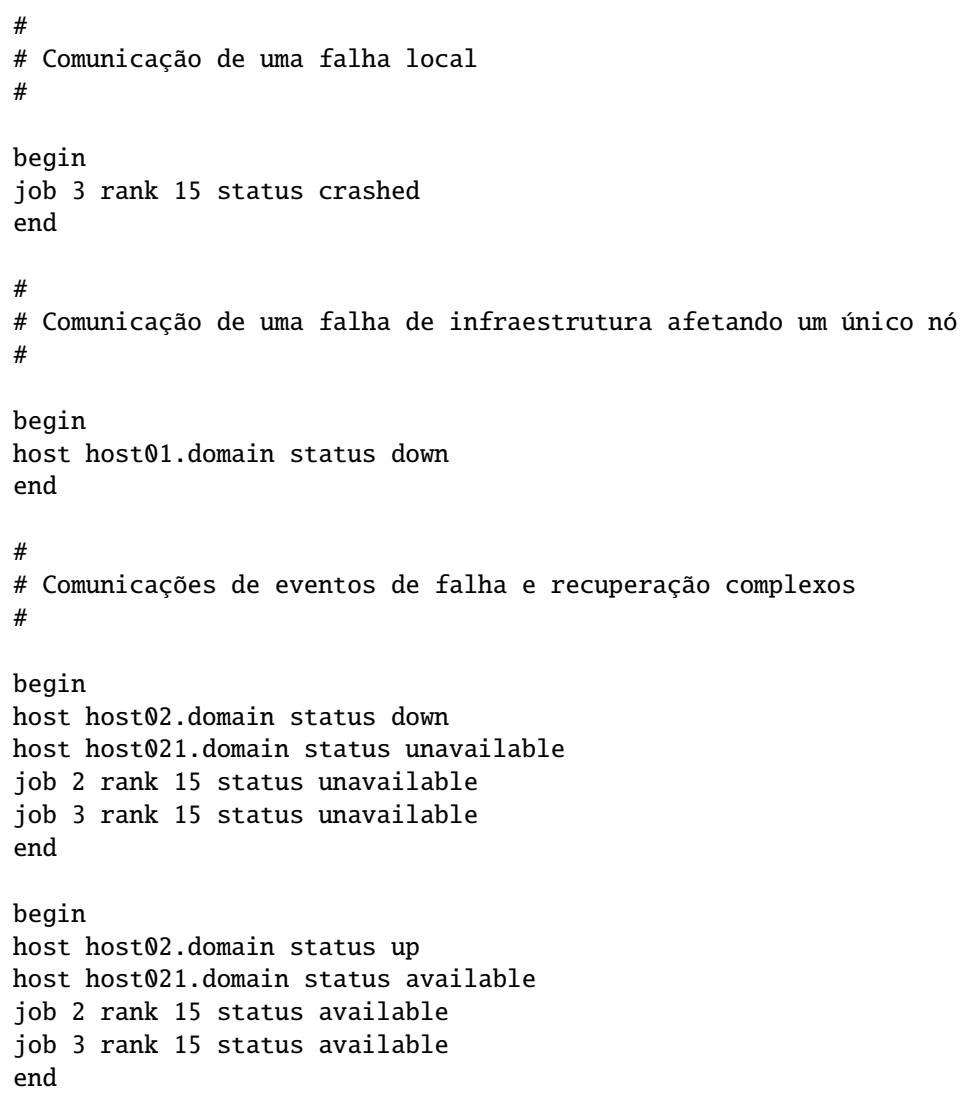

Figura B.1 - Exemplo de comunicação entre um gerenciador de falhas central e o consumidor final das notificações de falha. 